Florida International University FIU Digital Commons

FIU Electronic Theses and Dissertations

University Graduate School

10-18-2007

\title{
Role of Calcium in Inflammation: Relevance to Alzheimer's Disease
}

Amita Quadros

Florida International University, amitaq@hotmail.com

DOI: 10.25148 /etd.FI10022540

Follow this and additional works at: https://digitalcommons.fiu.edu/etd

\section{Recommended Citation}

Quadros, Amita, "Role of Calcium in Inflammation: Relevance to Alzheimer's Disease" (2007). FIU Electronic Theses and Dissertations. 210.

https://digitalcommons.fiu.edu/etd/210

This work is brought to you for free and open access by the University Graduate School at FIU Digital Commons. It has been accepted for inclusion in FIU Electronic Theses and Dissertations by an authorized administrator of FIU Digital Commons. For more information, please contact dcc@fiu.edu. 


\section{FLORIDA INTERNATIONAL UNIVERSITY}

Miami, Florida

\section{ROLE OF CALCIUM IN INFLAMMATION: RELEVANCE TO}

ALZHEIMER'S DISEASE

A dissertation submitted in partial fulfillment of the

requirements for the degree of

DOCTOR OF PHILOSOPHY

in

BIOLOGY

by

Amita Quadros

2007 
To: Interim Dean Mark D. Szuchman

College of Arts and Sciences

This dissertation, written by Amita Quadros, and entitled Role of Calcium in Inflammation: Relevance to Alzheimer's Disease, having been approved in respect to style and intellectual content, is referred to you for judgment.

We have read this dissertation and recommend that it be approved.

Michael Mullan

Daniel Paris

Fiona Crawford

Lidia Kos

Leung Kim

Robert Lickliter

Ophelia Weeks, Major Professor

Date of Defense: October 18, 2007

The dissertation of Amita Quadros is approved.

Interim Dean Mark D. Schuchman

College of Arts and Sciences

Dean George Walker

University Graduate School

Florida International University, 2007 


\section{DEDICATION}

I would like to dedicate my thesis to my husband Naveen Quadros and my daughter Nicole Quadros who have sacrificed a lot these past 6 years so that I could get my most sought after doctoral degree. They have encouraged and supported me throughout these years and helped me achieve this momentous task. I also would like to dedicate this thesis to my brother Savio D'Souza and all my friends and family who have been with me all through this long and arduous journey. 


\section{ACKNOWLEDGMENTS}

I would like to acknowledge a whole bunch of people who have helped me accomplish this huge milestone in my life. First of all I would like to thank my committee members from the Roskamp Institute, Dr. Daniel Paris, my immediate supervisor and mentor at the Roskamp Institute, Dr. Michael Mullan and Dr. Fiona Crawford. They have all supported and guided me throughout my Ph.D. journey from University of South Florida to Florida International University. Dr. Paris has guided me all through in planning my experiments and I have learnt a lot from him in terms of new techniques and assays. He is a great scientist and it has been an awesome experience working with him the past 6 years. I would also like to thank my committee members from FIU, Dr. Lidia Kos, Dr. Leung Kim and Dr. Robert Lickliter for their constant support, encouragement and guidance these past 3 years I have been with them. I owe special thanks to Dr. Ophelia Weeks who, despite everything, accepted me and two others as Ph.D. students. She came to our rescue and I am totally obliged and indebted to her for my doctoral degree. She has been a constant source of encouragement and support to me and I am sincerely grateful to her for all she has done for me. I would also like to acknowledge my friends Nikunj Patel and Claude-Henry Volmar who have been with me through all the hardships of attending lectures, driving early hours from Tampa to Miami and just being there for me. Nikunj Patel has also shared valuable information with regards to cell culture issues. 


\section{ABSTRACT OF THE DISSERTATION \\ ROLE OF CALCIUM IN INFLAMMATION: RELEVANCE TO \\ ALZHEIMER'S DISEASE}

by

Amita Quadros

Florida International University, 2007

Miami, Florida

Professor Ophelia Weeks, Major Professor

Alzheimer's disease (AD) is neuropathologically characterized by excessive beta -amyloid (A $\beta)$ plaques and neurofibrillary tangles composed of hyperphosphorylated tau in the brain. Although the etiology of genetic cases of AD has been attributed to mutations in presenilin and amyloid precursor protein (APP) genes, in most sporadic cases of $\mathrm{AD}$, the etiology is still unknown and various predisposing factors could contribute to the pathology of AD. Predominant among these possible predisposing factors that have been implicated in $\mathrm{AD}$ are age, hypertension, traumatic brain injury, diabetes, chronic neuroinflammation, alteration in calcium levels and oxidative stress. Since both inflammation and altered calcium levels are implicated in the pathogenesis of $\mathrm{AD}$, we wanted to study the effect of altered levels of calcium on inflammation and the subsequent effect of selective calcium channel blockers on the production of proinflammatory cytokines and chemokines. Our hypothesis is that $\mathrm{A} \beta$, depending on it conformation, may contribute to altered levels of intracellular calcium in neurons and glial cells. We wanted to determine which conformation of $A \beta$ was most pathogenic in terms of increasing inflammation and calcium influx and further elucidate the possibility 
of a link between altered calcium levels and inflammation. In addition, we wanted to test whether calcium channel blockers could inhibit the inflammation mediated by the most pathogenic form of $A \beta$, by antagonizing the calcium influx triggered by $A \beta$.

Our results in human glial and neuronal cells demonstrate that the high molecular weight oligomers are the most potent at stimulating the release of pro-inflammatory cytokines IL-6 and IL-8 as well as increasing intracellular levels of calcium compared to other conformations of $\mathrm{A} \beta$. Further, L-type calcium channel blockers and calmodulin kinase inhibitors are able to significantly reduce the levels of IL-6 and IL-8. These results suggest that $A \beta$-induced alteration of intracellular calcium levels contributes to its pro-inflammatory effect. 


\section{TABLE OF CONTENTS}

CHAPTER

PAGE

1. Introduction 1

1.1. Neuropathological features of Alzheimer's disease 1

1.1.1. Amyloid cascade hypothesis 2

1.1.2. Cytoskeleton hypothesis $\quad 5$

$\begin{array}{ll}\text { 1.1.3. Neurovascular hypothesis } & 7\end{array}$

1.2. Role of brain inflammation in Alzheimer's disease 9

1.3. Role of calcium in inflammation and AD $\quad 12$

1.3.1. Rationale for calcium channel blockers behaving $\quad 15$

$\begin{array}{ll}\text { References } & 17\end{array}$

2. Increased TNF $\alpha$ Production and Cox-2 Activity in 33

Organotypic Brain Slice Cultures from APPsw Transgenic

mice

$\begin{array}{ll}\text { References } & 42\end{array}$

3. Increase of calcium entry by $\mathrm{A} \beta$ promotes inflammation 45

in human astrocytes and microglia

$\begin{array}{ll}\text { References } & 70\end{array}$

4. Effect of calcium channel blockers on $A \beta$ induced 74

neurodegeneration in human neurons

References

5. Discussion and Conclusions $\quad 99$

$\begin{array}{ll}\text { References } & 104\end{array}$

$\begin{array}{ll}\text { Vita } & 109\end{array}$ 


\section{LIST OF FIGURES}

FIGURE

PAGE

1. PGE2 release in culture media from organotypic brain slices from TgAPPsw mice of ages 3month, 14 month and 17 month.

2. TNF $\alpha$ release in culture media from organotypic brain slices from TgAPPsw mice of ages 3month, 14 month and 17 month.

3. PGE2 release in culture media from organotypic brain slices from TgAPPsw mice of age 14 month treated with $20 \mu \mathrm{M}$ NS398.

4. TNF $\alpha$ release in culture media from organotypic brain slices from TgAPPsw mice of age 14 month treated with $20 \mu \mathrm{M}$ NS398.

5. Western blot of $\mathrm{A} \beta 1-42$ using 4G8 monoclonal antibody under denaturing and non-denaturing conditions.

6a. Measurement of intracellular calcium entry in human astrocytes following treatment with $1 \mu \mathrm{M} F S, \mathrm{LMWO}$ and HMWO A $\beta$.

6b. Quantification of calcium entry in astrocytes

6c. Measurement of intracellular calcium entry in human microglia following treatment with $1 \mu \mathrm{M}$ FS, LMWO and HMWO A $\beta$.

6d. Quantification of calcium entry in microglia

7a. IL-6 levels in astrocytes following treatment with $1 \mu \mathrm{M}$ FS, LMWO and HMWO A $\beta$.

7b. IL-6 levels in microglia following treatment with $1 \mu \mathrm{M} F S$, LMWO and HMWO A $\beta$.

7c. IL-8 levels in astrocytes following treatment with $1 \mu \mathrm{M} \mathrm{FS}$, LMWO and HMWO A $\beta$.

7d. IL-8 levels in microglia following treatment with $1 \mu \mathrm{M} F S$, LMWO and HMWO A $\beta$.

8a. IL-6 levels in astrocytes following treatment with $10 \mu \mathrm{M}$ A23187 and $20 \mu \mathrm{M}$ BAPTA-AM. 
8b. IL-6 levels in microglia following treatment with $10 \mu \mathrm{M}$ A23187 and $20 \mu \mathrm{M}$ BAPTA-AM.

8c. IL-8 levels in astrocytes following treatment with $10 \mu \mathrm{M}$ A23187 and $20 \mu \mathrm{M}$ BAPTA-AM.

8d. IL-8 levels in microglia following treatment with $10 \mu \mathrm{M}$ A23187 and $20 \mu \mathrm{M}$ BAPTA-AM.

9a. IL-6 levels in astrocytes following treatment with $1 \mu \mathrm{M}$ HMWO, $5 \mu \mathrm{M}$ Nilvadipine, $5 \mu \mathrm{M}$ KN62, $10 \mu \mathrm{M}$ U73122 alone and co-treated with HMWO A $\beta$.

9b. IL-6 levels in microglia following treatment with $1 \mu \mathrm{M}$ HMWO, $5 \mu \mathrm{M}$ Nilvadipine, $5 \mu \mathrm{M}$ KN62, 10 $\mu \mathrm{M}$ U73122 alone and co-treated with HMWO A $\beta$.

9c. IL-8 levels in astrocytes following treatment with $1 \mu \mathrm{M}$ HMWO, $5 \mu \mathrm{M}$ Nilvadipine, $5 \mu \mathrm{M}$ KN62, $10 \mu \mathrm{M}$ U73122 alone and co-treated with HMWO A $\beta$.

9d. IL-8 levels in microglia following treatment with $1 \mu \mathrm{M}$ HMWO, $5 \mu \mathrm{M}$ Nilvadipine, $5 \mu \mathrm{M}$ KN62, 10 $\mu \mathrm{M}$ U73122 alone and co-treated with HMWO A $\beta$.

10. Proposed hypothesis for $A \beta$ mediated neurotoxicity in HNPCs.

11a. IL-6 levels in HNPCs following treatment with $1 \mu \mathrm{M} F S$, LMWO and HMWO A $\beta$.

11b. IL-8 levels in HNPCs following treatment with $1 \mu \mathrm{M}$ FS, LMWO and HMWO A $\beta$.

12a. IL-6 levels in HNPCs following treatment with $1 \mu \mathrm{M}$ HMWO, $5 \mu \mathrm{M}$ Nilvadipine, $5 \mu \mathrm{M}$ KN62 alone and co-treatment with HMWO A $\beta$.

12b. IL-8 levels in HNPCs following treatment with $1 \mu \mathrm{M}$ HMWO, $5 \mu \mathrm{M}$ Nilvadipine, $5 \mu \mathrm{M}$ KN62 alone and co-treatment with HMWO A $\beta$.

13a. Measurement of intracellular calcium entry in HNPCs following treatment with $20 \mu \mathrm{M}$ HMWO $\mathrm{A} \beta, 5 \mu \mathrm{M}$ Nilvadipine and HMWO + Nilvadipine.

13b. Quantification of calcium entry in HNPCs with Nilvadipine 
14a. Measurement of intracellular calcium entry in HNPCs following treatment with $20 \mu \mathrm{M}$ HMWO A $\beta, 5 \mu \mathrm{M}$ NS398 and HMWO + NS398.

14b. Quantification of calcium entry in HNPCs with NS398

15a. Measurement of intracellular calcium entry in HNPCs following treatment with $20 \mu \mathrm{M}$ HMWO A $\beta, 25 \mu \mathrm{M}$ Ibuprofen and HMWO + Ibuprofen.

15b. Quantification of calcium entry in HNPCs with Ibuprofen

16. Neurotoxicity observed in HNPCs following treatment with $20 \mu \mathrm{M}$ HMWO A $\beta$ alone and in combination with Nilvadipine and KN62 after 96h.

17. Neurotoxicity observed in HNPCs following treatment with $20 \mu \mathrm{M}$ HMWO A $\beta$ alone and in combination with $25 \mu \mathrm{M}$ Ibuprofen and $5 \mu \mathrm{M}$ NS398 after $96 \mathrm{~h}$.

18. LDH ratio of media versus lysate of HNPCs after $96 \mathrm{~h}$ of 96 treatment with $20 \mu \mathrm{M}$ HMWO $\mathrm{A} \beta$ alone and in combination with Nilvadipine, KN62, NS398 and Ibuprofen. 


\section{CHAPTER ONE}

\section{INTRODUCTION:}

\subsection{NEUROPATHOLOGICAL FEATURES OF ALZHEIMER'S DISEASE}

Alzheimer's disease (AD) a protein misfolding disease named after Alois

Alzheimer, is the major cause of dementia in the elderly in Western countries. The neuropathology of AD brains is characterized by the progressive accumulation of intracellular neurofibrillary tangles (NFT) and extracellular parenchymal senile plaques (Wilcock and Esiri1982). The tangles consist of hyperphosphorylated tau while the plaques comprise of beta-amyloid (A $\beta$ ) peptides (Jellinger and Bancher1998). Biological markers like the presence of $\mathrm{A} \beta$ and tau in the cerebrospinal fluid (CSF) of AD patients provide an important tool in the diagnosis of the disease but they are not foolproof as other neurodegenerative diseases also show the presence of $\mathrm{A} \beta$ and tau in the CSF (Hampel et al. 2003). Reports have shown that compared to normal control patients, brains of AD patients exhibit significant cortical synaptic loss, A $\beta$ deposition, NFT formation, and inflammation (Lue et al.1996). Although senile plaques and NFTs are the neuropathological hallmarks of AD, significant microvascular pathology including reduced vascular density, atrophic vessels, and vascular amyloid deposits as cerebral amyloid angiopathy (CAA) have also been well described as part of AD pathology (Hashimura et al.1991, Buee et al.1994, Kalaria and Hedera 1996, Jeynes and Provias 2006). For over a decade it has been thought that $A \beta$ may play an important role in mediating the initial pathogenic events in $\mathrm{AD}$ since all the mutations associated with familial forms of $\mathrm{AD}$ affect processing of $\mathrm{A} \beta$ from its substrate amyloid precursor protein 
(APP) (Selkoe 1996). The familial cases of AD are mainly due to genetic mutations in the presenilin genes (PS1 and PS2) and in the APP gene. The APOE $\varepsilon 4$ allele is also reported as a genetic risk factor for $\mathrm{AD}$ (Wilhelmus et al. 2005). The two leading hypotheses for $\mathrm{AD}$ etiology are the 'amyloid cascade hypothesis' implicating $\mathrm{A} \beta$ as the central mediator while the 'neuronal cytoskeletal degeneration hypothesis' implicates tau as the prime suspect in causing AD. Other reports also implicate $\alpha$-synuclein a synaptic protein implicated in Lewy bodies to also be responsible for AD pathology (Wirths and Bayer 2003).

\subsubsection{AMYLOID CASCADE HYPOTHESIS:}

According to the 'amyloid cascade' hypothesis that was initiated in the 1980's, $\mathrm{A} \beta$, the major protein present in plaques is produced as a result of the endoproteolytic cleavage of APP by beta $(\beta)$ and gamma $(\gamma)$ secretases, and A $\beta$ aggregates deposited around neurons as senile plaques (Russo et al. 2002, Hardy and Higgins 1992, Glenner and Wong 1984). The processing of APP results in the formation of $A \beta$ that under normal circumstances is degraded by neprilysin or other proteases and then eliminated. In neurons of $\mathrm{AD}$ patients as compared to controls there may be a decrease in alpha $(\alpha)$ secretase activity over $\beta$-secretase activity resulting in increased $A \beta$ production or lack of neprilysin/clearance mechanisms to degrade $\mathrm{A} \beta$ and clear it from the body (Buee et al. 1994, Rojas-Fernandez et al. 2002, Iwata et al. 2001) The two major enzymes, which enable the generation of $\mathrm{A} \beta$ from APP, are the $\beta$ and $\gamma$ secretases. $\beta$-secretase cleaves APP at the N-terminus to release sAPP $\beta$, a $100-\mathrm{kD}$ soluble $\mathrm{N}$-terminal fragment 
and C99, a 12-kD C-terminal fragment which remains membrane bound (Benjannet et al. 2001). Cleavage by $\alpha$-secretase produces sAPP $\alpha$ and C83, a $10-\mathrm{kD}$ membrane-bound Cterminal fragment. Both C-terminal fragments, C99 and C83, then become the substrate for one or more $\gamma$-secretases that cleave the fragments within their transmembrane domains, leading to the release and secretion of $\mathrm{A} \beta$ and the nonpathogenic $\mathrm{p} 3$ peptide, respectively (Neve et al. 2000). Hence, preventing the $\beta$ - secretase cleavage and/or enhancing $\alpha$-secretase activity would decrease the formation of A $\beta$ (Citron 2002, Vassar 2002, Tyler et al. 2002). Many studies are being carried out in vitro and in vivo to determine if blocking $\beta$-secretase activity may reduce the pathology associated with AD. The relative amount of $\beta$ versus $\alpha$ secretase cleavage is higher in $\mathrm{AD}$ compared to controls and the major $\beta$-secretase is BACE 1 over BACE 2 (Zhao et al. 2007). Studies have shown that the subcellular localization and phosphorylation of BACE affects its cleavage specificity for APP (Walter et al. 2001).

Elucidation of the proteolytic processing of APP resulting in the release of A $\beta$ revealed that $\gamma$-secretase that cleaves intramembranous APP may most likely be presenilins (Xu et al. 2002) since mutations in PS resulted in early-onset Alzheimer's disease. Also the fact that PS could specifically influence the C-terminal cleavage of A $\beta$, in particular the A $\beta 1-40 / 1-42$ ratio was another reason for researchers to believe that PS could be the elusive $\gamma$-secretase enzyme. Other researchers disagreed with this theory because PS and APP are located in different secretory compartments, and nicastrin also plays an important role in $\gamma$-secretase activity ( $\mathrm{Li}$ et al. 2003). Researchers have been trying to elucidate a possible mechanism of APP cleavage by presenilin (Annaert et al. 
1999). There is an ongoing debate if PS1 is the actual $\gamma$-secretase due to the difference in subcellular localization of PS1 and APP and also because $\gamma$-secretase is composed of other proteins like nicastrin, PEN-2, Aph-1(Cupers et al. 2001).

$\mathrm{A} \beta$ peptide in $\mathrm{AD}$ brains is composed of $39-43$ amino acids. Data suggest that soluble forms of $A \beta$ correlate better with the severity of dementia observed in $A D$ patients than aggregated forms (Mclean et al. 1999, Kim et al. 2003). Several isoforms of $A \beta$ exist, however $A \beta 1-40$ is the more soluble isoform compared to $A \beta 1-42$ which aggregates more rapidly. However in $\mathrm{AD}$ brains, the amount of $\mathrm{A} \beta$ soluble oligomers found is elevated compared to control brains. Soluble oligomers are also referred to as amyloid-beta derived diffusible ligands (ADDLs). There are two pools of $A \beta$ in $A D$ brains, one pool with soluble forms include monomers/dimers and solube oligomers and the other pool of aggregated insoluble forms of $A \beta$ form the senile plaques and give rise to cerebral amyloid angiopathy (CAA). Several studies indicate that $A \beta$ undergoes conformational changes when it interacts with the cell membrane resulting in $A \beta$ assuming functional properties of an ion channel (Bhatia et al. 2000). It has been well established that the different forms of $A \beta$ induce neurotoxicity. However, the exact mechanism of action for this neurotoxicity has not been established and is still under investigation by various research groups. One of the mechanisms by which $\mathrm{A} \beta$ mediates toxicity is by forming ion channels (Lin et al. 2001). Researchers speculate that this neurotoxicity mediated by $A \beta$ due to its ion-channel forming abilities is because $A \beta$ undergoes conformational changes when it interacts with the lipid in the cell membrane (Arispe et al. 1993, Kayed et al. 2004). 


\subsubsection{CYTOSKELETON HYPOTHESIS:}

According to the 'cytoskeleton hypothesis' tau is implicated as the prime suspect in causing $\mathrm{AD}$. Weingarten and colleagues first discovered a microtubule-associated protein tau (MAPT) in 1975 (Weingarten et al. 1975). The major function of tau in the CNS is in the stabilization of microtubules in neurons and tau might be involved in the establishment and maintenance of neuronal polarity. The tau gene located on human chromosome $17 \mathrm{q} 21$ in the human genome, contains 16 exons with the major tau isoform being encoded by 11 exons (Goedert et al. 1989, Spillantini and Goedert 1998). Alternative pre-mRNA splicing of exons 2, 3 and 10 in the single tau gene results in the formation of six different isoforms in the adult human brain (Buee et al. 2000). These isoforms ranging from 352-441 amino acids are responsible for the modulation of tau function and are characterized by the presence of three (3R tau) or four (4R tau) tandem repeats of 31-32 amino acids located in the carboxy terminal end which is also the microtubule binding domain of tau (Goedert and Jakes 2005). In adult human brain the ratio of $3 \mathrm{R}$ tau to $4 \mathrm{R}$ tau is approximately 1 and this balance is disrupted in the case of tau mutations associated with exon 10 (D'Souza and Schellenberg 2005). Various kinases and phosphatases are involved in the regulation of tau phosphorylation that occurs at a number of serine, threonine and proline residues (Butler and Shelanski 1986, Ferrer et al. 2005).

Tau protein has been used in various configurations as a diagnostic marker of degenerative changes in the CNS. Tau hyperphosphorylation is at the crux of most tauopathies since hyperphosphorylation dissociates tau from microtubules, destabilizes them and forms paired helical filaments (PHF) in vitro (Lindwall and Cole 1984, Alonso 
et al. 1994). Tau phosphorylation is regulated by an exquisite equilibrium between kinase and phosphatase activities. An imbalance of these two enzymatic processes can result in abnormal hyperphosphorylation of tau and generation of PHF. Mutations in the tau gene and tau hyperphosphorylation have been observed in many neurodegenerative diseases as well as in senescent brains. Neurodegenerative diseases of note include Pick's disease, AD, Frontotemporal dementia with Parkinsonism linked to chromosome 17 (FTDP-17), progressive supranuclear palsy (PSP), corticobasal degeneration, Niemann Pick's disease, etc. These diseases are all referred to as tauopathies since they all share a common pathology which is aggregated tau.

Tau is a major constituent of microtubules, and since microtubules offer stabilization to neurons, tau hyperphosphorylation and subsequent aggregation may be central in the neurodegeneration observed in AD (Alonso et al. 2001). Studies suggest that cognitive deterioration occurs only after the development of neurofibrillary tangles with hyperphosphorylated tau. Tau hyperphosphorylation in AD results in the reduced ability of tau to bind to microtubules. In $\mathrm{AD}$, tau is hyperphosphorylated at 30 specific amino acid sequences throughout its 441 amino acids (Gong et al. 2005). In vitro studies suggest that increases in $A \beta$ production may potentiate tau phosphorylation by activation of kinases such as glycogen synthase kinase-3 (GSK-3) (Phiel et al. 2003). Phosphorylated tau protein at Threonine 231 is seen in postmortem brain tissue of patients with AD and can be detected in CSF (Buerger et al. 2002). In vitro studies with cultured cells have shown that $A \beta$ induced tau phosphorylation is neurotoxic to cultured cells (Busciglio et al. 1995). Other supportive evidence for the tau hypothesis in AD can be found from studies with transgenic mouse models of AD that overexpress mutant APP 
or PS. These animals develop senile plaques with age, but they fail to develop NFTs and exhibit little neuronal loss (Holcomb et al. 1998). Researchers supporting the tau hypothesis claim that tau alone is sufficient to cause dementia and neurodegenration since mutations in tau cause frontotemporal dementia (FTD). In addition, studies with transgenic mice having the 'Swedish' mutation (TgAPPsw), that causes early onset AD in humans, reveal the presence of abundant $A \beta$ deposits that are visible beginning at 9 months of age (Duff et al. 1996). However, these mice do not show substantial neurodegeneration despite the presence of $A \beta$ plaques. Although amyloid and tau are often present in the same brain areas, namely hippocampus and entorhinal cortex, a mechanistic link between them has yet to be established. Recent data suggest that $A \beta$ is upstream of tau and that $\mathrm{A} \beta$ deposition induces accumulation of tau resulting in memory impairment (Gotz et al. 2004, Ribe et al. 2005). Hence there could be a possible interaction between amyloid and tau which is responsible for the pathogenesis associated in $\mathrm{AD}$. However, there is no evidence to date demonstrating that abnormal tau phosphorylation or accumulation causes amyloid deposition.

\subsubsection{NEUROVASCULAR HYPOTHESIS:}

Another recent hypothesis that is gaining momentum with regards to the pathogenesis of $\mathrm{AD}$ is the neurovascular hypothesis. Due to the link between AD and atherosclerosis (Kalback et al. 2004) neurovascular dysfunction is believed to be responsible for the cognitive decline and neurodegeneration observed in AD. The neurovascular unit in the brain consists of astrocytes, neurons, pericytes in close association with the vascular endothelium to maintain cerebral homeostasis and serve as 
the first line of defense against pathogenic factors (Frontczak-Baniewicz and Walski 2006). According to the neurovascular hypothesis for AD faulty clearance of $A \beta$ across the blood-brain barrier (BBB) together with aberrations in angiogenesis results in brain hypoperfusion and neurovascular inflammation (Zlokovic 2005, Zlokovic et al. 2005). The $\mathrm{BBB}$ regulates $\mathrm{A} \beta$ transport via two main receptors, the low density lipoprotein receptor related protein 1 (LRP1) and the receptor for advanced glycation end products (RAGE) (Deane and Zlokovic 2007). The RAGE receptor is thought to be a primary transporter of $\mathrm{A} \beta$ across the $\mathrm{BBB}$ into the brain from the systemic circulation, while the LRP-1 mediates transport of $A \beta$ out of the brain (Donahue et al. 2006). The RAGE receptor is a member of the immunoglobulin superfamily and exists in three major isoforms in the brain. They are expressed in neurons, microglia, astrocytes, pericytes, smooth muscle cells and cerebral endothelial cells. The adverse consequences of RAGE interaction with $\mathrm{A} \beta$ include perturbation of neuronal properties and functions, amplification of glial inflammatory responses, elevation of oxidative stress and amyloidosis, increased $\mathrm{A} \beta$ influx at the $\mathrm{BBB}$ and vascular dysfunction (Lue et al. 2005). Previous studies on microglia demonstrate that binding of $A \beta$ to RAGE receptor results in the production of macrophage-colony stimulating factor (M-CSF) via the NFkB dependent pathway thereby suggesting that inflammation is one of the mechanisms involved in AD neurotoxicity (Du et al. 1997). The neurovascular hypothesis in AD suggests that $A \beta$ causes a reduction in cerebral blood flow (CBF) due to vasoconstriction of cerebrovessels. A $\beta$ also causes regression of cerebrovessels due to faulty mechanisms involving angiogenesis and subsequent activation of glial cells resulting in 
neuroinflammation. Hence therapies aimed at clearance of $A \beta$ from the brain, enhancing $\mathrm{CBF}$ and preventing regression of cerebrovessels are new therapeutic targets for $\mathrm{AD}$ according to the neurovascular hypothesis.

The differentiation of AD from vascular dementia (VD) is hampered by clinical diagnostic criteria with lowered sensitivity and specificity. The most frequently examined biomarkers in the diagnosis of dementia are cerebrospinal fluid (CSF) tau, phospho-tau which is phosphorylated at threonine 181, and A $\beta 1-42$ (de Jong et al. 2006). Studies indicate that total tau and IL-6 levels were not significantly different between AD patients and VD patients. However, AD patients had higher level of phospho-tau as compared to VD patients (Jia et al. 2005). This is also supported by other studies that show higher levels of CSF phosphor-tau in $\mathrm{AD}$ patients as compared to VD patients thereby suggesting that phopho-tau is a valuable diagnostic tool to differentiate between $\mathrm{AD}$ and VD cases (Hu et al. 2002).

\subsection{ROLE OF BRAIN INFLAMMATION IN ALZHEIMER'S DISEASE:}

The vast majority of $\mathrm{AD}$ cases are sporadic with no history of associated mutations. In addition to plaques and NFT's, gliosis is another important feature of AD pathology (McGeer and McGeer 2001, McGeer et al. 1989). Microglia the resident macrophages of the brain may identify $A \beta$ oligomers or $A \beta$ aggregates as foreign material and this recognition may prompt their activation. Activated microglia found in and around amyloid plaques are morphologically characterized by short tortuous ramified processes (Meda et al. 1995). Astrocytes that become activated in AD brain are characterized by morphologically long sinuous processes that reach in and around the 
amyloid plaque. These cells upregulate glial fibrillary acidic protein (GFAP) the most specific marker of astrocytosis. The release of pro-inflammatory molecules accounts for the activated astrocytes which express GFAP (Little et al. 2001). Reactive astrocytes result in the production of other acute phase reactants such as $\alpha$-1-antichymotrypsin which are found co-localized with fibrillar cores of mature $A \beta$ plaques thereby promoting $A \beta$ aggregation (Abraham and Potter 1989). These activated microglia and astrocytes are considered to be signs of an inflammatory response in $\mathrm{AD}$ brain. The cyclooxygenase (COX) enzymes COX-1 and COX-2 responsible for the production of prostaglandins (PGs) from the substrate arachidonic acid are also upregulated in regions of the AD brain undergoing degeneration supporting the inflammation hypothesis (Masferrer et al. 1995, Zhang et al. 1997, Hoozemans et al. 2001). Also, pro-inflammatory cytokines have shown to be neurotoxic in vitro at high doses (Meda et al. 1995, Downen et al. 1999). Studies reveal that $A \beta$ is responsible for the stimulation and production of proinflammatory eicosanoids and cytokines such as TNF $\alpha$ in various in vitro models (Paris et al. 2000, Lue et al. 1999). Pro-inflammatory cytokines such as IL-1 $\beta$, TNF $\alpha$, IL-6 and IL-8 are typically found to be elevated in $\mathrm{AD}$ brain compared to non-AD subjects (McGeer and McGeer 1999, Lue et al. 2001). IL-6 stimulation in AD brains increases tau phosphorylation which further causes neurodegeneration (Quintanilla et al. 2004). IL-6 cytokine is produced within the CNS by astrocytes and microglia and under normal physiologial conditions have a neuroprotectant and neurotrophic role. However, chronic exposure of IL-6 causes neurodegeneration (Nelson et al. 2002). Patients with traumatic brain injury revealed higher levels of IL-6 and IL-8 (Kushi et al. 2003) suggesting that 
these cytokines and other chemokines could also serve as potential biomarkers for neuroinflammatory diseases such as $\mathrm{AD}$, multiple sclerosis and Parkinson's disease (Tan et al. 2007, Nagatsu et al. 2000). Converging lines of evidence from epidemiological studies, post mortem evaluations and animal models of $\mathrm{AD}$ all support the hypothesis that chronic inflammation plays a deleterious role in the pathophysiology of AD. Numerous epidemiological studies have demonstrated that NSAIDs such as ibuprofen and indomethacin significantly reduce the risk for the incidence of $\mathrm{AD}$ (McGeer and McGeer 1999, Imbimbo 2004).

TgAPPsw mice develop age dependent gliosis with increasing amyloid levels. AD-like pathology is also observed in double transgenic mice with the PS1 M146L mutation together with the TgAPPsw mutation (Holcomb et al. 1998, Duff et al. 1996). These mice develop gliosis as detected by thioflavin $\mathrm{S}$ staining and anti-A $\beta$ antibody (Holcomb et al. 1998). Studies with 10 month old TgAPPsw mice treated with ibuprofen showed reduced amyloid pathology and decreased microglial activation (Lim et al. 2000). Other studies demonstrate that this amyloid lowering property of ibuprofen in transgenic mice was due to its ability to reduce A $\beta 1-42$ production by affecting APP processing (Yan et al. 2003). Thus animal models of AD develop not only A $\beta$ deposit pathology but also manifest gliosis comparable to that found in AD patient brains. Studies in transgenic mouse models of AD particularly suggest that severity of microgliosis is directly proportional to $A \beta$ burden. One study showed that high levels of $A \beta 1-42$ rather than A $\beta 1-40$ were able to activate microglia more potently as measured by the release of TNF $\alpha$ and nitric oxide secretion (Meda et al. 1995). 
Although a plethora of research has been carried out on $\mathrm{AD}$, there is to date no known cure for this disease and the neurodegeneration is without remission. All treatments available on the market today, namely, acetylcholine esterase inhibitors, NMDA receptor blockers, anti-inflammatory drugs, antioxidants offer only symptomatic relief and slow progression of the disease to some extent (Prasad et al. 2002).

\subsection{ROLE OF CALCIUM IN INFLAMMATION AND AD:}

Altered calcium homeostasis is considered to play an important role in neurodegeneration associated with normal aging, $\mathrm{AD}$ and related disorders (Mattson 1992). In vitro studies on cultured neurons with the calcium ionophore A23187 indicated that calcium influx resulted in microtubule disruption due to altered tau phosphorylation (Mattson et al. 1991). Studies of brain tissue from AD patients reveal increased activation of calcium-dependent proteases in neurofibrillary tangles. Abnormalities in calcium regulation in astrocytes, oligodendrocytes, and microglia have also been documented in experimental models of AD (Mattson and Chan 2003, Nusslein et al. 1996).

Calcium ion is vital for neuronal signaling and is tightly regulated. Receptor mediated changes in intracellular calcium is one of the major pathways involved in signal transduction. Calcium mediated signals are generated by four main processes namely calcium influx from extracellular spaces across the plasma membrane into the cytoplasm, calcium release from internal stores into the cytoplasm, calcium extrusion from cytoplasm across the plasma membrane and calcium sequestration into intracellular calcium stores (Moller 2002). Calcium influx across the plasma membrane into the cytoplasm occurs via receptor operated channels (ROCs) triggered by ligand binding, 
voltage gated calcium channels (VGCCs) and calcium permeable store-operated channels (SOCs) which open up when intracellular stores of calcium are depleted. VGCCs are a group of voltage-gated ion channels found in neurons, glial cells, muscle cells, etc. involved in the release of neurotransmitters and hormones, muscular contraction, excitability of neurons and gene expression (Dolphin 2006). VGCCs include the neural $\mathrm{N}$-type channel blocked by $\omega$-conotoxins, the residual R-type channel involved in processes in the brain and muscle, the closely related P/Q-type channel blocked by $\omega$ agatoxins, and the dihydropyridine-sensitive L-type channels responsible for excitationcontraction coupling of skeletal, smooth, and cardiac muscle and hormone secretion in endocrine cells. The reason I evaluated the effect of L-type calcium channel blockers over other type of calcium channel blockers on reducing inflammation was due to studies in aging hippocampal or cortical neurons of rodents and rabbits that reveal an increase in L-VGCC activity. Their hypothesis is that increased L-VGCC activity drives many of the other calcium related biomarkers of hippocampal aging together with ryanodine receptors (RyR) (Thiebault et al. 2007). Other studies have demonstrated that the age-related learning impairment in rabbits is reversed by the specific L-type calcium channel blocker nimodipine thereby suggesting that elevation of L-type channel activity causes neuronal dysfunction during aging (Davare and Hell 2003).

Studies reveal that pro-inflammatory cytokines like IFN $\gamma$ and IL- $1 \beta$ induce calcium response and cause subsequent activation of microglia (Franciosi et al. 2002, Goghari et al. 2000). Influx of calcium also results in the release of PGs from the substrate arachidonic acid, the mediators of inflammation. Our previous data further support the hypothesis that $A \beta$ can activate calcium dependent secretory phospholipase 
A2 (PLA2) resulting in the production of arachidonic acid which is metabolized into proinflammatory eicosanoids (Paris et al. 2000). PGE2 induces increases in intracellular calcium both in astrocytes and in neurons. The intracellular calcium increase in neurons may be mediated by glutamate released from astrocytes (Bezzi et al. 1998). Studies on rat hippocampal neurons treated with IL-6 resulted in an increased calcium influx via NMDA-receptor, since NMDA receptor antagonists blocked this IL-6 mediated calcium influx. Further this increase in cytosolic calcium induced tau protein hyperphosphorylation via the JAK/STAT pathway (Orellana et al. 2005). Previous studies with chronic exposure of Purkinje neurons to IL-6 reveal similar increases in intracellular calcium resulting in neurodegenration (Nelson et al. 2002). Increases in intracellular calcium cause activation of microglia and release of cytokines and chemokines which are blocked when calcium is chelated (Hoffmann et al. 2003). Hence, my rationale was that perhaps calcium channel blockers (CCBs) or inhibitors of the calcium signaling pathway could help alleviate inflammation in AD. Several studies in patients with cardiovascular disease and hypertension indicate that these CCBs increase blood flow, dilate blood vessels, reduce nitric oxide release, which in turn prevents oxidative stress and reduces inflammation (Mason et al. 2003, Sudano et al. 2007). Clinical studies with Amlodipine, a calcium channel blocker showed reduced risk in the development and progression of coronary artherosclerosis on the basis of its anti-oxidant and anti-inflammatory properties. Amlodipine caused a reduction of the inflammatory chemokine monocyte chemotactic protein-1 (MCP-1) (Kataoka et al. 2004). 


\subsubsection{RATIONALE FOR CALCIUM CHANNEL BLOCKERS BEHAVING AS ANTI-INFLAMMATORY AGENTS}

Our previous studies in transgenic mouse models of AD have shown that $A \beta$ causes vasoconstriction of cerebral blood vessels and is also responsible for stimulating Cox-2 activity resulting in the production of pro-inflammatory eicosanoids (Paris et al. 2003). This $A \beta$ mediated vasoactivity can be alleviated by using calcium channel blockers both in vitro and in vivo (Paris et al. 2004). I also showed that organotypic brain slice cultures from TgAPPsw mice over 9 months produced significant levels of TNF $\alpha$ and Cox-2 activity. These mice had significant amyloid pathology and when brain slices of these mice were treated with a selective Cox-2 inhibitor NS-398, levels of TNF $\alpha$ was significantly reduced (Quadros et al. 2003) A $\beta$ has been shown to cause synaptic dysfunction and can render neurons vulnerable to excitotoxicity and apoptosis by a mechanism involving disruption of cellular calcium homeostasis (Mattson et al. 1992). Since it has been well established that inflammation and alteration in cellular calcium levels are some of the factors responsible for the pathogenesis in $\mathrm{AD}$, I hypothesized that there could be a link between altered calcium levels and inflammation. My hypothesis was that $A \beta$ could mediate inflammation by possibly altering cellular calcium levels. I also wanted to identify which conformation of $A \beta$ was most potent in mediating inflammation in glial cells and correlate this pro-inflammatory effect to altered calcium levels. My other aim was to determine the effect of the various conformations of $A \beta$ with respect to neurodegeneration and evaluate if this $A \beta$ mediated neurotoxicity

could be blocked by using calcium channel blockers or other inhibitors that are part of the 
calcium signaling pathway. The other inhibitors of the calcium signaling pathway include nuclear factor-kappa B (NFkB) inhibitors, phospholipase C (PLC) inhibitors, protein kinase C (PKC) inhibitors and calmodulin kinase inhibitors. These inhibitors could possibly have anti-inflammatory effects with $A \beta$ induced inflammation because of their property of reducing intracellular calcium. In vitro studies on neurons have shown that calcium is responsible for the stimulation of NFkB activity (Lilienbaum and Israel 2003). Other studies revealed that NFkB activity could be significantly reduced by using PKC or calmodulin kinase inhibitors (Bonizzi et al. 1999, Han and Logsdon 2000). Both PKC kinase and calmodulin kinase are activated by calcium entry into the cytosol which further activates NFkB activity in neurons (Lilienbaum and Israel 2003). Evidence from earlier studies reveals that NFkB activation causes inflammation (Hata et al. 2002, Granet et al. 2003). In addition, calcium channel blockers like amlodipine have shown to behave as anti-inflammatory agents in rat models of arteriosclerosis (Kataoka et al. 2004, Yoshii et al. 2006). Other studies on amlodipine reveal that it exerts protective vascular effects by probably suppressing pro-inflammatory cytokines and free radical generation (Chou et al. 2002, Richard 2005). Other calcium channel blockers more specifically the dihydropyridines such as nitrendipine, manidipine including amlodipine have also demonstrated anti-inflammatory properties with respect to other inflammatory diseases such as multiple sclerosis, experimental autoimmune encephalomyelitis (Toba et al. 2005, Brand-Schieber and Werner 2004). Hence my rationale that calcium channel blockers and other inhibitors of the calcium signaling pathway could have potential antiinflammatory effects in human glial cells thereby protecting neurons from the pathogenic inflammatory insults mediated by $\mathrm{A} \beta$ in $\mathrm{AD}$. 


\section{REFERENCES:}

1. Abraham CR, Potter H. Alpha 1-antichymotrypsin in brain aging and disease. Prog Clin Biol Res. 1989;317:1037-48.

2. Alonso AC, Zaidi T, Grundke-Iqbal I, Iqbal K. Role of abnormally phosphorylated tau in the breakdown of microtubules in Alzheimer disease. Proc Natl Acad Sci U S A. 1994 Jun 7;91(12):5562-6.

3. Alonso A, Zaidi T, Novak M, Grundke-Iqbal I, Iqbal K. Hyperphosphorylation induces self-assembly of tau into tangles of paired helical filaments/straight filaments. Proc Natl Acad Sci U S A. 2001 Jun 5;98(12):6923-8.

4. Alonso AD, Zaidi T, Novak M, Barra HS, Grundke-Iqbal I, Iqbal K. Interaction of tau isoforms with Alzheimer's disease abnormally hyperphosphorylated tau and in vitro phosphorylation into the disease-like protein.J Biol Chem. 2001 Oct 12;276(41):3796773.

5. Annaert WG, Levesque L, Craessaerts K, Dierinck I, Snellings G, Westaway D, George-Hyslop PS, Cordell B, Fraser P, De Strooper B. Presenilin 1 controls gammasecretase processing of amyloid precursor protein in pre-golgi compartments of hippocampal neurons.J Cell Biol. 1999 Oct 18;147(2):277-94.

6. Arispe N, Pollard HB, Rojas E. Giant multilevel cation channels formed by Alzheimer disease amyloid beta-protein [A beta P-(1-40)] in bilayer membranes. Proc Natl Acad Sci U S A. 1993 Nov 15;90(22):10573-7.

7. Benjannet S, Elagoz A, Wickham L, Mamarbachi M, Munzer JS, Basak A, Lazure C, Cromlish JA, Sisodia S, Checler F, Chretien M, Seidah NG. Post-translational processing of beta-secretase (beta-amyloid-converting enzyme) and its ectodomain shedding. The 
pro- and transmembrane/cytosolic domains affect its cellular activity and amyloid-beta production. J Biol Chem. 2001 Apr 6; 276(14): 10879-87.

8. Bezzi P, Carmignoto G, Pasti L, Vesce S, Rossi D, Rizzini BL, Pozzan T, Volterra A. Prostaglandins stimulate calcium-dependent glutamate release in astrocytes. Nature. 1998 Jan 15; 391(6664): 281-5.

9. Bhatia R, Lin H, Lal R. Fresh and globular amyloid beta protein (1-42) induces rapid cellular degeneration: evidence for AbetaP channel-mediated cellular toxicity. FASEB J. 2000 Jun;14(9):1233-43.

10. Bonizzi G, Piette J, Schoonbroodt S, Merville MP, Bours V. Role of the protein kinase $\mathrm{C}$ lambda/iota isoform in nuclear factor-kappaB activation by interleukin-1beta or tumor necrosis factor-alpha: cell type specificities. Biochem Pharmacol. 1999 Mar $15 ; 57(6): 713-20$.

11. Brand-Schieber E, Werner P. Calcium channel blockers ameliorate disease in a mouse model of multiple sclerosis. Exp Neurol. 2004 Sep;189(1):5-9.

12. Buee, L., Hof, P.R., Bouras, C., Delacourte, A., Perl, D.P, Morrison J.H., Fillit, H.M. Pathological alterations of the cerebral microvasculature in Alzheimer's disease and related dementing disorders. Acta. Neuropathol. (Berl). 87, 469-480 (1994).

13. Buee L, Bussiere T, Buee-Scherrer V, et al.: Tau protein isoforms, phosphorylation and role in neurodegenerative disorders. Brain Res Brain Res Rev. 33: 95-130, 2000. 14. Buerger K, Zinkowski R, Teipel SJ, Tapiola T, Arai H, Blennow K, Andreasen N, Hofmann-Kiefer K, DeBernardis J, Kerkman D, McCulloch C, Kohnken R, Padberg F, Pirttila T, Schapiro MB, Rapoport SI, Moller HJ, Davies P, Hampel H. Differential 
diagnosis of Alzheimer disease with cerebrospinal fluid levels of tau protein phosphorylated at threonine 231. Arch Neurol. 2002 Aug;59(8):1267-72.

15. Busciglio J, Lorenzo A, Yeh J, Yankner BA. beta-amyloid fibrils induce tau phosphorylation and loss of microtubule binding. Neuron. 1995 Apr; 14(4): 879-88.

16. Butler M, Shelanski ML. Microheterogeneity of microtubule-associated tau proteins is due to differences in phosphorylation. J Neurochem. 1986 Nov;47(5):1517-22.

17. Chou TC, Yang SP, Pei D. Amlodipine inhibits pro-inflammatory cytokines and free radical production and inducible nitric oxide synthase expression in lipopolysaccharide/interferon-gamma-stimulated cultured vascular smooth muscle cells. Jpn J Pharmacol. 2002 Jun;89(2):157-63.

18. Citron M. Emerging Alzheimer's disease therapies: inhibition of beta-secretase. Neurobiol Aging. 2002 Nov-Dec; 23(6): 1017-22.

19. Cupers P, Bentahir M, Craessaerts K, Orlans I, Vanderstichele H, Saftig P, De Strooper B, Annaert W. The discrepancy between presenilin subcellular localization and gamma-secretase processing of amyloid precursor protein. J Cell Biol. 2001 Aug 20;154(4):731-40.

20. Davare MA, Hell JW. Increased phosphorylation of the neuronal L-type $\mathrm{Ca}(2+)$ channel Ca(v)1.2 during aging. Proc Natl Acad Sci U S A. 2003 Dec 23;100(26):1601823.

21. Deane R, Zlokovic BV. Role of the blood-brain barrier in the pathogenesis of Alzheimer's disease. Curr Alzheimer Res. 2007 Apr;4(2):191-7. 
22. de Jong D, Jansen RW, Kremer BP, Verbeek MM. Cerebrospinal fluid amyloid beta42/phosphorylated tau ratio discriminates between Alzheimer's disease and vascular dementia. J Gerontol A Biol Sci Med Sci. 2006 Jul;61(7):755-8.

23. Dolphin AC. A short history of voltage-gated calcium channels. Br J Pharmacol. 2006 Jan;147 Suppl 1:S56-62.

24. Donahue JE, Flaherty SL, Johanson CE, Duncan JA 3rd, Silverberg GD, Miller MC, Tavares R, Yang W, Wu Q, Sabo E, Hovanesian V, Stopa EG. RAGE, LRP-1, and amyloid-beta protein in Alzheimer's disease. Acta Neuropathol (Berl). 2006 Oct;112(4):405-15.

25. Downen M, Amaral TD, Hua LL, Zhao ML, Lee SC. Neuronal death in cytokineactivated primary human brain cell culture: role of tumor necrosis factor-alpha. Glia. 1999 Nov;28(2):114-27.

26. D'Souza I, Schellenberg GD. Regulation of tau isoform expression and dementia. Biochim Biophys Acta. 2005 Jan 3;1739(2-3):104-15.

27. Duff K, Eckman C, Zehr C, Yu X, Prada CM, Perez-tur J, Hutton M, Buee L, Harigaya Y, Yager D, Morgan D, Gordon MN, Holcomb L, Refolo L, Zenk B, Hardy J, Younkin S. Increased amyloid-beta42(43) in brains of mice expressing mutant presenilin 1. Nature. 1996 Oct 24;383(6602):710-3.

28. Du Yan S, Zhu H, Fu J, Yan SF, Roher A, Tourtellotte WW, Rajavashisth T, Chen X, Godman GC, Stern D, Schmidt AM. Amyloid-beta peptide-receptor for advanced glycation endproduct interaction elicits neuronal expression of macrophage-colony stimulating factor: a proinflammatory pathway in Alzheimer disease. Proc Natl Acad Sci U S A. 1997 May 13;94(10):5296-301. 
29. Ferrer I, Gomez-Isla T, Puig B, Freixes M, Ribe E, Dalfo E, Avila J. Current advances on different kinases involved in tau phosphorylation, and implications in Alzheimer's disease and tauopathies. Curr Alzheimer Res. 2005 Jan;2(1):3-18.

30. Franciosi S, Choi HB, Kim SU, McLarnon JG. Interferon-gamma acutely induces calcium influx in human microglia. J Neurosci Res. 2002 Sep 1;69(5):607-13.

31. Frontczak-Baniewicz M, Walski M. Ultrastructural features of the neurovascular unit in Alzheimer's neurodegeneration. J Physiol Pharmacol. 2006 Sep;57 Suppl 4:91-6. 32. Glenner GG, Wong CW. Alzheimer's disease and Down's syndrome: sharing of a unique cerebrovascular amyloid fibril protein. Biochem Biophys Res Commun. 1984 Aug 16; 122(3): 1131-5.

33. Goedert M, Spillantini MG, Potier MC, Ulrich J, Crowther RA. Cloning and sequencing of the cDNA encoding an isoform of microtubule-associated protein tau containing four tandem repeats: differential expression of tau protein mRNAs in human brain. EMBO J. 1989 Feb;8(2):393-9.

34. Goedert M, Jakes R. Mutations causing neurodegenerative tauopathies.Biochim Biophys Acta. 2005 Jan 3;1739(2-3):240-50.

35. Goghari V, Franciosi S, Kim SU, Lee YB, McLarnon JG. Acute application of interleukin-1beta induces $\mathrm{Ca}(2+)$ responses in human microglia. Neurosci Lett. 2000 Mar 10; 281(2-3): 83-6.

36. Gong CX, Liu F, Grundke-Iqbal I, Iqbal K. Post-translational modifications of tau protein in Alzheimer's disease. J Neural Transm. 2005 Jun;112(6):813-38. 
37. Gotz J, Schild A, Hoerndli F, Pennanen L. Amyloid-induced neurofibrillary tangle formation in Alzheimer's disease: insight from transgenic mouse and tissue-culture models. Int J Dev Neurosci. 2004 Nov;22(7):453-65.

38. Granet C, Maslinski W, Miossec P. Increased AP-1 and NF-kappaB activation and recruitment with the combination of the proinflammatory cytokines IL-1beta, tumor necrosis factor alpha and IL-17 in rheumatoid synoviocytes. Arthritis Res Ther. 2004;6(3):R190-8.

39. Hampel H, Goernitz A, Buerger K. Advances in the development of biomarkers for Alzheimer's disease: from CSF total tau and Abeta (1-42) proteins to phosphorylated tau protein. Brain Res Bull. 2003 Aug 15; 61(3):243-53.

40. Han B, Logsdon CD. CCK stimulates mob-1 expression and NF-kappaB activation via protein kinase $\mathrm{C}$ and intracellular $\mathrm{Ca}(2+)$. Am J Physiol Cell Physiol. 2000 Feb;278(2):C344-51.

41. Hardy JA, Higgins GA. Alzheimer's disease: the amyloid cascade hypothesis. Science. 1992 Apr 10; 256(5054): 184-5.

42. Hashimura, T., Kimura, T. \& Miyakawa, T. Morphological changes of blood vessels in the brain with Alzheimer's disease. Jpn. J. Psychiatry Neurol. 45, 661-665 (1991). 43. Hata K, Andoh A, Shimada M, Fujino S, Bamba S, Araki Y, Okuno T, Fujiyama Y, Bamba T. IL-17 stimulates inflammatory responses via NF-kappaB and MAP kinase pathways in human colonic myofibroblasts. Am J Physiol Gastrointest Liver Physiol. 2002 Jun;282(6):G1035-44.

44. Hoffmann A, Kann O, Ohlemeyer C, Hanisch UK, Kettenmann H. Elevation of basal intracellular calcium as a central element in the activation of brain macrophages 
(microglia): suppression of receptor-evoked calcium signaling and control of release function. J Neurosci. 2003 Jun 1; 23(11): 4410-9.

45. Holcomb L, Gordon MN, McGowan E, Yu X, Benkovic S, Jantzen P, Wright K, Saad I, Mueller R, Morgan D, Sanders S, Zehr C, O'Campo K, Hardy J, Prada CM, Eckman C, Younkin S, Hsiao K, Duff K. Accelerated Alzheimer-type phenotype in transgenic mice carrying both mutant amyloid precursor protein and presenilin 1 transgenes. Nat Med. 1998 Jan;4(1):97-100.

46. Hoozemans JJ, Veerhuis R, Janssen I, Rozemuller AJ, Eikelenboom P. Interleukin1beta induced cyclooxygenase 2 expression and prostaglandin E2 secretion by human neuroblastoma cells: implications for Alzheimer's disease. Exp Gerontol. 2001 Mar;36(3):559-70.

47. Hu YY, He SS, Wang X, Duan QH, Grundke-Iqbal I, Iqbal K, Wang J. Levels of nonphosphorylated and phosphorylated tau in cerebrospinal fluid of Alzheimer's disease patients: an ultrasensitive bienzyme-substrate-recycle enzyme-linked immunosorbent assay. Am J Pathol. 2002 Apr;160(4):1269-78.

48. Imbimbo BP. The potential role of non-steroidal anti-inflammatory drugs in treating Alzheimer's disease. Expert Opin Investig Drugs. 2004 Nov;13(11):1469-81.

49. Iwata N, Tsubuki S, Tacky Y, Shirting K, Lu B, Gerard NP, Gerard C, Ham E, Lee HJ, Saido TC. Metabolic regulation of brain Abeta by neprilysin. Science. 2001 May 25; 292(5521): 1550-2.

50. Jellinger KA, Bancher C. Neuropathology of Alzheimer's disease: a critical update. J Neural Transm Suppl. 1998; 54:77-95. 
51. Jeynes B, Provias J. The possible role of capillary cerebral amyloid angiopathy in Alzheimer lesion development: a regional comparison. Acta Neuropathol (Berl). 2006 Oct;112(4):417-27.

52. Jia JP, Meng R, Sun YX, Sun WJ, Ji XM, Jia LF. Cerebrospinal fluid tau, Abeta1-42 and inflammatory cytokines in patients with Alzheimer's disease and vascular dementia. Neurosci Lett. 2005 Jul 22-29;383(1-2):12-6.

53. Kalaria, R.N. \& Hedera, P. Differential degeneration of the cerebral microvasculature in Alzheimer's disease. NeuroReport 6, 477-480 (1995).

54. Kalback W, Esh C, Castano EM, Rahman A, Kokjohn T, Luehrs DC, Sue L, Cisneros R, Gerber F, Richardson C, Bohrmann B, Walker DG, Beach TG, Roher AE. Atherosclerosis, vascular amyloidosis and brain hypoperfusion in the pathogenesis of sporadic Alzheimer's disease. Neurol Res. 2004 Jul;26(5):525-39.

55. Kataoka C, Egashira K, Ishibashi M, Inoue S, Ni W, Hiasa K, Kitamoto S, Usui M, Takeshita A. Novel anti-inflammatory actions of amlodipine in a rat model of arteriosclerosis induced by long-term inhibition of nitric oxide synthesis.Am J Physiol Heart Circ Physiol. 2004 Feb;286(2):H768-74.

56. Kayed R, Sokolov Y, Edmonds B, McIntire TM, Milton SC, Hall JE, Glabe CG. Permeabilization of lipid bilayers is a common conformation-dependent activity of soluble amyloid oligomers in protein misfolding diseases. J Biol Chem. 2004 Nov $5 ; 279(45): 46363-6$.

57. Kim HJ, Chae SC, Lee DK, Chromy B, Lee SC, Park YC, Klein WL, Krafft GA, Hong ST. Selective neuronal degeneration induced by soluble oligomeric amyloid beta protein. FASEB J. 2003 Jan; 17(1): 118-20. 
58. Kushi H, Saito T, Makino K, Hayashi N. IL-8 is a key mediator of neuroinflammation in severe traumatic brain injuries. Acta Neurochir Suppl. 2003;86:347-50.

59. Li T, Ma G, Cai H, Price DL, Wong PC. Nicastrin is required for assembly of presenilin/gamma-secretase complexes to mediate Notch signaling and for processing and trafficking of beta-amyloid precursor protein in mammals. J Neurosci. 2003 Apr $15 ; 23(8): 3272-7$

60. Lilienbaum A, Israel A. From calcium to NF-kappa B signaling pathways in neurons. Mol Cell Biol. 2003 Apr;23(8):2680-98.

61. Lim GP, Yang F, Chu T, Chen P, Beech W, Teter B, Tran T, Ubeda O, Ashe KH, Frautschy SA, Cole GM. Ibuprofen suppresses plaque pathology and inflammation in a mouse model for Alzheimer's disease. J Neurosci. 2000 Aug 1;20(15):5709-14.

62. Lin H, Bhatia R, Lal R. Amyloid beta protein forms ion channels: implications for Alzheimer's disease pathophysiology. FASEB J. 2001 Nov;15(13):2433-44. Erratum in: FASEB J 2002 May;16(7):759.

63. Lindwall G, Cole RD. Phosphorylation affects the ability of tau protein to promote microtubule assembly. J Biol Chem. 1984 Apr 25;259(8):5301-5.

64. Little AR, O'Callagha JP. Astrogliosis in the adult and developing CNS: is there a role for proinflammatory cytokines? Neurotoxicology. 2001 Oct;22(5):607-18.

65. Lue L.F, Brachova L, Civin W.H, Rogers J.J. Inflammation, A beta deposition, and neurofibrillary tangle formation as correlates of Alzheimer's disease neurodegeneration. Neuropathol Exp Neurol 1996 Oct; 55(10): 1083-8. 
66. Lue, L.F., Kuo Y.M., Roher, A.E., Brachova, L., Shen, Y., Sue, L., Beach, T., Kurth, J.H., Rydel, R.E., Rogers, J. Soluble amyloid beta peptide concentration as a predictor of synaptic change in Alzheimer's disease. Am J Pathol. 155, 853-62 (1999).

67. Lue LF, Rydel R, Brigham EF, Yang LB, Hampel H, Murphy GM Jr, Brachova L, Yan SD, Walker DG, Shen Y, Rogers J. Inflammatory repertoire of Alzheimer's disease and nondemented elderly microglia in vitro. Glia. $2001 \mathrm{Jul} ; 35(1): 72-9$.

68. Lue LF, Yan SD, Stern DM, Walker DG. Preventing activation of receptor for advanced glycation endproducts in Alzheimer's disease. Curr Drug Targets CNS Neurol Disord. 2005 Jun;4(3):249-66.

69. Mattson MP, Engle MG, Rychlik B. Effects of elevated intracellular calcium levels on the cytoskeleton and tau in cultured human cortical neurons. Mol Chem Neuropathol. 1991 Oct;15(2):117-42.

70. Masferrer JL, Zweifel BS, Colburn SM, Ornberg RL, Salvemini D, Isakson P, Seibert K. The Role of Cyclooxygenase-2 in Inflammation. Am J Ther. 1995 Sep;2(9):607-610. 71. Mason RP, Marche P, Hintze TH. Novel vascular biology of third-generation L-type calcium channel antagonists: ancillary actions of amlodipine. Arterioscler Thromb Vasc Biol. 2003 Dec; 23(12): 2155-63.

72. Mattson MP, Cheng B, Davis D, Bryant K, Lieberburg I, Rydel RE. beta-Amyloid peptides destabilize calcium homeostasis and render human cortical neurons vulnerable to excitotoxicity. J Neurosci. 1992 Feb; 12(2): 376-89.

73. Mattson MP. Calcium as sculptor and destroyer of neural circuitry. Exp Gerontol. 1992;27(1):29-49. 
74. Mattson MP, Chan SL. Neuronal and glial calcium signaling in Alzheimer's disease. Cell Calcium. 2003 Oct-Nov; 34(4-5): 385-97.

75. McGeer PL, Akiyama H, Itagaki S, McGeer EG. Activation of the classical complement pathway in brain tissue of Alzheimer patients. Neurosci Lett. 1989 Dec 15; 107(1-3): 341-6.

76. McGeer EG, McGeer PL. Brain inflammation in Alzheimer disease and the therapeutic implications. Curr Pharm Des. 1999 Oct;5(10):821-36.

77. McGeer PL, McGeer EG. Inflammation, autotoxicity and Alzheimer disease. Neurobiol Aging. 2001 Nov-Dec;22(6):799-809.

78. McLean, C.A, Cherny, R.A, Fraser, F.W, Fuller, S.J, Smith, M.J, Beyreuther, K, Bush, A.I, Masters, C.L. Soluble pool of Abeta amyloid as a determinant of severity of neurodegeneration in Alzheimer's disease. Ann Neurol. 46, 860-6 (1999).

79. Meda L, Cassatella MA, Szendrei GI, Otvos L Jr, Baron P, Villalba M, Ferrari D, Rossi F. Activation of microglial cells by beta-amyloid protein and interferon-gamma. Nature. 1995 Apr 13; 374(6523):647-50.

80. Nagatsu T, Mogi M, Ichinose H, Togari A. Cytokines in Parkinson's disease. J Neural Transm Suppl. 2000; (58):143-51.

81. Nelson TE, Ur CL, Gruol DL. Chronic interleukin-6 exposure alters electrophysiological properties and calcium signaling in developing cerebellar purkinje neurons in culture. J Neurophysiol. 2002 Jul;88(1):475-86.

82. Neve RL, McPhie DL, Chen Y. Alzheimer's disease: a dysfunction of the amyloid precursor protein (1). Brain Res. 2000 Dec 15; 886(1-2): 54-66. Review. 
83. Nusslein HG, Frosch KH, Woith W, Lane P, Kalden JR, Manger B. Increase of intracellular calcium is the essential signal for the expression of CD40 ligand. Eur $\mathbf{J}$ Immunol. 1996 Apr; 26(4): 846-50.

84. Orellana DI, Quintanilla RA, Gonzalez-Billault C, Maccioni RB. Role of the JAKs/STATs pathway in the intracellular calcium changes induced by interleukin-6 in hippocampal neurons. Neurotox Res. 2005 Nov;8(3-4):295-304.

85. Paris D, Town T, Mori T, Parker TA, Humphrey J, Mullan M. Soluble beta-amyloid peptides mediate vasoactivity via activation of a pro-inflammatory pathway. Neurobiol Aging. 2000 Mar-Apr;21(2):183-97.

86. Paris D, Humphrey J, Quadros A, Patel N, Crescentini R, Crawford F, Mullan M. Vasoactive effects of A beta in isolated human cerebrovessels and in a transgenic mouse model of Alzheimer's disease: role of inflammation. Neurol Res. 2003 Sep;25(6):642-51. 87. Paris D, Quadros A, Humphrey J, Patel N, Crescentini R, Crawford F, Mullan M. Nilvadipine antagonizes both Abeta vasoactivity in isolated arteries, and the reduced cerebral blood flow in APPsw transgenic mice. Brain Res. 2004 Feb 27;999(1):53-61. 88. Phiel CJ, Wilson CA, Lee VM, Klein PS. GSK-3alpha regulates production of Alzheimer's disease amyloid-beta peptides. Nature. 2003 May 22;423(6938):435-9. 89. Prasad KN, Cole WC, Prasad KC. Risk factors for Alzheimer's disease: role of multiple antioxidants, non-steroidal anti-inflammatory and cholinergic agents alone or in combination in prevention and treatment. J Am Coll Nutr. 2002 Dec; 21(6): 506-22. 90. Quadros A, Patel N, Crescentini R, Crawford F, Paris D, Mullan M. Increased TNFalpha production and Cox-2 activity in organotypic brain slice cultures from APPsw transgenic mice. Neurosci Lett. 2003 Dec 15;353(1):66-8. 
91. Quintanilla RA, Orellana DI, Gonzalez-Billault C, Maccioni RB. Interleukin-6 induces Alzheimer-type phosphorylation of tau protein by deregulating the cdk $5 / \mathrm{p} 35$ pathway. Exp Cell Res. 2004 Apr 15;295(1):245-57.

92. Ribe EM, Perez M, Puig B, Gich I, Lim F, Cuadrado M, Sesma T, Catena S, Sanchez B, Nieto M, Gomez-Ramos P, Moran MA, Cabodevilla F, Samaranch L, Ortiz L, Perez A, Ferrer I, Avila J, Gomez-Isla T. Accelerated amyloid deposition, neurofibrillary degeneration and neuronal loss in double mutant APP/tau transgenic mice. Neurobiol Dis. 2005 Dec;20(3):814-22.

93. Richard S. Vascular effects of calcium channel antagonists: new evidence. Drugs. 2005;65 Suppl 2:1-10.

94. Rojas-Fernandez CH, Chen M, Fernandez HL. Implications of amyloid precursor protein and subsequent beta-amyloid production to the pharmacotherapy of Alzheimer's disease. Pharmacotherapy. 2002 Dec; 22(12): 1547-63.

95. Russo C, Venezia V, Salis S, Dolcini V, Schettini G. Molecular aspects of neurodegeneration in Alzheimer's disease. Funct Neurol. 2002 Apr-Jun; 17(2): 65-70. 96. Selkoe DJ. Amyloid beta-protein and the genetics of Alzheimer's disease. J Biol Chem. 1996 Aug 2;271(31):18295-8. Review.

97. Spillantini MG, Goedert M.: Tau protein pathology in neurodegenerative diseases.Trends Neurosci. 21: 428-433, 1998.

98. Sudano I, Virdis A, Taddei S, Spieker L, Corti R, Noll G, Salvetti A, Luscher TF. Chronic treatment with long-acting nifedipine reduces vasoconstriction to endothelin-1 in essential hypertension. Hypertension. 2007 Feb;49(2):285-90. 
99. Tan ZS, Beiser AS, Vasan RS, Roubenoff R, Dinarello CA, Harris TB, Benjamin EJ, Au R, Kiel DP, Wolf PA, Seshadri S. Inflammatory markers and the risk of Alzheimer disease: the Framingham Study. Neurology. 2007 May 29;68(22):1902-8.

100. Thibault O, Gant JC, Landfield PW. Expansion of the calcium hypothesis of brain aging and Alzheimer's disease: minding the store.Aging Cell. 2007 Jun;6(3):30717.

101.Toba H, Nakagawa Y, Miki S, Shimizu T, Yoshimura A, Inoue R, Asayama J, Kobara M, Nakata T. Calcium channel blockades exhibit anti-inflammatory and antioxidative effects by augmentation of endothelial nitric oxide synthase and the inhibition of angiotensin converting enzyme in the N(G)-nitro-L-arginine methyl esterinduced hypertensive rat aorta: vasoprotective effects beyond the blood pressurelowering effects of amlodipine and manidipine. Hypertens Res. 2005 Aug;28(8):689-700. 102. Tyler SJ, Dawbarn D, Wilcock GK, Allen SJ. alpha- and beta-secretase: profound changes in Alzheimer's disease. Biochem Biophys Res Commun. 2002 Dec 6; 299(3): 373-6.

103. Vassar R. beta-Secretase (BACE) as a drug target for alzheimer's disease. Adv Drug Deliv Rev. 2002 Dec 7; 54(12): 1589-602.

104. Walter J, Fluhrer R, Hartung B, Willem M, Kaether C, Capell A, Lammich S, Multhaup G, Haass C. Phosphorylation regulates intracellular trafficking of betasecretase. J Biol Chem. 2001 May 4;276(18):14634-41.

105. Weingarten MD, Lockwood AH, Hwo SY, Kirschner MW. A protein factor essential for microtubule assembly. Proc Natl Acad Sci U S A. 1975 May;72(5):1858-62. 
106. Wilcock GK, Esiri MM. Plaques, tangles and dementia. A quantitative study. J Neurol Sci. 1982 Nov;56(2-3):343-56.

107. Wilhelmus MM, Otte-Holler I, Davis J, et al.: Apolipoprotein E genotype regulates amyloid-beta cytotoxicity. J Neurosci. 2005 Apr 6;25(14):3621-7.

108. Wirths O, Bayer TA. Alpha-synuclein, Abeta and Alzheimer's disease. Prog Neuropsychopharmacol Biol Psychiatry. 2003 Feb;27(1):103-8.

109. Xu M, Lai MT, Huang Q, DiMuzio-Mower J, Castro JL, Harrison T, Nadin A, Neduvelil JG, Shearman MS, Shafer JA, Gardell SJ, Li YM. gamma-Secretase:

characterization and implication for Alzheimer disease therapy. Neurobiol. Aging. 2002 Nov-Dec; 23(6): 1023-30.

110. Yan Q, Zhang J, Liu H, Babu-Khan S, Vassar R, Biere AL, Citron M, Landreth G. Anti-inflammatory drug therapy alters beta-amyloid processing and deposition in an animal model of Alzheimer's disease. J Neurosci. 2003 Aug 20;23(20):7504-9.

111. Yoshii T, Iwai M, Li Z, Chen R, Ide A, Fukunaga S, Oshita A, Mogi M, Higaki J, Horiuchi M. Regression of atherosclerosis by amlodipine via anti-inflammatory and antioxidative stress actions. Hypertens Res. 2006 Jun;29(6):457-66.

112. Zhang Y, Shaffer A, Portanova J, et al. Inhibition of cyclooxygenase-2 rapidly reverses inflammatory hyperalgesia and prostaglandin E2 production. J Pharmacol Exp Ther. 1997; 283(3):1069-75.

113. Zhao J, Fu Y, Yasvoina M, Shao P, Hitt B, O'Connor T, Logan S, Maus E, Citron M, Berry R, Binder L, Vassar R. Beta-site amyloid precursor protein cleaving enzyme 1 levels become elevated in neurons around amyloid plaques: implications for Alzheimer's disease pathogenesis. J Neurosci. 2007 Apr 4;27(14):3639-49. 
114. Zlokovic BV. Neurovascular mechanisms of Alzheimer's neurodegeneration. Trends Neurosci. 2005 Apr;28(4):202-8.

115. Zlokovic BV, Deane R, Sallstrom J, Chow N, Miano JM. Neurovascular pathways and Alzheimer amyloid beta-peptide. Brain Pathol. 2005 Jan;15(1):78-83. 


\title{
CHAPTER TWO
}

\section{Increased TNF $\alpha$ Production and Cox-2 Activity in Organotypic Brain Slice Cultures from APPsw Transgenic Mice}

\begin{abstract}
$\beta$-amyloid $(\mathrm{A} \beta)$ peptides are the principal component of senile plaques and vascular deposits in Alzheimer's disease (AD) and are derived from the proteolytic cleavage of the $\beta$-amyloid precursor protein (APP). I have previously shown that synthetic $A \beta$ can stimulate cyclooxygenase-2 (Cox-2) activity in brain organotypic slice cultures. In the present study, I used brain slices from transgenic APP Swedish (TgAPPsw) mice and control littermates of different age groups to determine the effect of APP overexpression on the levels of prostaglandin and TNF $\alpha$ release. The production of eicosanoid and TNF $\alpha$ was increased as a function of age in organotypic brain slice culture from TgAPPsw mice compared to age matched control littermates. I also showed that the selective Cox-2 inhibitor NS-398 reduces the production of eicosanoid and TNF $\alpha$ in organotypic brain slice cultures of TgAPPsw mice. In conclusion, my data suggest that either activity or expression of Cox-2 is increased in TgAPPsw mice brains as a function of age, contributing to an increased production of pro-inflammatory eicosanoids and TNF $\alpha$.
\end{abstract}

Keywords: Alzheimer's disease, inflammation, Cox-2, TgAPPsw mice, $\mathrm{PGE}_{2}$, TNF $\alpha$ 


\section{INTRODUCTION:}

Alzheimer's disease (AD) is a neurodegenerative disease characterized by extracellular $\mathrm{A} \beta$ deposits and intracellular neurofibrillary tangles (Wilcock and Esiri 1982). AD is a multifactorial disease, of which neuroinflammation is suggested to be one of the major contributing factors in the progression of the disease (Bamberger and Landreth 2002, Eikelenboom et al. 2002). This is evidenced by the upregulation of both cyclooxygenase (Cox) enzymes, Cox-1 and Cox-2 in AD brain (Ho et al. 2001) and by the fact that several epidemiological studies have revealed that non-steroidal antiinflammatory drugs (NSAIDs) reduce the risk for developing AD (McGeer and McGeer 1998). NSAIDs block Cox-1 and Cox-2 that are responsible for the production of prostaglandins (Dannhardt and Kiefer 2001). Cerebral amyloid plaques in AD patients are co-localized with activated microglia and astrocytes. Several reports have revealed that activated microglia and astrocytes release eicosanoids and cytokines that may contribute to the inflammatory response observed in AD brains (Vehmas et al. 2003). We have shown previously in organotypic rat brain slices, that synthetic $A \beta$ peptide can stimulate the production of prostaglandin $\mathrm{E}_{2}\left(\mathrm{PGE}_{2}\right)$ and $\mathrm{TNF} \alpha$ via a Cox-2 dependent manner (Paris et al. 2002). A $\beta$ progressively accumulates in the brains of transgenic mice overexpressing APP with the Swedish mutation (TgAPPsw line 2576). Before 9 months of age, no $\beta$-amyloid plaque can be observed in the brain of these animals, after 9 months the amount of $A \beta$ deposits increase with age (Kuo et al. 2001). 


\section{METHODS:}

$1 \mathrm{~mm}$ thick brain slices were sectioned using a mouse brain slicer from TgAPPsw and control animals at different ages (3 month, 10 month, 14 month, 17 month) and cultured in neurobasal media supplemented with 5\% B27 (Gibco-Invitrogen, CA) and Penicillin-Streptomycin-Fungizone mixture. The levels of $\mathrm{PGE}_{2}$ (Fig. 1) and TNF $\alpha$ (Fig.2) that accumulate in the culture medium surrounding the brain slices after $24 \mathrm{~h}$ incubation at $37^{\circ} \mathrm{C}$ was measured using ELISA kits (Biosource, CA).

\section{RESULTS:}

No difference in the accumulation of $\mathrm{PGE}_{2}$ and $\mathrm{TNF} \alpha$ were observed between 3 month-old TgAPPsw and control organotypic brain slice cultures. An increased accumulation of both $\mathrm{PGE}_{2}$ and $\mathrm{TNF} \alpha$ was observed in TgAPPsw brain slice cultures compared to control brain slices cultures isolated from 10, 14 and 17 month-old animals. To determine whether the increased production of $\mathrm{PGE}_{2}$ were dependent on $\mathrm{COX}-2$ activity, I treated the brain slices with $20 \mu \mathrm{M}$ of the selective COX-2 inhibitor NS-398. NS-398 completely inhibited the increased production of $\mathrm{PGE}_{2}$ (Fig. 3) in $14 \mathrm{M}$ TgAPPsw brain slice culture compared to control cultures suggesting that the increased $\mathrm{PGE}_{2}$ production observed is mediated by COX-2. Interestingly, NS-398 also partially alleviated the increased TNF $\alpha$ production observed in organotypic brain slice culture from TgAPPsw mice (Fig. 4). 


\section{DISCUSSION:}

Microgliosis and astrocytosis are known to be associated with $\beta$-amyloid deposits in the brain of TgAPPsw mice (Gasic-Milenkovic et al. 2003) and in vitro, activated microglia and astrocytes are known to produce eicosanoids and TNF $\alpha$ (Casal et al. 2002). My data suggest that the increased production of $\mathrm{PGE}_{2}$ and $\mathrm{TNF} \alpha$ by organotypic brain slice cultures from TgAPPsw mice older than 9 months may be related to the glial reaction occurring in the brain of TgAPPsw mice. The fact that the selective Cox-2 inhibitor NS-398 was able to reduce TNF $\alpha$ levels suggests that metabolites of the Cox-2 pathway are also important for regulating $\mathrm{TNF} \alpha$ release. $\mathrm{TNF} \alpha$ is a cytokine produced in response to inflammation and brain injury by astrocytes and microglia (Lee et al. 2000). Studies in transgenic and knockout mouse models of TNF $\alpha$ have revealed that this cytokine plays a dual role in the brain (Probert et al. 1997). TNF $\alpha$ can be both protective and damaging depending on the levels produced and the duration of action (Pober 1987). Increased levels of $\mathrm{TNF} \alpha$ activate microglia resulting in the production of additional cytokines that may cause neurodegeneration (Neumann et al. 2002). Altogether my data show that the brains of TgAPPsw mice are subjected to inflammatory stress with aging leading to increased Cox-2 activity and $\mathrm{TNF} \alpha$ production. We have previously shown in vitro using rat brain slices that synthetic $\mathrm{A} \beta$ is capable of inducing the production of proinflammatory cytokines and TNF $\alpha$ (Paris et al 2002). My results using organotypic brain slice cultures from TgAPPsw and control littermates reveal a progressive stimulation of Cox-2 activity and TNF- $\alpha$ production in function of age. Products of the Cox-2 enzyme are known to play a role in long-term potentiation (LTP) in hippocampal 
neurons and postsynaptic membrane excitability (Chen et al. 2002) suggesting that a stimulation of Cox-2 activity by A $\beta$ may impair neuronal functions and affect learning and memory. My data support the fact that there is an active inflammatory process occurring in the brain of TgAPPsw mice. The fact that young TgAPPsw mice do not show this inflammatory condition suggests that inflammation parallels the accumulation of $\mathrm{A} \beta$ in the brain and might be associated with gliosis. Moreover, my data demonstrate that the use of selective Cox-2 inhibitors can block the increased $\mathrm{PGE}_{2}$ release observed in TgAPPsw brain slices suggesting that Cox-2 activity is upregulated in the brain of TgAPPsw mice. Metabolites of the arachidonic acid cascade are important mediators of LTP and neuronal plasticity; the abnormal stimulation of Cox-2 activity observed may therefore lead to impaired neuronal function. Besides, other studies with TNF $\alpha$ suggest that, through activation of the transcription factor NF-kappaB, TNF $\alpha$ may modulate neuronal excitability and vulnerability to excitotoxicity (Furukawa and Mattson 1998). My data demonstrate that the selective Cox-2 inhibitor NS-398 can also reduce TNF $\alpha$ levels significantly. Hence, blocking Cox-2 enzyme activity by using selective Cox-2 inhibitors may be efficient at reducing neuroinflammatory events occurring in AD brains.

\section{ACKNOWLEDGMENTS:}

This work was funded by the James Haley Veterans Administration Merit Award. I wish to also thank Bob and Diane Roskamp for additional support, which helped to make this work possible. 
Figure 1:

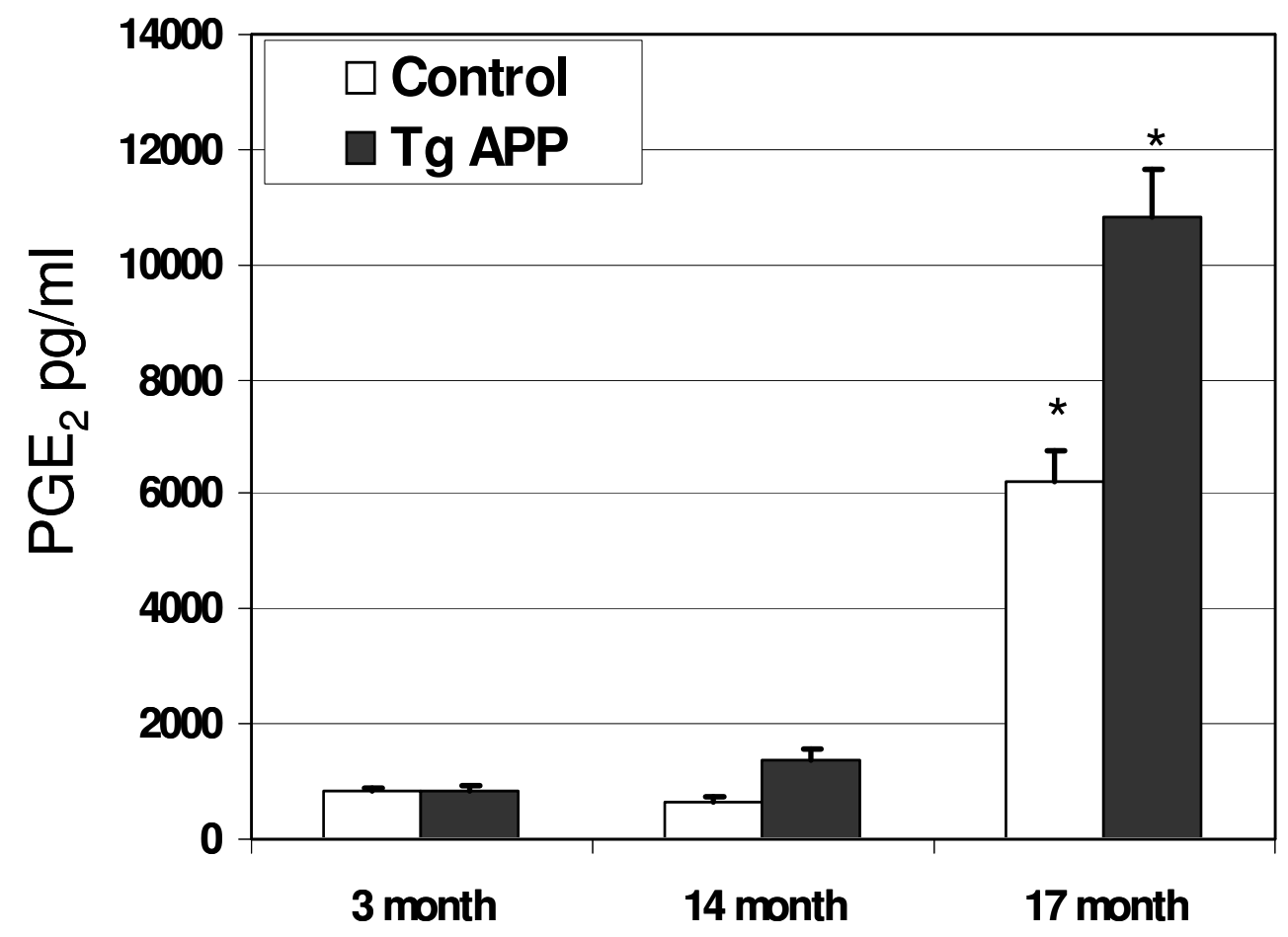

Fig. 1: $\mathrm{PGE}_{2}$ release in culture media surrounding $3 \mathrm{M}, 14 \mathrm{M}, 17 \mathrm{M}$ old control and TgAPP sw mice brain slices. ANOVA revealed significant main effect of age $(p<0.001)$, of transgenicity $(\mathrm{p}<0.001)$, interactivity between age and transgenicity $(\mathrm{p}<0.001)$. Post-hoc analysis showed significant differences in $\mathrm{PGE}_{2}$ levels between control and TgAPP sw $17 \mathrm{M}$ of age brain slice culture media. 
Figure 2:

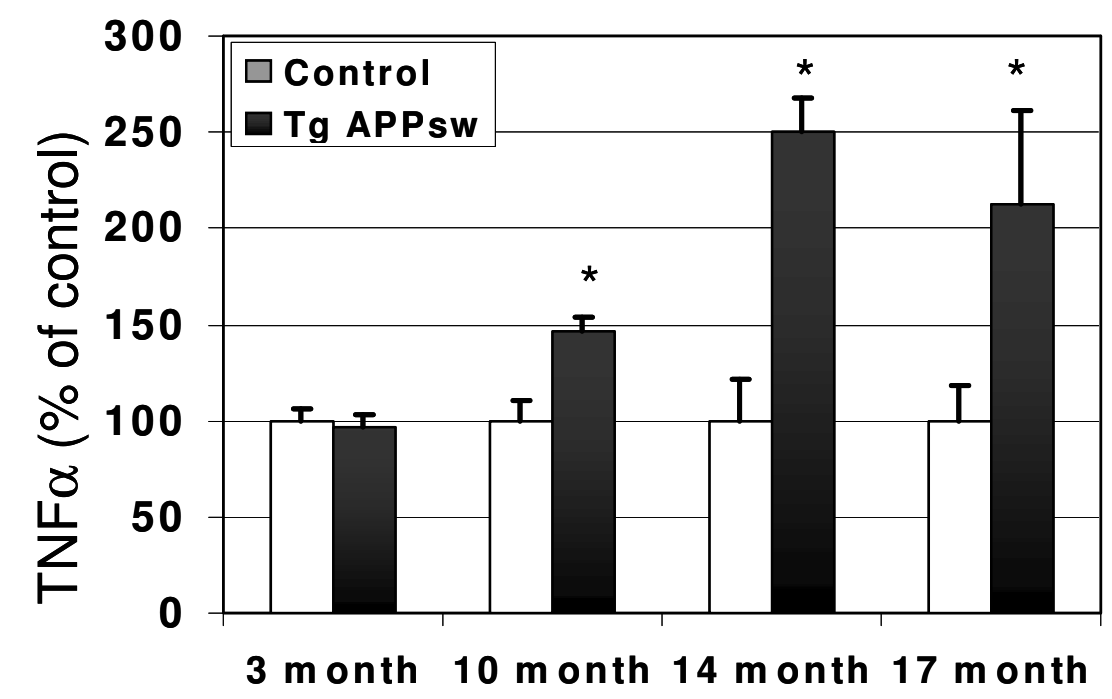

Fig. 2: TNF $\alpha$ levels in culture media surrounding $3 \mathrm{M}, 10 \mathrm{M}, 14 \mathrm{M}$ and $17 \mathrm{M}$ old control and TgAPP sw mice brain slices. ANOVA revealed significant main effect of age $(\mathrm{p}<0.009)$, main effect of transgenicity $(\mathrm{p}<0.001)$ and an interactivity between them $(\mathrm{p}<0.009)$. Post-hoc analysis revealed significant differences in $\mathrm{TNF} \alpha$ production between control 14M \& TgAPP 14M $(\mathrm{p}<0.009)$ as well as significance difference between control 17M \& TgAPP 17M $(\mathrm{p}<0.05)$. 
Figure 3:

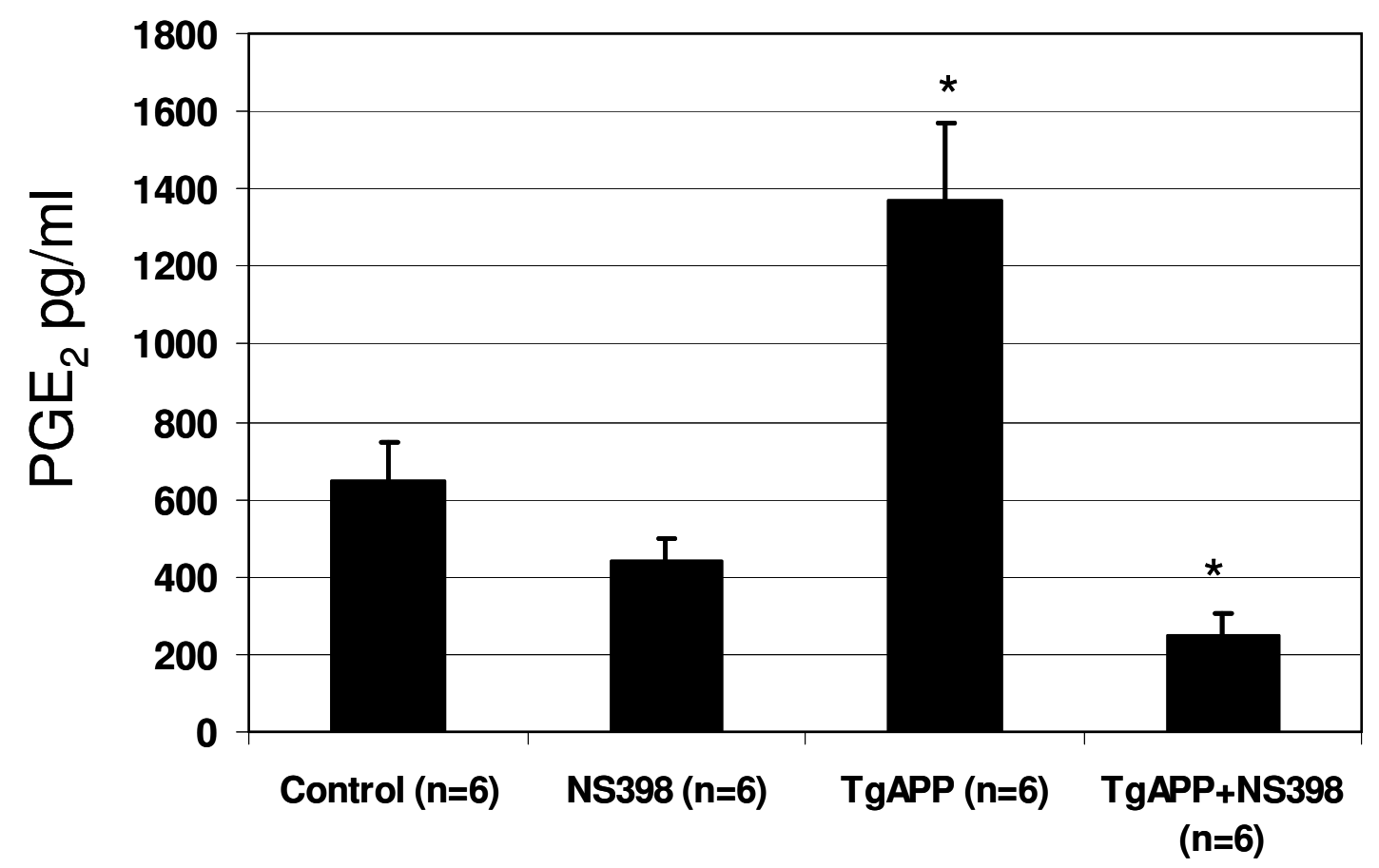

Fig. 3: $\mathrm{PGE}_{2}$ release in culture media surrounding $14 \mathrm{M}$ old brain slices of control and TgAPP sw mice treated with and without $20 \mu \mathrm{M}$ NS398. ANOVA revealed significant main effect of transgenicity $(\mathrm{p}=0.038)$, a main effect of NS398 $(\mathrm{p}<0.001)$ as well as interactivity between NS398 and transgenicity $(\mathrm{p}<0.001)$. Post-hoc analysis showed significant differences between $\mathrm{PGE}_{2}$ production in control cortex \& TgAPP cortex but no significant differences between control cortex \& TgAPP cortex \& between NS398 and TgAPP cortex $(\mathrm{p}=0.4)$ showing that NS398 completely inhibits the production of $\mathrm{PGE}_{2}$ in TgAPP brain slice. 
Figure 4:

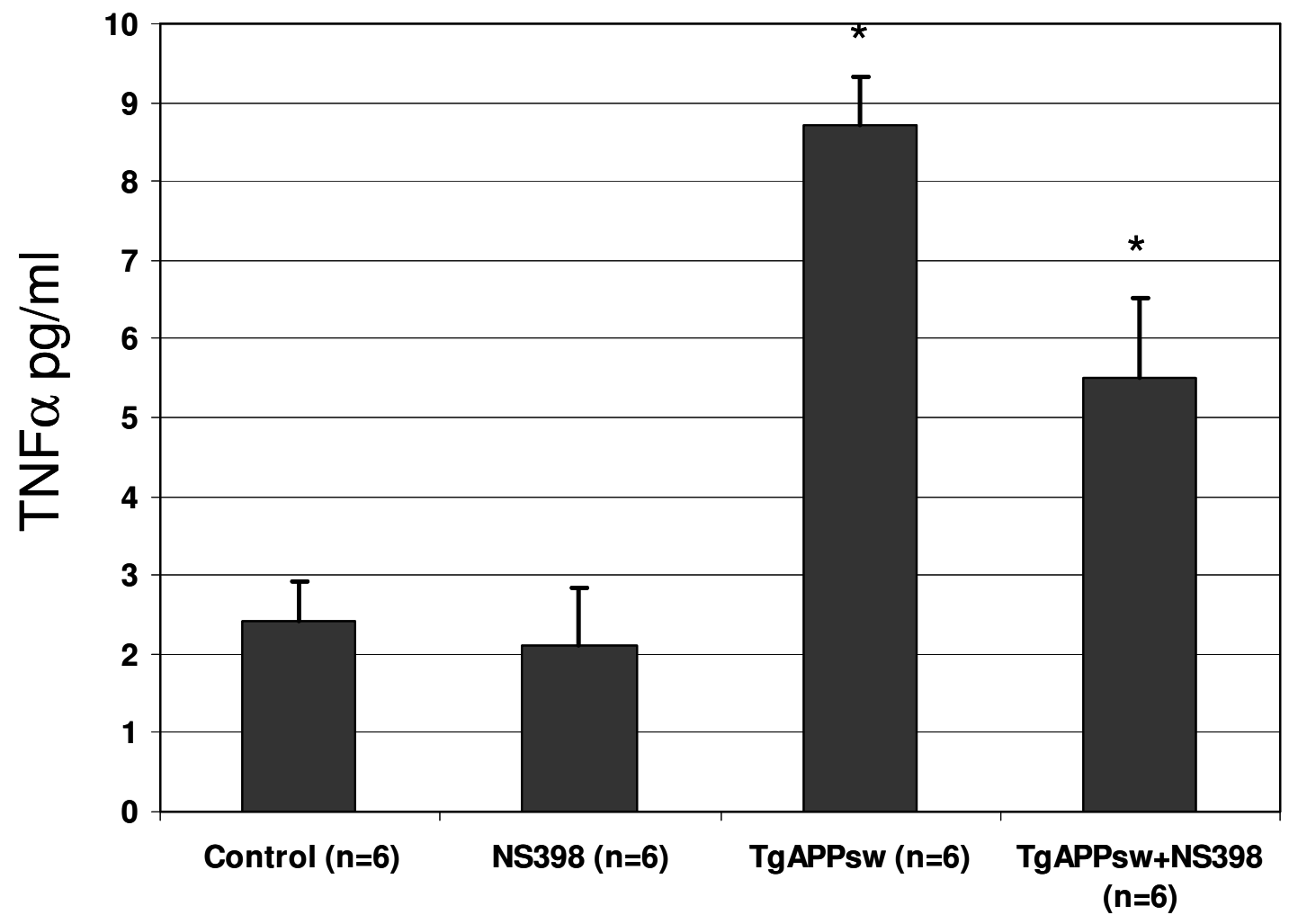

Fig. 4: TNF $\alpha$ levels in culture media surrounding 14M old brain slices of control and TgAPPsw mice treated with and without $20 \mu \mathrm{M}$ NS398. ANOVA revealed significant main effect of NS398 $(\mathrm{p}<0.04)$, main effect of transgenicity $(\mathrm{p}<0.001)$ as well as interactivity between the two $(\mathrm{p}<0.04)$. Post-hoc analysis revealed significant difference in TNF $\alpha$ production between control and TgAPPsw cortex $(\mathrm{p}<0.001)$. Hence, NS398 inhibits TNF $\alpha$ production by TgAPP sw brain slice. 


\section{REFERENCES:}

[1] Bamberger ME, Landreth GE. Inflammation, apoptosis, and Alzheimer's disease. Neuroscientist. 2002 Jun;8(3): 276-83. Review.

[2] Casal C, Serratosa J, Tusell JM. Relationship between beta-AP peptide aggregation and microglial activation.Brain Res. 2002 Feb 22;928(1-2):76-84.

[3] Chen C, Magee JC, Bazan NG. Cyclooxygenase-2 regulates prostaglandin E2 signaling in hippocampal long-term synaptic plasticity.J Neurophysiol. 2002 Jun; 87(6): 2851-7.

[4] Dannhardt G, Kiefer W. Cyclooxygenase inhibitors--current status and future prospects.Eur J Med Chem. 2001 Feb;36(2):109-26. Review.

[5] Eikelenboom P, Bate C, Van Gool WA, Hoozemans JJ, Rozemuller JM, Veerhuis R, Williams A. Neuroinflammation in Alzheimer's disease and prion disease. Glia. 2002 Nov; 40(2): 232-9. Review.

[6] Furukawa K, Mattson MP. The transcription factor NF-kappaB mediates increases in calcium currents and decreases in NMDA- and AMPA/kainate-induced currents induced by tumor necrosis factor-alpha in hippocampal neurons. J Neurochem. 1998 May; 70(5): 1876-86.

[7] Gasic-Milenkovic J, Dukic-Stefanovic S, Deuther-Conrad W, Gartner U, Munch G. beta-Amyloid peptide potentiates inflammatory responses induced by lipopolysaccharide, interferon -gamma and 'advanced glycation endproducts' in a murine microglia cell line. Eur J Neurosci. 2003 Feb; 17(4): 813-21. 
[8] Ho L, Purohit D, Haroutunian V, Luterman JD, Willis F, Naslund J, Buxbaum JD, Mohs RC, Aisen PS, Pasinetti GM. Neuronal cyclooxygenase 2 expression in the hippocampal formation as a function of the clinical progression of Alzheimer disease. Arch Neurol. 2001 Mar; 58(3): 487-92.

[9] Kuo YM, Beach TG, Sue LI, Scott S, Layne KJ, Kokjohn TA, Kalback WM, Luehrs DC, Vishnivetskaya TA, Abramowski D, Sturchler-Pierrat C, Staufenbiel M, Weller RO, Roher AE. The evolution of A beta peptide burden in the APP23 transgenic mice: implications for A beta deposition in Alzheimer disease.Mol Med. 2001 Sep;7(9):609-18. [10] Lee YB, Schrader JW, Kim SU. p38 map kinase regulates TNF-alpha production in human astrocytes and microglia by multiple mechanisms. Cytokine. $2000 \mathrm{Jul}$; 12(7): 87480.

[11] McGeer EG, McGeer PL. The importance of inflammatory mechanisms in Alzheimer disease. Exp Gerontol. 1998 Aug; 33(5): 371-8. Review.

[12] Neumann H, Schweigreiter R, Yamashita T, Rosenkranz K, Wekerle H, Barde YA. Tumor necrosis factor inhibits neurite outgrowth and branching of hippocampal neurons by a rho-dependent mechanism. J Neurosci. 2002 Feb 1; 22(3): 854-62.

[13] Paris D, Townsend KP, Obregon DF, Humphrey J, Mullan M. Pro-inflammatory effect of freshly solubilized beta-amyloid peptides in the brain. Prostaglandins Other Lipid Mediat. 2002 Sep; 70 (1-2): 1-12.

[14] Pober JS. Effects of tumour necrosis factor and related cytokines on vascular endothelial cells. Ciba Found Symp. 1987; 131:170-84. Review.

[15] Probert L, Akassoglou K, Kassiotis G, Pasparakis M, Alexopoulou L, Kollias G. TNF-alpha transgenic and knockout models of CNS inflammation and degeneration. 
J Neuroimmunol. 1997 Feb; 72(2): 137-41. Review.

[16] Vehmas AK, Kawas CH, Stewart WF, Troncoso JC. Immune reactive cells in senile plaques and cognitive decline in Alzheimer's disease. Neurobiol Aging. 2003 Mar-Apr; 24 (2): 321-31.

[17] Weggen S, Eriksen JL, Das P, Sagi SA, Wang R, Pietrzik CU, Findlay KA, Smith TE, Murphy MP, Bulter T, Kang DE, Marquez-Sterling N, Golde TE, Koo EH. A subset of NSAIDs lower amyloidogenic Abeta42 independently of cyclooxygenase activity. Nature. 2001 Nov 8; 414(6860): 212-6

[18] Wilcock GK, Esiri MM. Plaques, tangles and dementia. A quantitative study. J Neurol Sci. 1982 Nov; 56(2-3): 343-56.

[19] Xiang Z, Ho L, Yemul S, Zhao Z, Qing W, Pompl P, Kelley K, Dang A, Qing W, Teplow D, Pasinetti GM. Cyclooxygenase-2 promotes amyloid plaque deposition in a mouse model of Alzheimer's disease neuropathology. Gene Expr. 2002; 10(5-6): 271-8. 


\title{
CHAPTER THREE
}

\section{Increase of calcium entry by $A \beta$ promotes inflammation in human astrocytes and microglia}

\begin{abstract}
:
BACKGROUND: A $\beta$ has been shown to cause synaptic dysfunction and can render neurons vulnerable to excitotoxicity and apoptosis by a mechanism involving disruption of cellular calcium homeostasis. Studies have shown that an increase in intracellular calcium plays an important role in the activation of glia and in the propagation of inflammatory reactions in the CNS. My aim was to identify whether A $\beta$ could affect calcium entry in human astrocytes and microglia and whether a correlation between calcium dysregulation and the pro-inflammatory effect of $\mathrm{A} \beta$ could be established. My data show that high molecular weight oligomers (HMWO) of A $\beta 1-42$ stimulate calcium entry in microglia and astrocytes more potently than low molecular weight oligomers (LMWO) of A $\beta 1-42$ or preparations of freshly solubilized (FS) $A \beta$ containing essentially dimeric forms of the peptide. In addition, I show that the HMWO forms of A $\beta$ are more potent at stimulating inflammation in astrocytes and microglia than LMWO A $\beta$ or FSA $\beta$. METHODS: Primary culture of human astrocytes and microglia were used to determine the impact of the various forms of $\mathrm{A} \beta$ (FS, LMWO, HMWO) on calcium entry and on the levels of pro- inflammatory cytokines IL-6 and IL-8. The production of cytokines was quantified using Bio-plex cytokine profiling assay while calcium entry in the cells was monitored fluorimetrically.
\end{abstract}


RESULTS: My results indicate that HMWO A $\beta$ are more potent than LMWO or FSA $\beta$ at stimulating IL-6 and IL-8 levels in human astrocytes and microglia. The increase in proinflammatory cytokines induced by the oligomeric species of $A \beta$ is inhibited by the intracellular chelator BAPTA-AM. The HMWO are more potent at stimulating IL-6 and IL-8 in astrocytes and microglia than LMWO A $\beta$ or FSA $\beta$. In addition, HMWO are also more potent than FSA $\beta$ at stimulating calcium entry in human astrocytes and microglia. CONCLUSION: My data therefore suggests a link between the inflammatory effect of $\mathrm{A} \beta$ oligomeric species and their effect on calcium entry in human astrocytes and microglia.

\section{BACKGROUND:}

Several studies have revealed that cytokines serve as powerful regulators of glial cell function and contribute to CNS pathology. Studies have shown that an increase in intracellular calcium plays an important role in the production of cytokines by glia resulting in the propagation of inflammatory reactions in the CNS (Hoffmann et al. 2003). Although in principle, glial activation aims at CNS protection, excessive or sustained activation could significantly contribute to acute and chronic neuropathologies. Dysregulation of glial cytokine production could therefore disturb neural cell functions and result in neurotoxicity (Benveniste 1998, Benveniste et al. 2001). In AD, soluble A $\beta$ comprises mainly of monomeric/dimeric and oligomeric species, whereas, insoluble A $\beta$ consists of aggregated forms which are the major components of senile plaques. Studies in rodent hippocampus reveal that soluble $A \beta$ mediates an inhibition of LTP, resulting in 
memory loss (Rowan et al. 2005). My aims were to identify which form of Aß1-42 (FS, LMWO, HMWO) are most potent in activating microglia and astrocytes, as well as determine if this effect of $A \beta$ is mediated in part by an alteration of intracellular calcium levels. Pro-inflammatory cytokines, have been shown to induce calcium response and activate glial cells in experimental models of AD (Mattson et al. 1997, Goghari et al. 2000). In the present study I compared the effects of the various forms of $A \beta 1-42$ on calcium entry and their corresponding impact on the levels of pro-inflammatory cytokines.

\section{METHODS AND MATERIALS:}

Preparation of the different forms of $A \beta 1-42$ :

Freshly solubilized: Lyophilized A $\beta 1-42$ peptide (Purity greater than 95\%, Biosource, CA) was dissolved to $1 \mathrm{mg} / \mathrm{ml}$ in 1,1,1,3,3,3-hexafluoro-2-propanol (HFIP) (SigmaAldrich, MO) in order to minimize formation of $\beta$-sheet structures and promote $\alpha$-helical secondary structure. $A \beta 1-42$ was allowed to air dry in a chemical fume hood for $1 \mathrm{~h}$, followed by further drying in a speed-vac for 30 minutes. The resulting clear film was resuspended in $100 \%$ DMSO to a concentration of $1 \mathrm{mM}$. Peptides were subsequently aliquoted and stored at $-80^{\circ} \mathrm{C}$. LMWO: An aliquot of the DMSO stock of A $1-42$ was diluted to $100 \mu \mathrm{M}$ in HBSS (Invitrogen, CA) not containing calcium and incubated overnight at $4^{\circ} \mathrm{C}$. The peptide was then centrifuged at $16,000 \mathrm{~g}$ for $30 \mathrm{mins}$ at $4^{\circ} \mathrm{C}$. The supernatent (containing LMW A $\beta$ species) was collected and dissolved to appropriate concentration in HBSS. HMWO: HFIP treated A $\beta 1-42$ was diluted in DMSO to $100 \mu \mathrm{M}$ 
in PBS and incubating for 5 days at $37^{\circ} \mathrm{C}$. HMWO were pelleted by centrifugation at $15,000 \mathrm{~g}$ for 15 mins and resuspended in HBSS. A $\beta 1-42$ concentrations in the different preparations were estimated by using A $\beta 1-42$ ELISA (Biosource, CA) after denaturing the different forms of $A \beta$ with $80 \%$ formic acid. In addition, the different preparations of $\mathrm{A} \beta$ were evaluated on native and denaturing conditions using 4-20\% gradient PAGE followed by electroblotting on Polyvinylidene fluoride (PVDF) membranes and immunodetection with the antibody 4G8 (Signet laboratories).

Cell culture: Primary cultures of human astrocytes and human microglia (ScienCell, MD) were cultured in astrocyte medium and microglia media respectively (ScienCell, MD) supplemented with $10 \%$ fetal bovine serum, astrocyte growth medium/microglia growth medium and $1 \mathrm{X}$ Penicillin-Streptomycin-Fungizone mixture (Cambrex Corp., NJ). The treatment groups included various forms (FS, LMWO, HMWO) of A $\beta 1-42$ at $1 \mu \mathrm{M}$. Cells were also treated with $10 \mu \mathrm{M}$ of the calcium ionophore A23187 (Sigma-Aldrich, MO), $20 \mu \mathrm{M}$ of the intracellular calcium chelator BAPTA-AM (Sigma-Aldrich, MO), a PLC

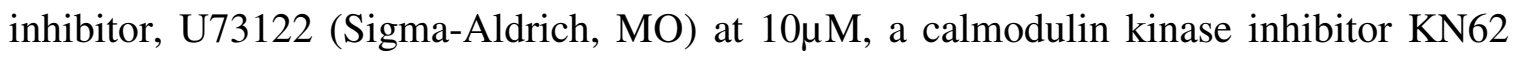
(Sigma-Aldrich, MO) at $5 \mu \mathrm{M}$ and a L-type calcium channel blocker Nilvadipine (Fujisawa, Japan) at $5 \mu \mathrm{M}$. Cell culture plates were incubated at $37^{\circ} \mathrm{C}$ and culture media collected $24 \mathrm{~h}$ after treatment. IL-6 and IL-8 were quantified in the culture medium using the Luminex fluorescent-bead-based technology (de Jager et al. 2003, Patel et al. 2005). Human cytokine 2-plex panel kits (Bio-Rad, CA) were used according to the recommendation of the manufacturer. 
Measurement of intracellular calcium levels: Intracellular calcium levels were evaluated by spectrofluorometry using Fluo-4 (Molecular Probes). Human astrocytes and microglia were grown on a black costar 96-well plates previously coated with collagen for $24 \mathrm{hrs}$. Confluent cells were treated with $5 \mu \mathrm{M}$ of Fluo-4 in DMEM for 30 minutes in a cell culture incubator. Cells were subsequently washed in DMEM followed by 3 washes in HBSS containing no calcium in order to remove any unincorporated Fluo-4. Intracellular calcium levels were quantified using a Bio-tek spectrofluorometer equipped with two plate microinjectors (Bio-tek Inc., VT) at specific excitation $(485 \mathrm{~nm})$ and emission (516 $\mathrm{nm}$ ) wavelengths. Baseline intracellular calcium levels were continuously recorded for 1 minute. Immediately following treatment of the cells with $1 \mu \mathrm{M}$ FS, LMWO and HMWO A $\beta 1-42$, intracytoplasmic calcium was continuously recorded for one minute to determine the possible impact of the different forms of $A \beta$ on calcium release by intracellular calcium stores. Finally, following one minute of treatment with different forms of $\mathrm{A} \beta, 2 \mathrm{mM}$ of $\mathrm{CaCl}_{2}$ was added to the cells and intracellular calcium levels were continuously monitored for another minute in order to evaluate the impact of the different forms of $A \beta$ on calcium entry.

\section{Statistical analyses}

For statistical analyses, ANOVA followed by post-hoc analysis using Bonferroni were performed using SPSS for Windows release 10.1. Results are represented as Mean +/SEM. 


\section{RESULTS:}

Analysis and evaluation of the different soluble forms of A $\beta 1-42$ :

FS, LMWO and HMWO Aß1-42 loaded on a 4-20\% gradient PAGE under nondenaturing conditions revealed that HFIP treated FS A $\beta$ displayed tetramers in addition to dimers on immunodetection, LMWO A $\beta$ prepared by aging HFIP $A \beta$ for $24 \mathrm{~h}$ at $4^{\circ} \mathrm{C}$ was detected as a band at 20kd and HMWO A $\beta$ prepared by aging HFIP A $\beta$ for 5 days at $37^{\circ} \mathrm{C}$ revealed a large band comprising of the different forms of $\mathrm{A} \beta$, more specifically the large oligomers >90kd. Under denaturing conditions (Tris/gylcine/SDS), immunodetection with the monoclonal antibody $4 \mathrm{G} 8$ showed that FSA $\beta$ formed a band at around 4kd, LMWO bands were detected at 20kd while HMWO formed a large band at around 70kd indicating that oligomers are SDS resistant (Fig.1).

Effect of HMWO, LMWO and FS AB1-42 on calcium influx in human astrocytes and microglia:

Data show that HMWO, LMWO and FSA $\beta 1-42$ tested do not have any major impact on the release of calcium by internal stores following one minute of treatment in human astrocytes and microglia in calcium-free HBSS (Fig. 2a, 2c). However, following addition of extracellular calcium in microglia and astrocytes, calcium entry was differentially stimulated by HMWO, LMWO and FS A $\beta 1-42$. Interestingly, HMWO and LMWO of A $\beta 1-42$ appear more potent than FSA $\beta$. at stimulating calcium entry in astrocytes and microglia. Mean peak amplitude of calcium entry was quantified for the three forms of $A \beta 1-42$ (Fig. 2b, 2d). 
Effect of HMWO, LMWO and FS AB1-42 on the production of IL-6 and IL-8 in human astrocytes and microglia:

Levels of IL-6 and IL-8 were quantified in media collected from human astrocytes and microglia following $24 \mathrm{~h}$ treatment with HMWO, LMWO and FS A $\beta 1-42$. Proinflammatory cytokines IL-6 and IL-8 were elevated in both astrocytes and microglia following treatment with the HMWO as compared to control and FSA (Fig.3a-3d) Levels of IL-6 and IL-8 in microglia were slightly increased by LMWO compared to control and FSA $\beta$ (Fig. 3b, 3d). IL-8 levels in astrocytes were slightly increased by LMWO as compared to control and FSA $\beta$ (Fig 3c).

Effect of A23187 and BAPTA-AM on the release of IL-6 and IL-8 by human astrocytes and microglia:

The calcium ionophore A23187 significantly increased IL-6 and IL-8 levels, whereas the intracellular calcium chelator BAPTA-AM reduced basal cytokine production of IL-6 and IL-8 in both astrocytes and microglia (Fig 4a-4d) showing that the production of IL-6 and IL-8 by microglia and astrocytes is dependent on intracellular calcium levels.

Effect of HMWO A $\beta 1-42$ on IL-6 and IL-8 production by human astrocytes and microglia after co-treatment with the other calcium signaling inhibitor and Nilvadipine, the L-type calcium channel blocker:

After establishing that the HMWO A $\beta 1-42$ is most potent in stimulating both IL-6 and IL-8 in astrocytes and microglia, we wanted to determine if Nilvadipine (the L-type 
calcium channel blocker), U73122 (a PLC inhibitor) and KN62 (a calmodulin kinase inhibitor) could inhibit or reduce levels of these pro-inflammatory molecules stimulated by $1 \mu \mathrm{M}$ HMWO $\mathrm{A} \beta 1-42$. My results demonstrated that $5 \mu \mathrm{M}$ Nilvadipine significantly reduces the production of both IL- 6 and IL- 8 mediated by $1 \mu \mathrm{M}$ HMWO A $\beta$ in both astrocytes and microglia (Fig.5a-5d), suggesting that $\mathrm{A} \beta$ mediates the production of IL-6 and IL-8 in astrocytes and microglia by stimulating calcium entry via L-type calcium channels. My results also revealed a significant reduction in both IL-6 and IL-8 in

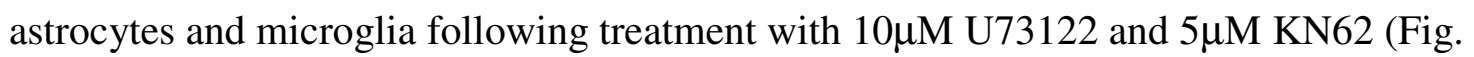
5a-5d), strongly suggesting that compounds affecting calcium signaling pathways can have anti-inflammatory properties.

\section{DISCUSSION:}

Activation of glia resulting in the production of pro-inflammatory cytokines is a feature observed in mouse models of $\mathrm{AD}$ and in pathological tissue samples from $\mathrm{AD}$ patients (Tarkowski et al. 2003, Patel et al. 2005). My previous studies with brain slices from TgAPPsw mice reveal that $\mathrm{A} \beta$ causes an increase in pro-inflammatory cytokines (Quadros 2003). Several studies have shown that dysregulation of calcium homeostasis and/or increases in intracellular levels of calcium are also responsible for the activation of glia and in the propagation of inflammatory reactions in the CNS (Hoffmann et al. 2003, Mattson and Chan 2003). Evidence from various studies reveal that intracellular calcium stimulates the release of pro-inflammatory cytokine IL-6 and chemokine IL-8 in human mast cells via activation of NFkB (Kim et al. 2005, Mitsuyama et al. 2004, Kempuraj et 
al. 2003). Studies in human microglia treated with IL-8 reveal that it enhances A $\beta 1-42$ to release other pro-inflammatory cytokines and increases the activity of COX-2 resulting in the production of eicosanoids (Franciosi et al. 2005). My aim was to determine which particular forms of $A \beta 1-42$ differentially affect calcium influx in glial cells and to determine to what extent this increase of calcium influx in glial cells mediates the production of the major proinflammatory cytokines IL- 6 and IL-8. I observed that HMWO A $\beta 1-42$ is more potent than FS or LMWO at increasing calcium influx and cytokine production in both astrocytes and microglia. To further demonstrate that $\mathrm{A} \beta$ induced increases in pro-inflammatory interleukins IL-6 and IL-8 was dependent on increased intracellular levels of calcium, I used BAPTA-AM, an intracellular calcium chelator. My results demonstrated that the intracellular calcium chelator BAPTA-AM can oppose cytokine production triggered by HMWO and LMWO A $\beta 1-42$ suggesting that calcium increases induced by $A \beta$ is necessary to promote the proinflammatory action of $A \beta$. Interestingly, I also observed that FSA $\beta 1-42$ was not a potent stimulus for increasing pro-inflammatory levels of IL-6 and IL-8 and was also not able to increase intracellular calcium levels.

In addition, both astrocytes and microglia produced elevated levels of both IL-6 and IL-8 in response to the calcium ionophore A23187. The elevated levels of IL-6 and IL-8 were reduced by treatment with Nilvadipine, U73122, and KN62. Studies on rat astrocytes have revealed that PLC stimulates the production of IL-6 in response to endothelins (Morga et al. 2000). Other studies on astrocytes have shown that a proinflammatory stimulus can induce the production of IL-6 via activation of the NFkB by 
calmodulin kinase enzyme (Schwaninger et al. 1999). Therefore, my data in glial cells treated with oligomeric forms of $A \beta$ suggest that blocking calcium entry either by blocking L-type channels or by inhibiting PLC (which regulates intracellular calcium stores) or by inhibiting calmodulin kinase may be of interest for preventing glial activation in AD patients. Several reports indicate that calcium channel blockers used for the treatment of hypertension can lower the risk of developing dementia, including $\mathrm{AD}$ (Forette et al. 2002, Menne et al. 2006). Studies indicate that the brain loses its ability to downregulate intracellular levels of calcium with age (Toescu et al. 2004) and the reduced risk of dementia associated with calcium channel blockers is presumed to be related to their ability to prevent excess entry of calcium into neurons (Trompet et al. 2006). The relationship between glial activation and neurodegeneration remains unclear, although several cytokines and inflammatory mediators produced by activated microglia and astrocytes have the potential to initiate or exacerbate the progression of neuropathology in several CNS disorders. Hence, my data suggest that changes in intracellular levels of calcium mediated by oligomeric forms of A $\beta 1-42$ (mainly HMWO) may be responsible for the activation of glial cells in AD. Neuroinflammation is a prominent feature of AD pathology as evidenced by astrogliosis and microgliosis reported in various studies (Akiyama et al. 1999, Akiyama et al. 2000). Recent studies using primary cultures of human astrocytes demonstrate that $A \beta$ mediated increases in NFkB activity further stimulate inflammation, activating glial cells resulting in the production of more $A \beta$ via activation of BACE 1 enzyme (Bourne et al. 2007). The reason HMWO A $\beta$ are more potent than LMWO and FSA $\beta$ in stimulating calcium influx 
and cytokine release may be due to the fact that HMWO A $\beta$ contains more $\beta$-sheet than the other two forms. Studies on neurons have indicated that neurotoxicity mediated by $\mathrm{A} \beta$ is related to the $\beta$-sheet content of the peptide (Watson et al. 2005). Our results indicate that the inflammation mediated by HMWO A $\beta$ is caused by an increase in intracellular calcium levels, which can be blocked by using Nilvadipine. Calmodulin kinase inhibitors decrease the production of IL- 6 and IL-8 in astrocytes and microglia by inhibiting intracellular calcium signaling. Our results strongly suggest that compounds that modulate calcium influx in glial cells decrease inflammation and therefore can be neuroprotective. Further studies on human neuronal cells need to be performed to determine the effect of these calcium channel blockers on HMWO A $\beta 1-42$ mediated neurotoxicity.

\section{List of abbreviations:}

CNS: Central Nervous system

AD: Alzheimer's disease

A $\beta$ : beta amyloid

ELISA: Enzyme linked immunosorbent assay

IL-x: Interleukin-X

HBSS: Hank's balanced salt solution

NFkB: Nuclear factor kappa B

$\mathrm{CaCl} 2$ : Calcium chloride

BAPTA: 1, 2-Bis (2-aminophenoxy) ethane- $N, N, N^{\prime}, N^{\prime}$-tetraacetic acid PIP2: phosphatidylinositol 4, 5-biphosphate 
IP3: inositol 1, 4, 5- triphosphate

\section{Competing interests:}

The authors declare that they have no competing interests.

\section{Author's contributions:}

AQ carried out the Bio-plex assay, performed the calcium entry experiments and drafted the manuscript. NP aided in calcium entry assays and treatment of the of the primary cell cultures. BB and ML aided in growing of the primary cells, collecting media for the Bioplex assays. MM aided in manuscript preparation and gave critical analysis of the manuscript. DP conceived and developed the methodology to perform calcium measurements and aided in manuscript preparation.

\section{Acknowledgments:}

The authors would like to thank Bob and Diane Roskamp for their generous support. 
Figure 5:
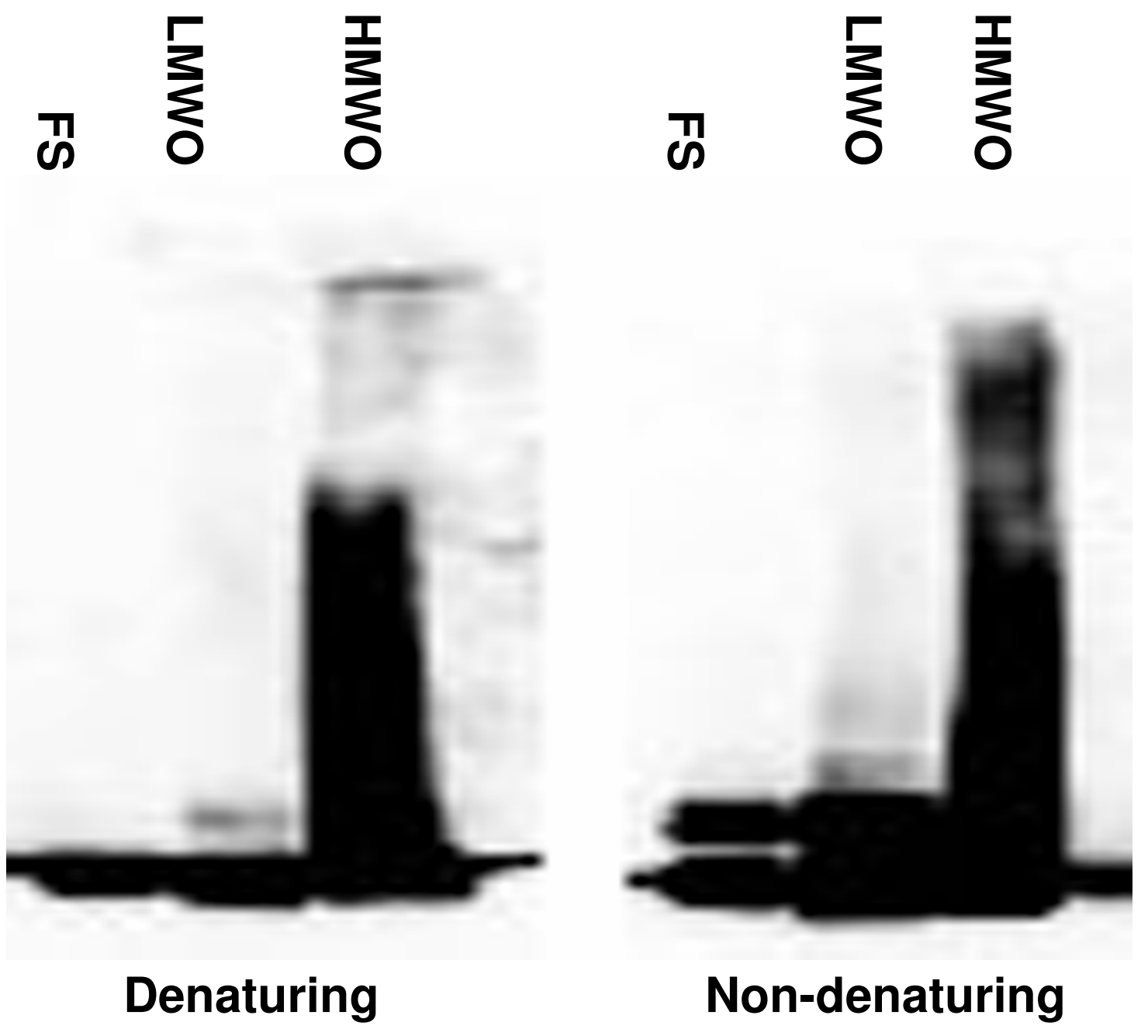

Fig. 5: Western blot of A $\beta 1-42$ using 4G8 monoclonal antibody under denaturing and non-denaturing conditions. FS, LMWO and HMWO A $\beta 1-42$ loaded on a 4-20\% gradient PAGE under denaturing conditions (Tris/gylcine/SDS) followed by electroblotting on PVDF and immunodetection with the monoclonal antibody 4G8 showed that FSA $\beta$ formed a band at around 4kd, LMWO bands were detected at 20kd while HMWO formed a large band at around 70kd. 
Figure 6a: Astrocytes

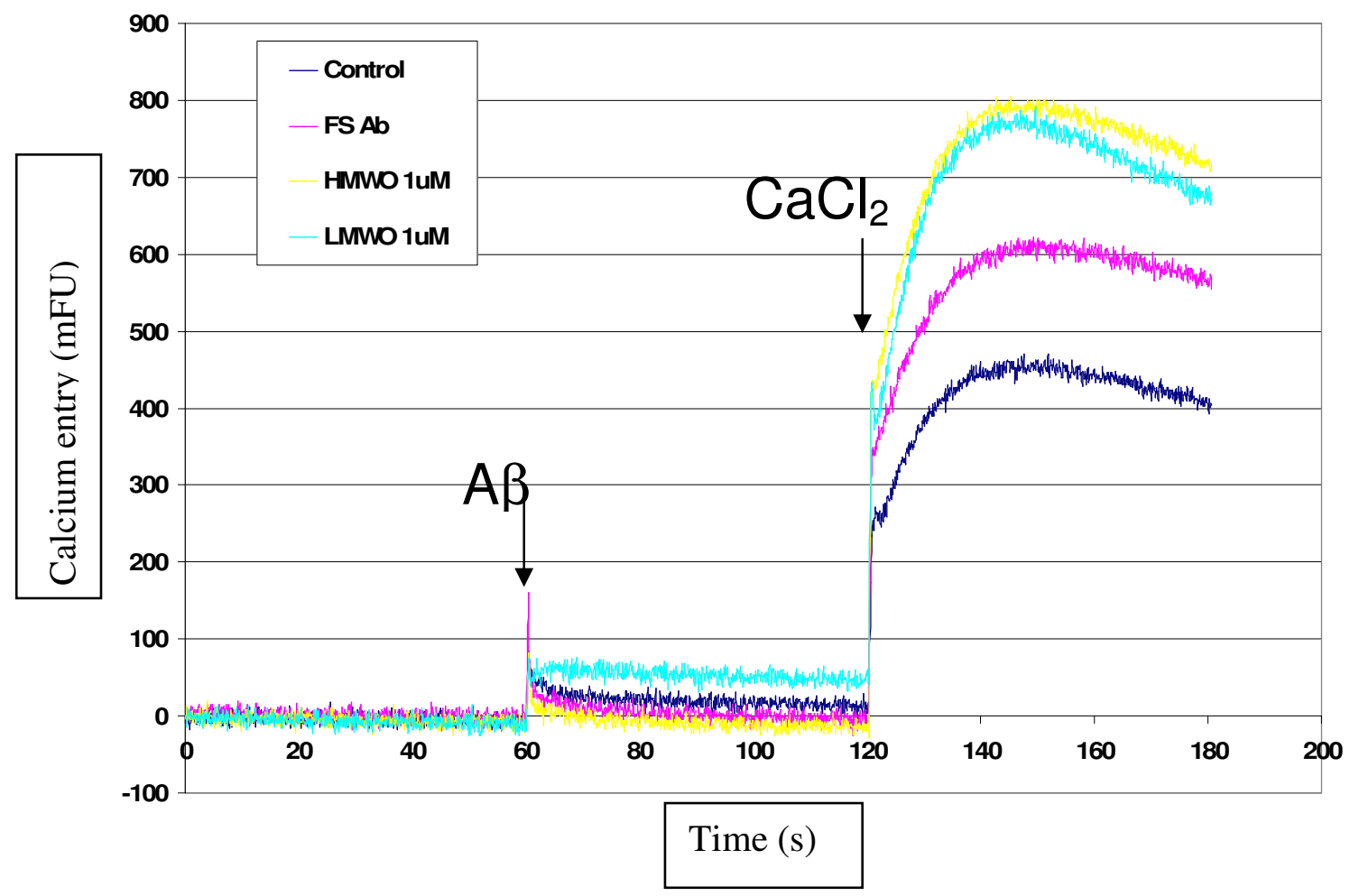

Figure 6b: Astrocytes

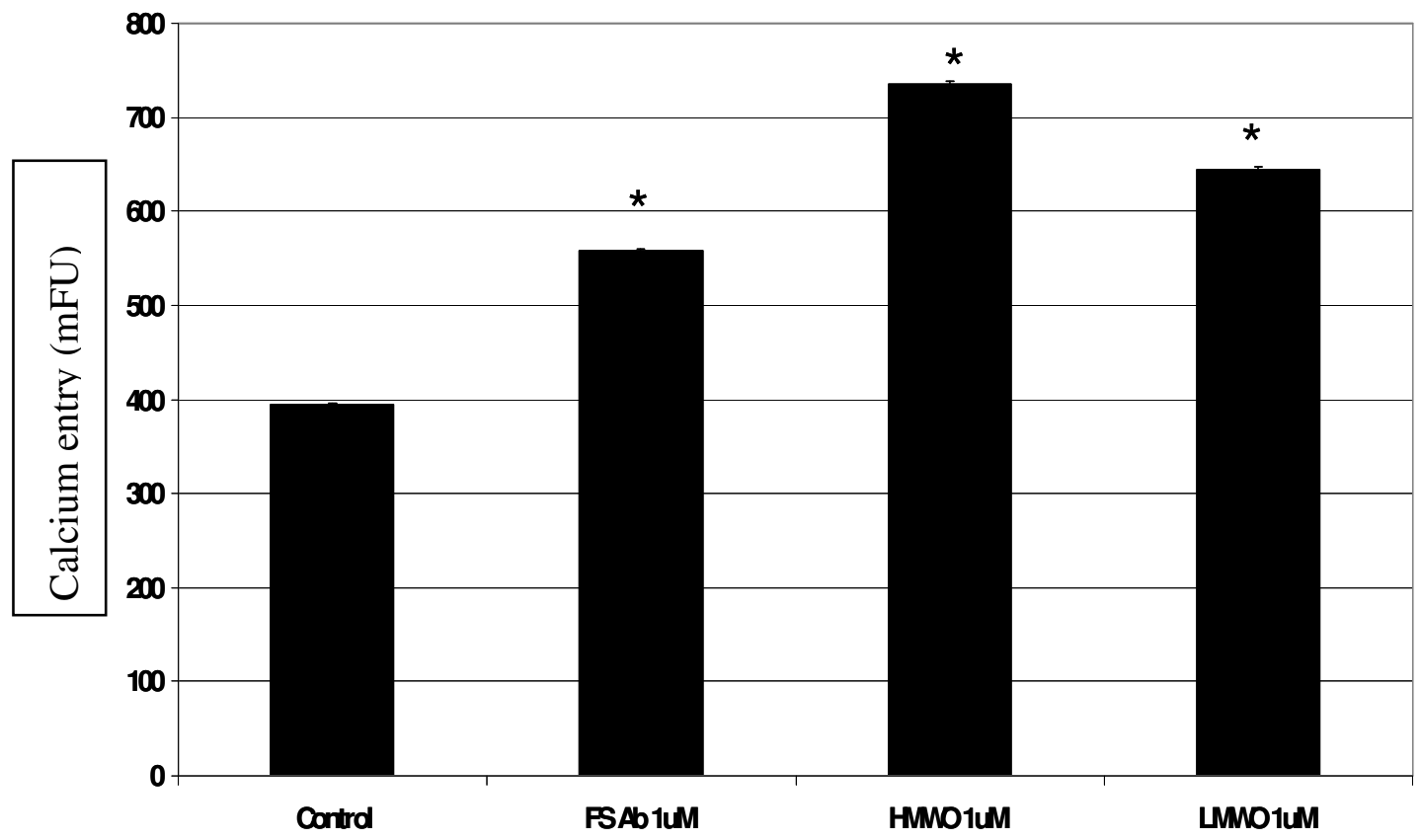


Figure 6c: Microglia

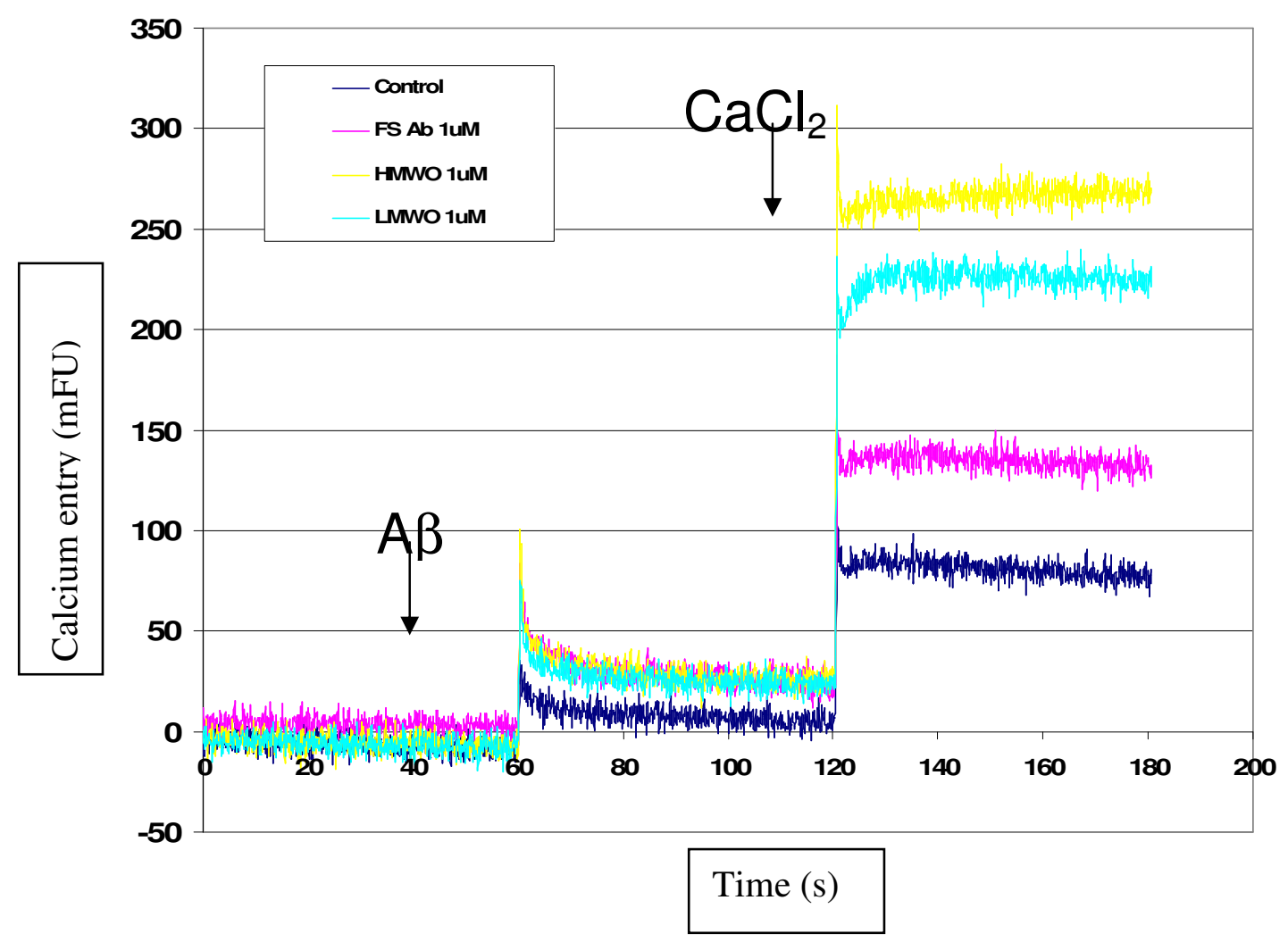

Figure 6d: Microglia

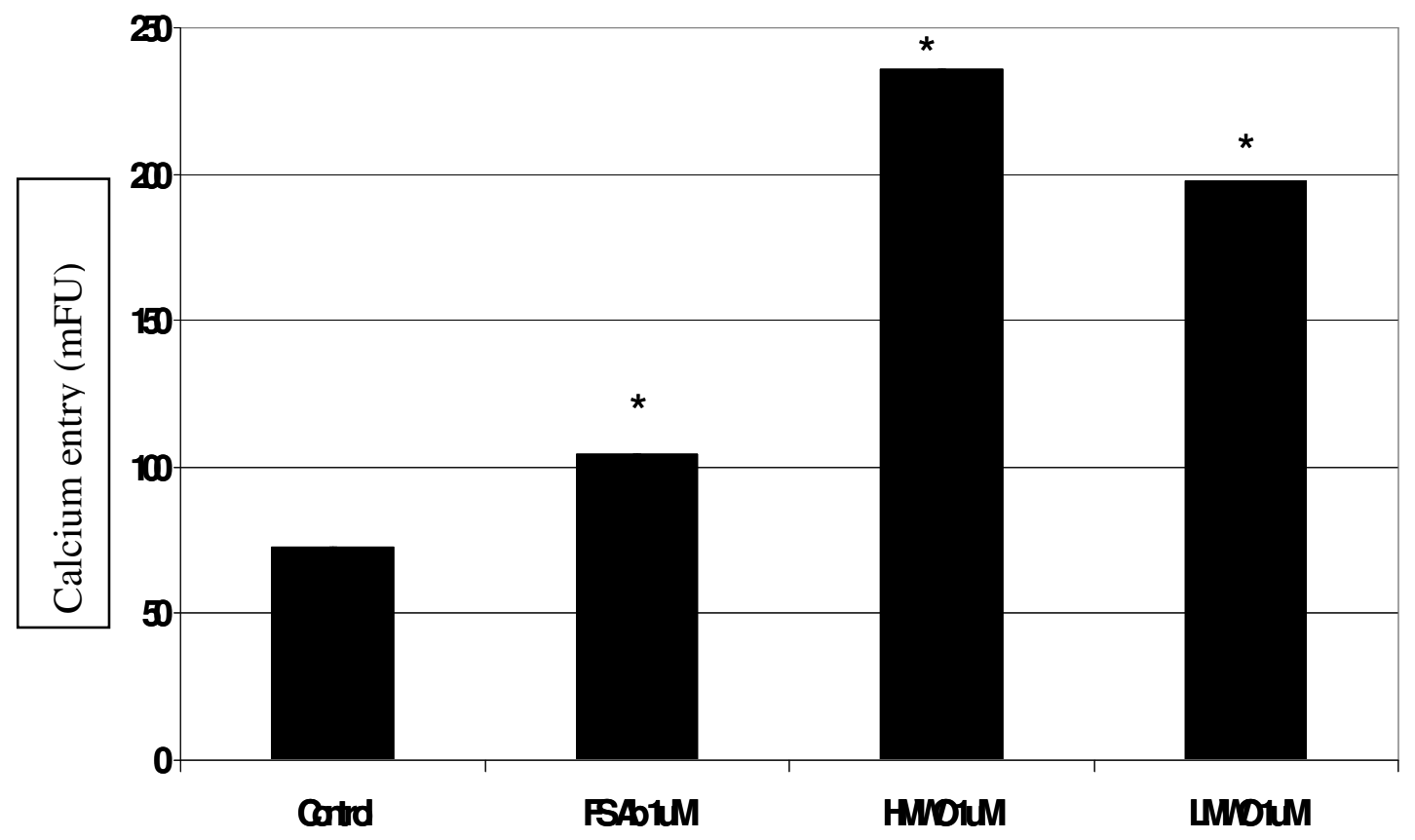


Fig. 6: a) Real time measurement of calcium entry in human astrocytes following treatment with FS, LMWO and HMWO $A \beta 1-42$ at $1 \mu \mathrm{M}$ dose $(\mathrm{n}=6$ for each treatment group). b) Quantification of intracellular calcium entry in human astrocytes. ANOVA revealed significant main effects between control and HMWO, control and LMWO and control and FSA $\beta$ in astrocytes. Post-hoc analysis by Bonferroni showed significant effect of all three treatment groups $(\mathrm{p}<0.05)$. c) Real time measurement of calcium entry in human microglia following treatment with FS, LMWO and HMWO A $\beta 1-42$ at $1 \mu \mathrm{M}$ dose ( $n=6$ for each treatment group). d) Quantification of intracellular calcium entry in human microglia. ANOVA followed by post-hoc analysis showed significant main effects between control and HMWO, control and LMWO $(\mathrm{p}<0.05)$ but no significant difference between control and FSA $\beta$ in microglia $(p>0.05)$. 
Figure 7a: Astrocytes

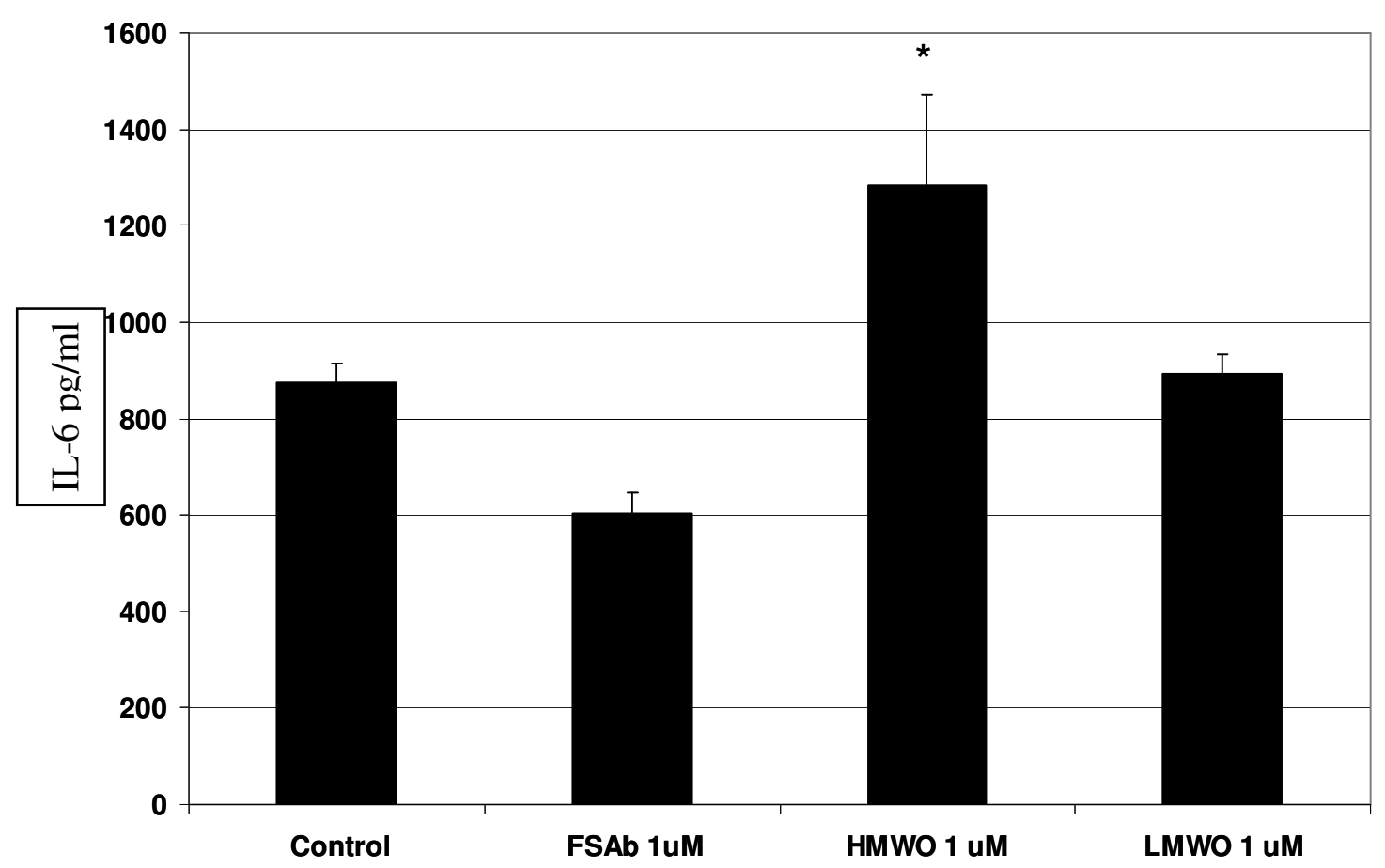

Figure 7b: Microglia

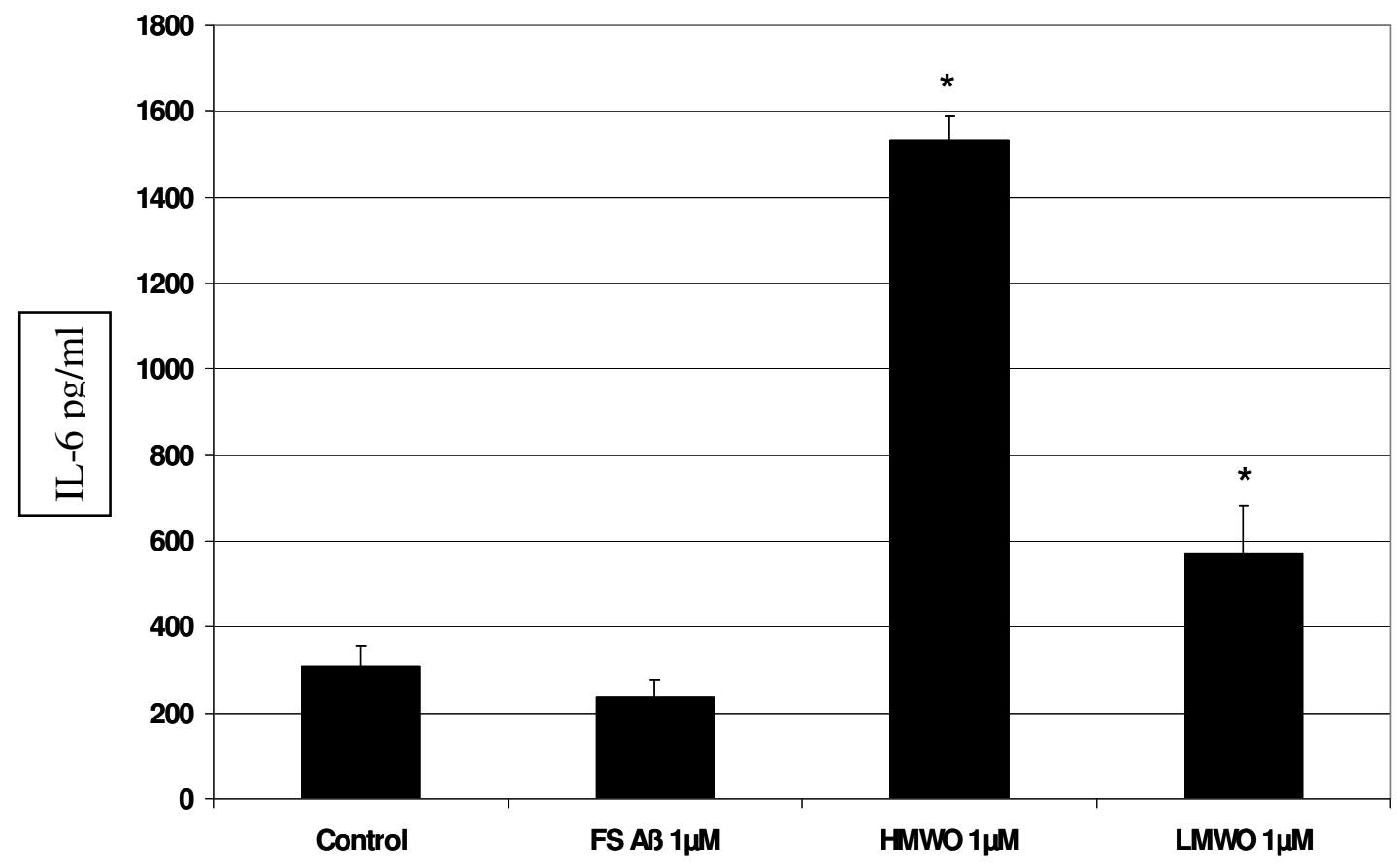


Figure 7c: Astrocytes

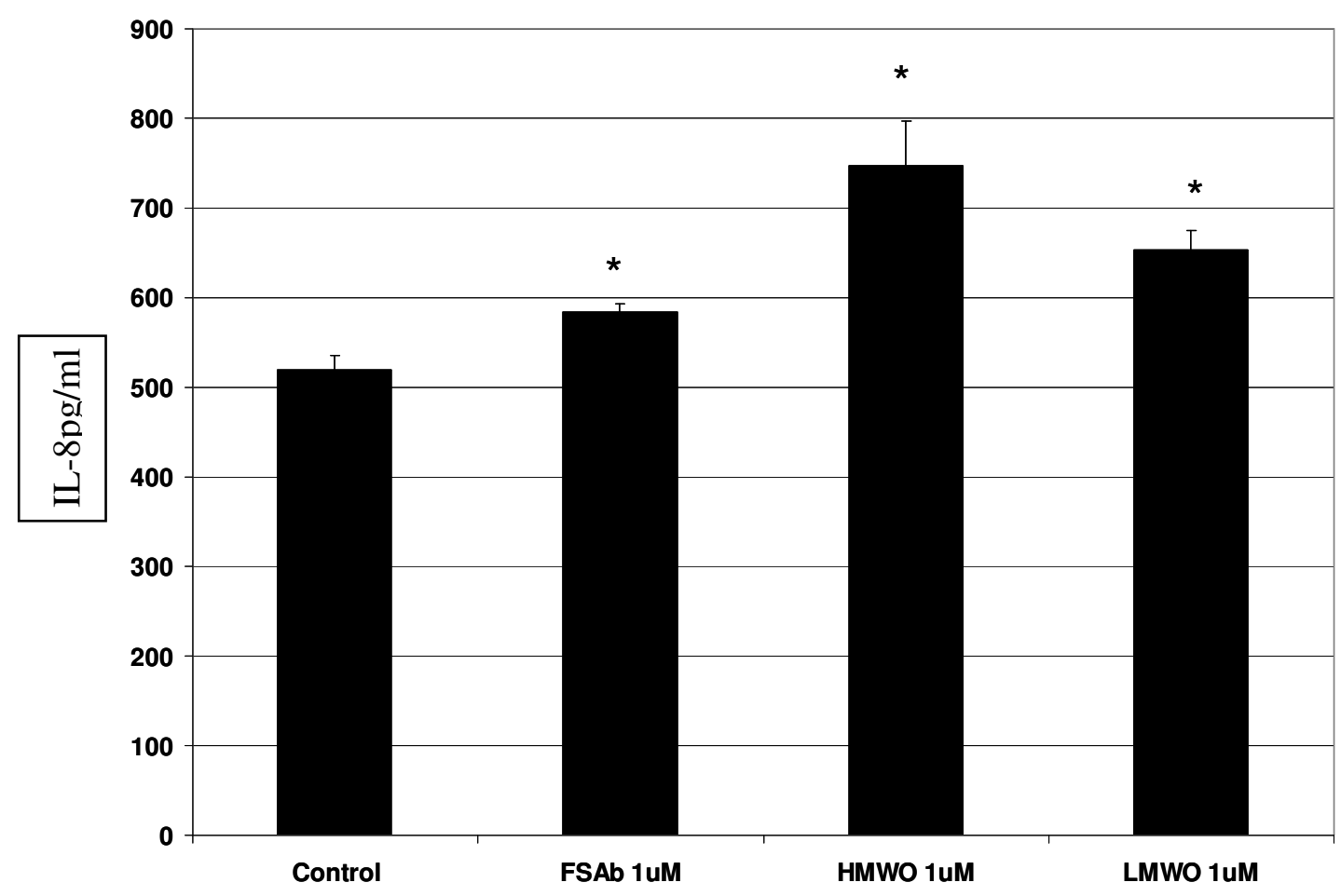

Figure 7d: Microglia

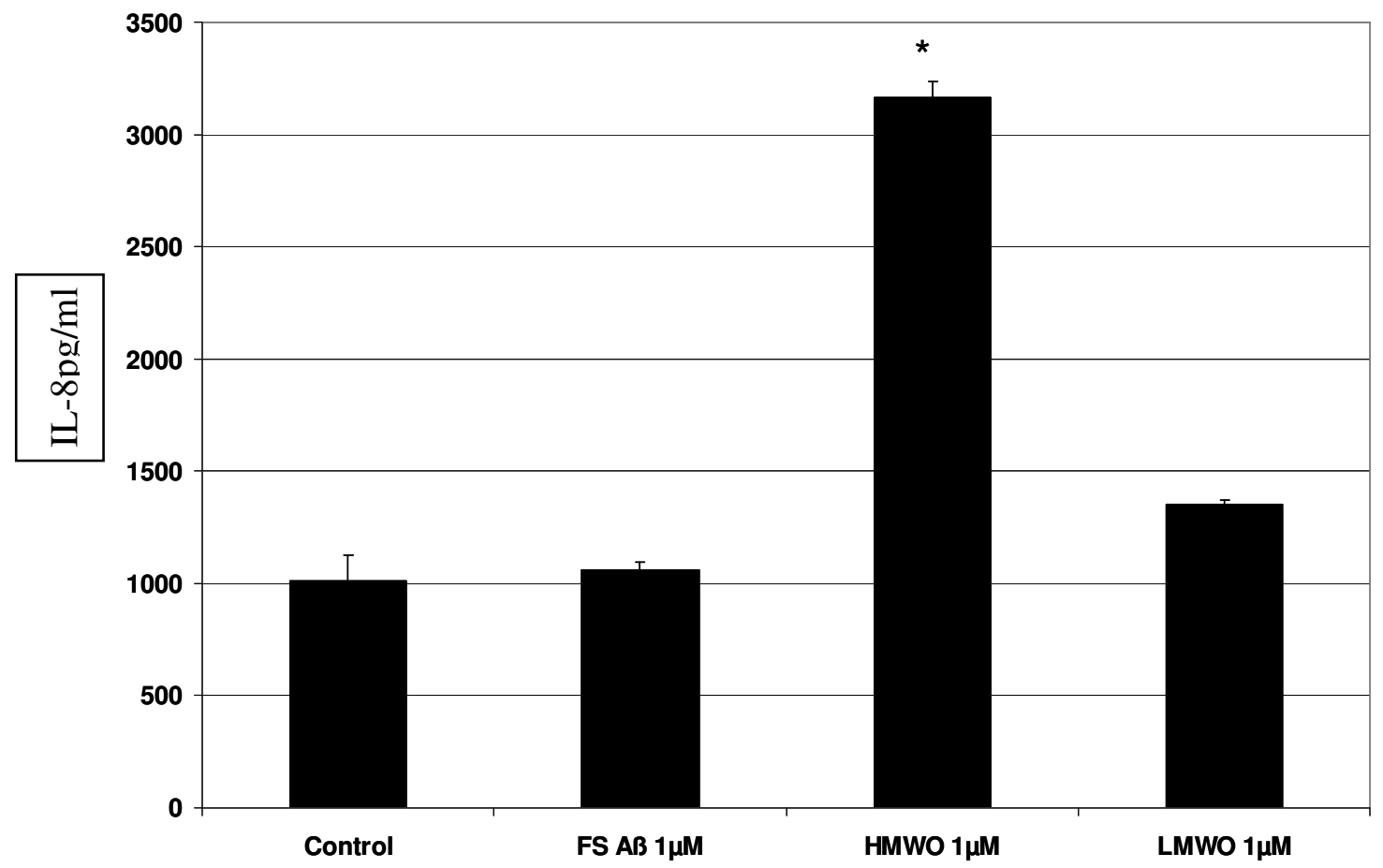


Fig. 7: a) Bar graph of IL-6 levels in media after $24 \mathrm{~h}$ following treatment with FS, LMWO and HMWO A $\beta 1-42$ at $1 \mu \mathrm{M}$ dose ( $\mathrm{n}=6$ for each treatment group) in astrocytes. ANOVA followed by post-hoc analysis revealed significant main effects between control and HMWO $(\mathrm{p}<0.05)$ but no significant difference between control and LMWO ( $p>0.05) . b)$ Bar graph of IL-6 levels in media after $24 \mathrm{~h}$ following treatment with FS, LMWO and HMWO A $\beta 1-42$ at $1 \mu \mathrm{M}$ dose ( $\mathrm{n}=6$ for each treatment group) in microglia. ANOVA followed by post-hoc analysis revealed significant main effects between control and HMWO $(\mathrm{p}<0.05)$ but no significant difference between control and LMWO or FSA $\beta$ (p>0.05). c) Bar graph of IL-8 levels in media after $24 \mathrm{~h}$ following treatment with FS, LMWO and HMWO A $\beta 1-42$ at $1 \mu \mathrm{M}$ dose ( $\mathrm{n}=6$ for each treatment group) in astrocytes. ANOVA followed by post-hoc analysis revealed significant main effects between control and HMWO $(\mathrm{p}<0.05)$ but no significant difference between control and LMWO, and control or FSA $\beta(p>0.05)$. d) Bar graph of IL-8 levels in media after 24 h following treatment with FS, LMWO and HMWO A $\beta 1-42$ at $1 \mu \mathrm{M}$ dose (n=6 for each treatment group) in microglia. ANOVA followed by post-hoc analysis revealed significant main effects between control and HMWO $(\mathrm{p}<0.01)$ but no significant difference between control and LMWO or FSA $\beta$ ( $\mathrm{p}>0.01)$. 
Figure 8a: Astrocytes

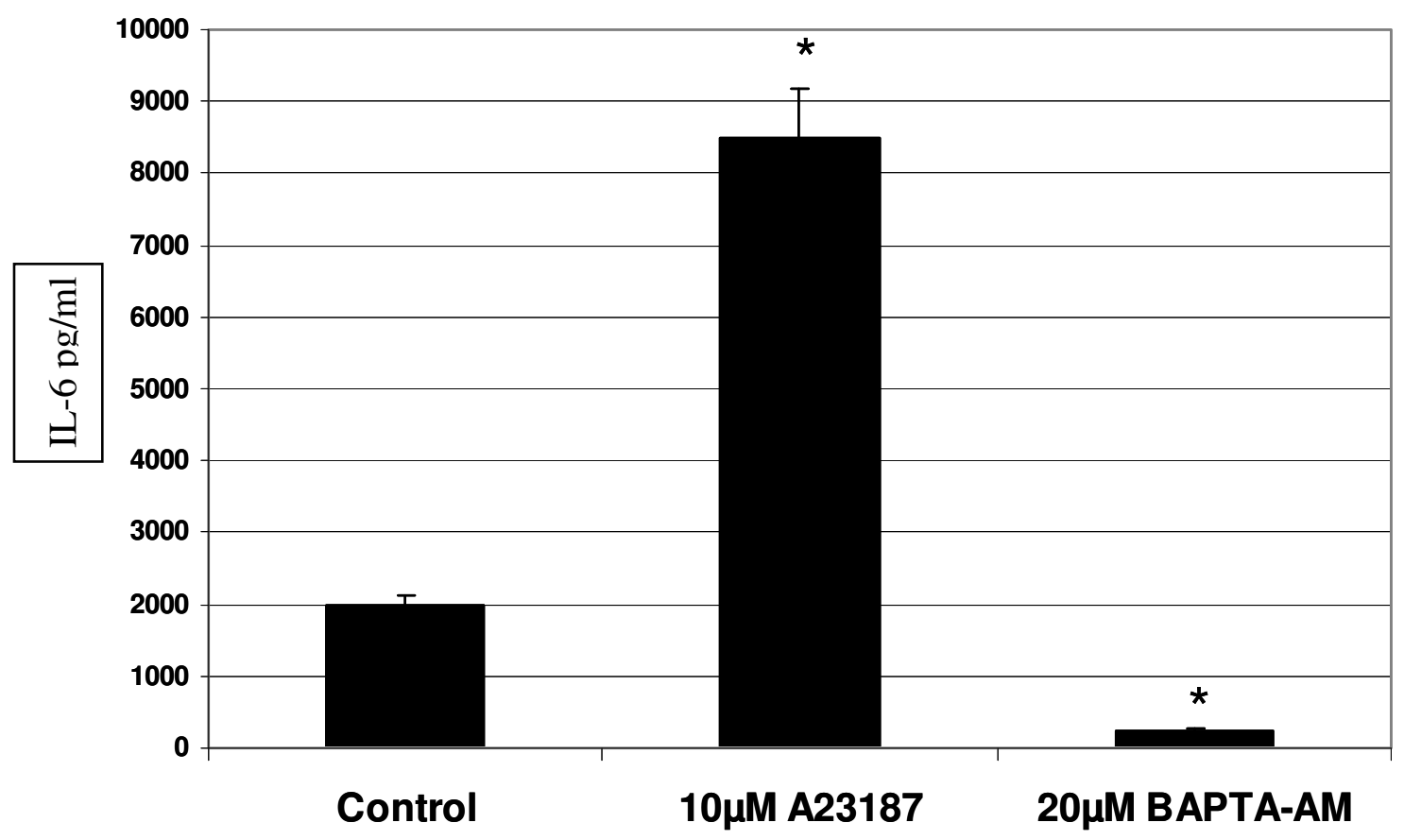

Figure 8b: Microglia

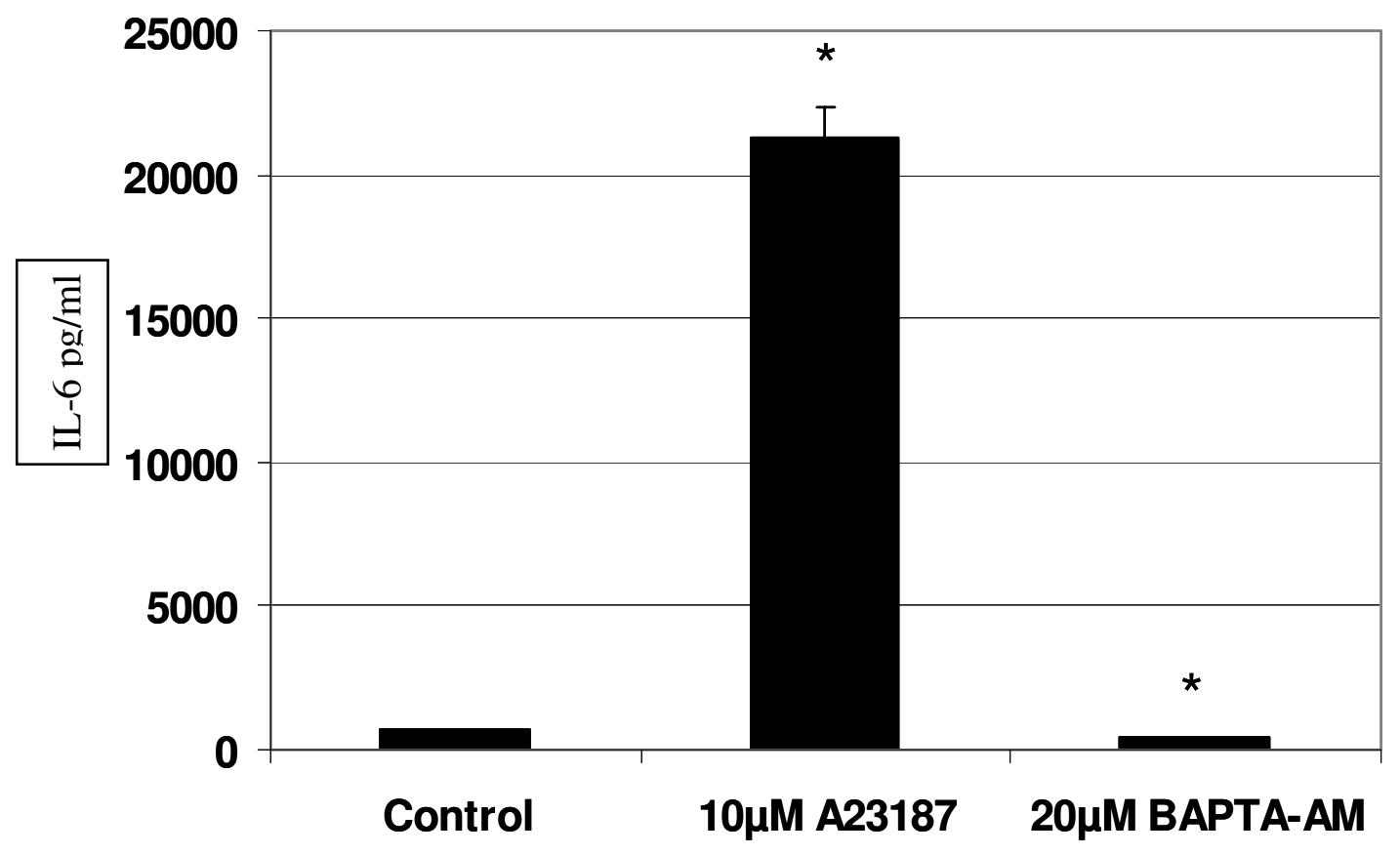


Figure 8c: Astrocytes

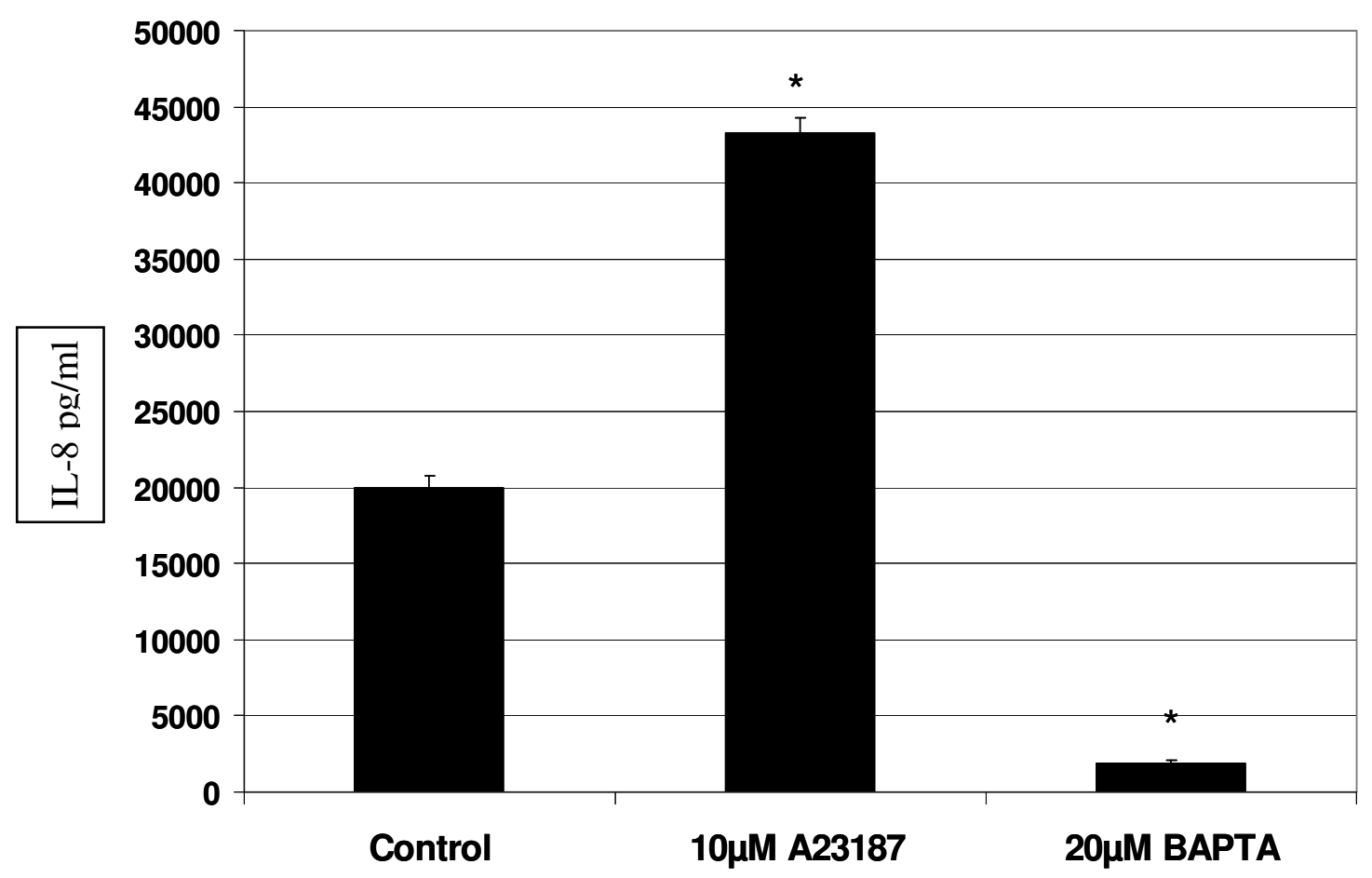

Figure 8d: Microglia

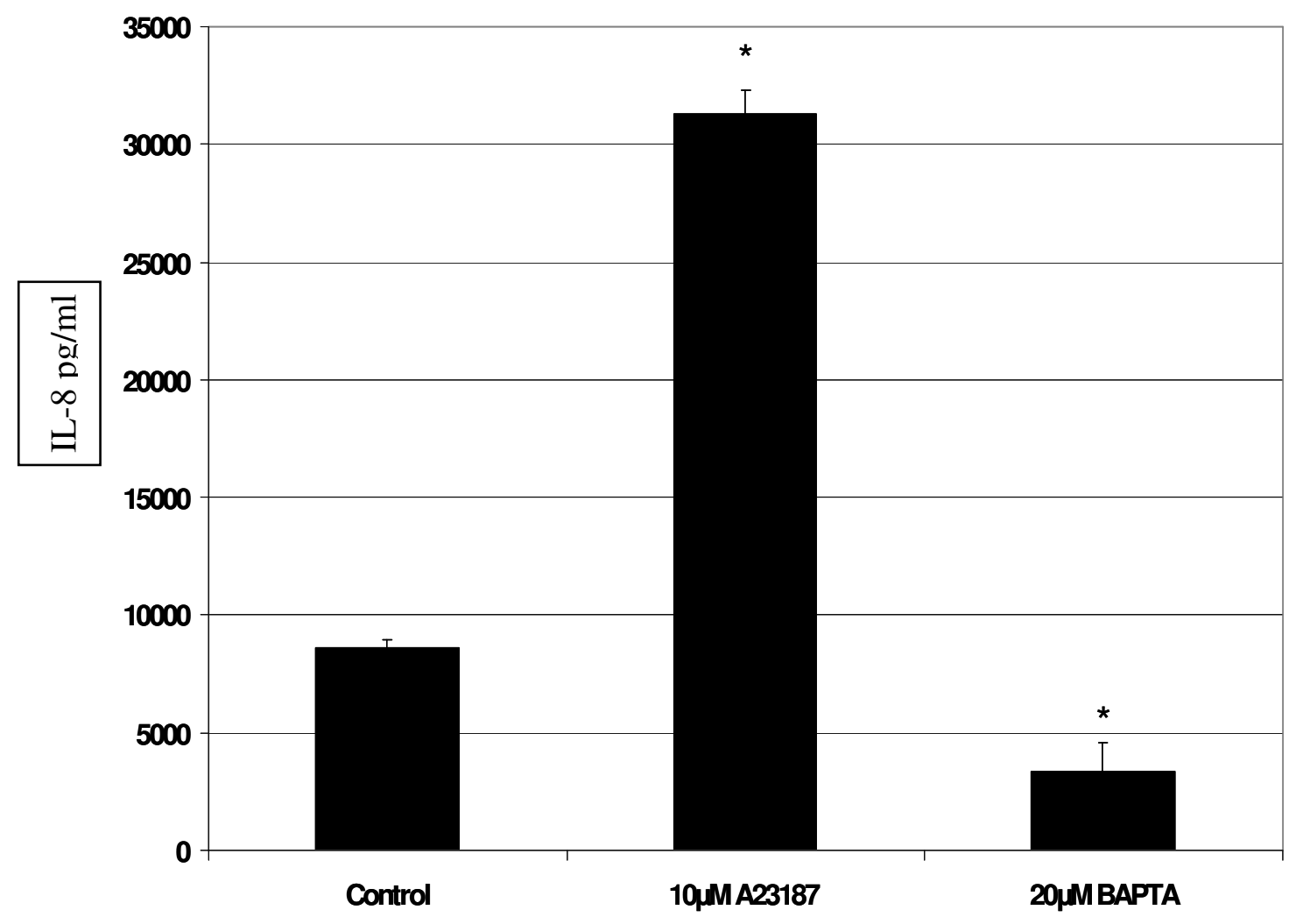


Fig. 8: a \& c) Bar graph of IL-6 and IL-8 levels in media after 24h following treatment with $10 \mu \mathrm{M}$ A23187, 20 $\mu$ M BAPTA-AM and control (untreated cells) in astrocytes ( $\mathrm{n}=6$ for each treatment group). ANOVA followed by post-hoc analysis revealed significant main effects between control and A23187 ( $\mathrm{p}<0.05)$, control and BAPTA-AM ( $\mathrm{p}<0.05)$ and A23187 and BAPTA-AM $(\mathrm{p}<0.05)$ for IL-6 and IL-8. b\& d) Bar graph of IL-6 and IL-8 levels in media after $24 \mathrm{~h}$ following treatment with $10 \mu \mathrm{M}$ A23187, 20 $\mu \mathrm{M}$ BAPTA$\mathrm{AM}$ and control (untreated cells) in microglia ( $\mathrm{n}=6$ for each treatment group). ANOVA followed by post-hoc analysis revealed significant main effects between control and A23187 (p<0.05), control and BAPTA-AM (p<0.05), A23187 and BAPTA-AM (p<0.05) for both IL-6 and IL-8. 
Figure 9a: Astrocytes

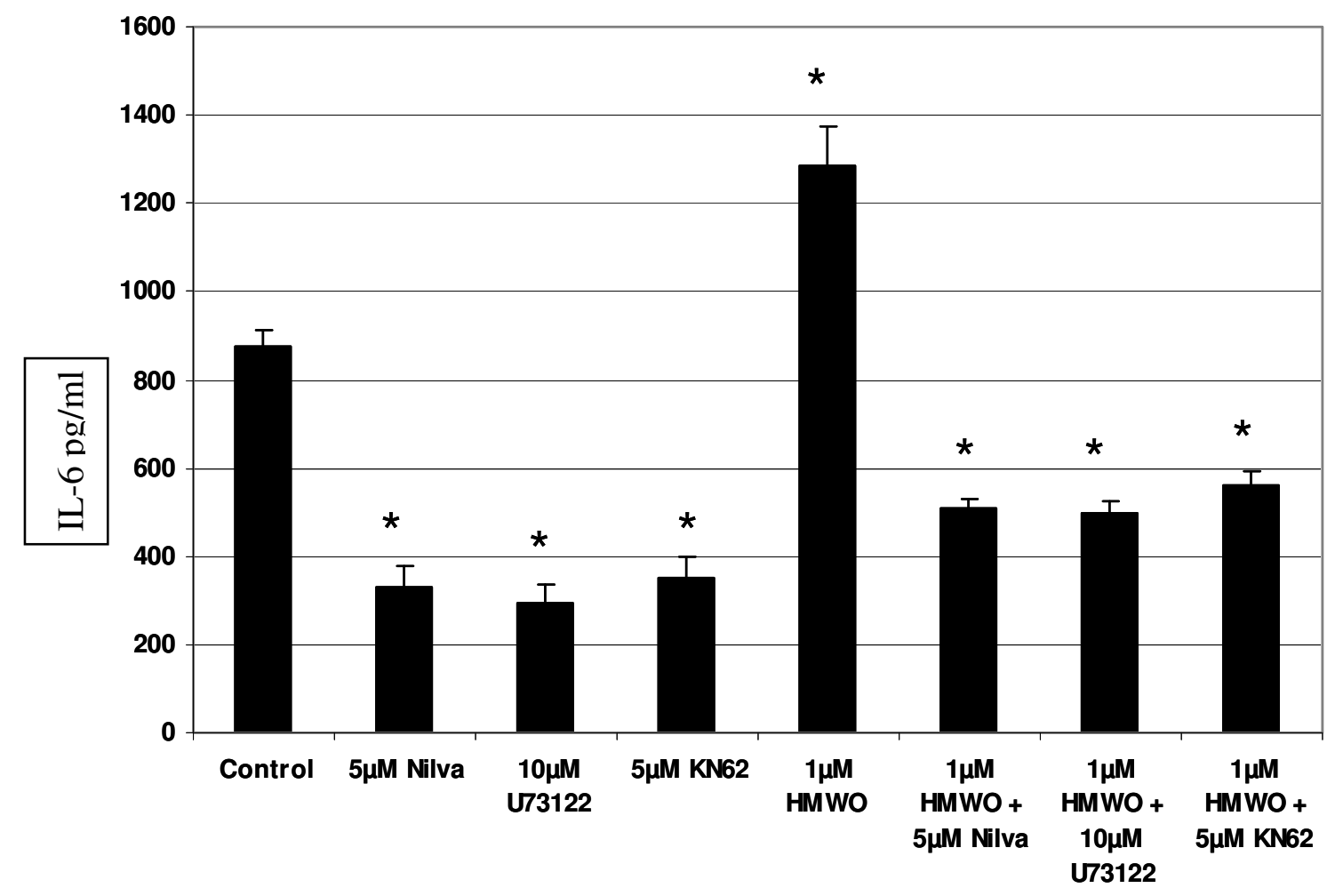

Figure 9b: Microglia

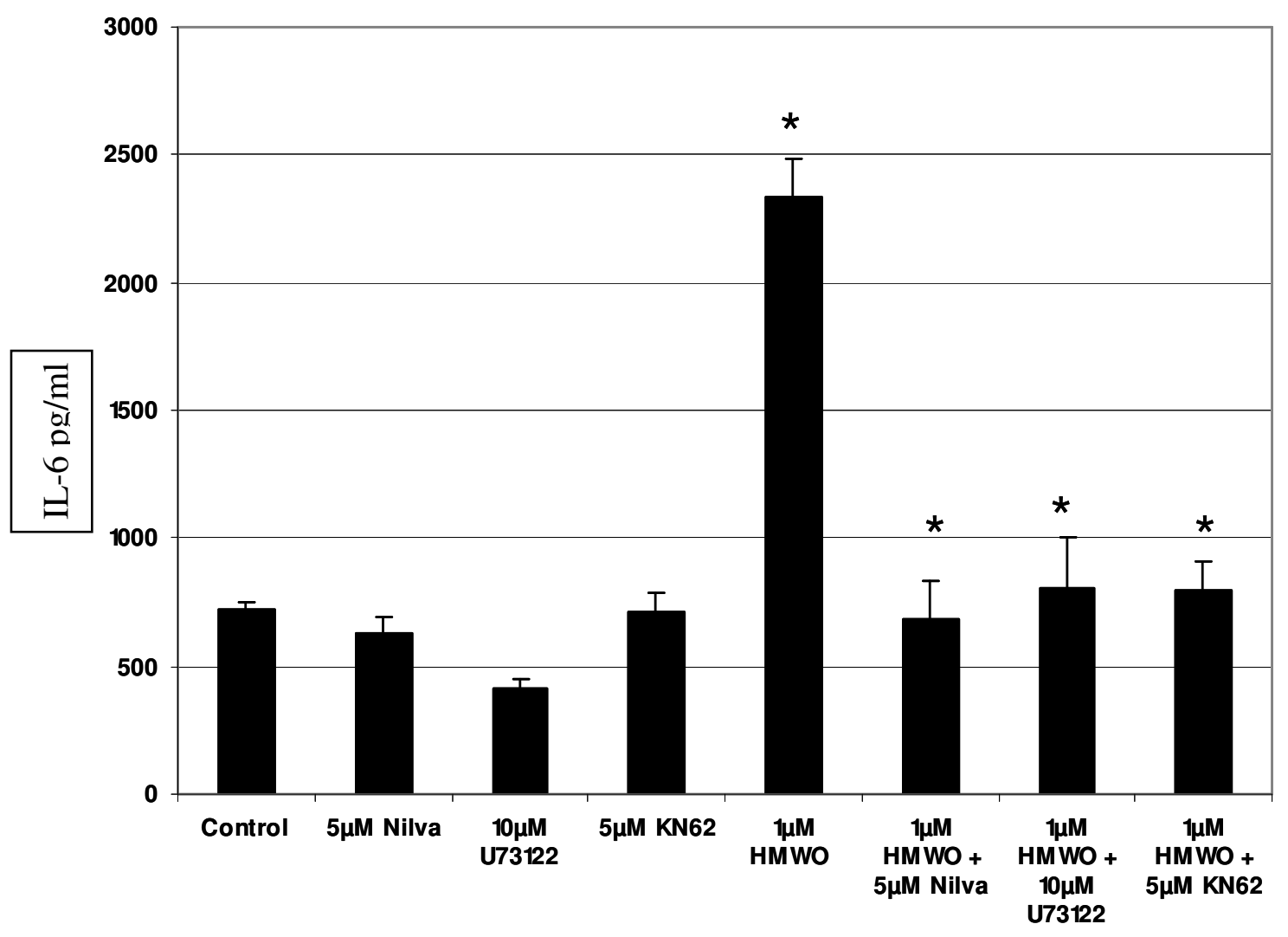


Figure 9c: Astrocytes

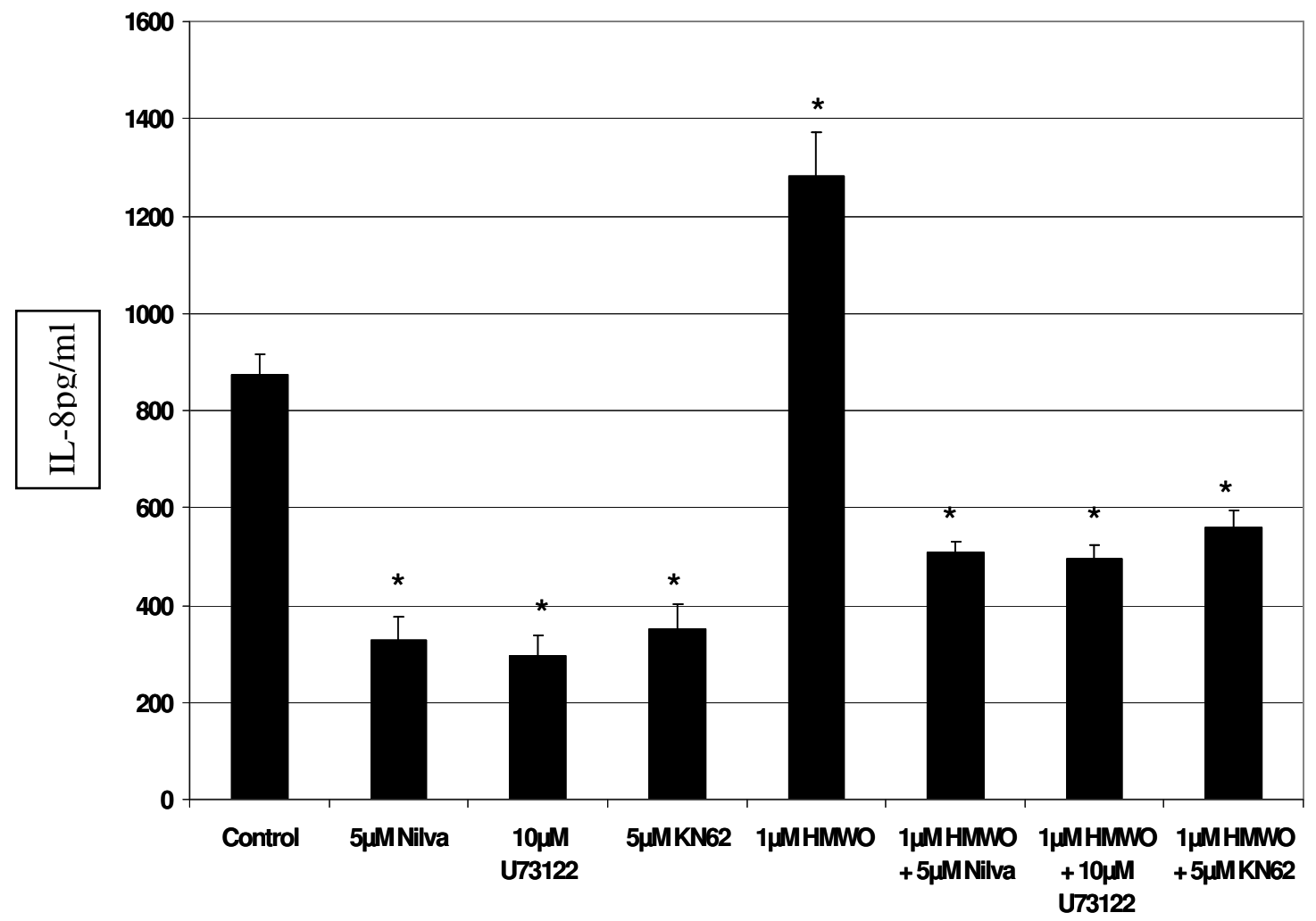

Figure 9d: Microglia

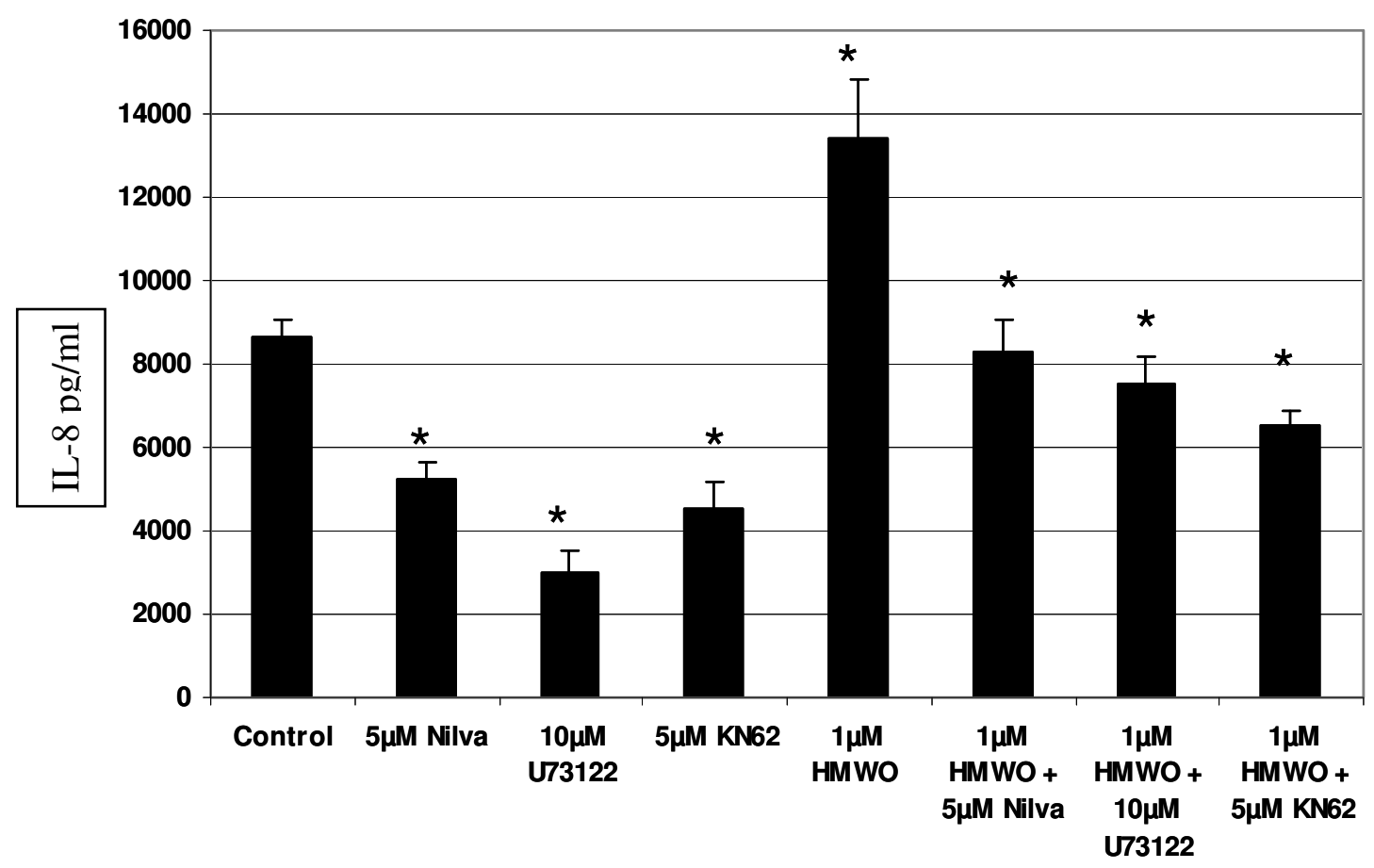


Fig. 9: a \& c) Bar graph of IL-6 and IL-8 levels in media after 24h following treatment with HMWO A $\beta 1-42$ at $1 \mu \mathrm{M}, 5 \mu \mathrm{M}$ Nilvadipine alone, 10 $\mu \mathrm{M}$ U73122 alone, $5 \mu \mathrm{M}$ KN62 alone and in combination respectively ( $\mathrm{n}=6$ for each treatment group) in astrocytes. ANOVA followed by post-hoc analysis revealed significant main effects between control and HMWO ( $<<0.05)$, HMWO and HMWO + Nilva ( $<<0.01)$, HMWO and HMWO + U73122 ( $<<0.01)$, HMWO and HMWO + KN62 $(\mathrm{p}<0.01)$ for both IL-6 and IL-8. b\& d) Bar graph of IL-6 and IL-8 levels in media after 24h following treatment with HMWO $\mathrm{A} \beta 1-42$ at $1 \mu \mathrm{M}, 5 \mu \mathrm{M}$ Nilvadipine alone $10 \mu \mathrm{M}$ U73122 alone, $5 \mu \mathrm{M}$ KN62 alone and in combination respectively ( $\mathrm{n}=6$ for each treatment group) in microglia. ANOVA followed by post-hoc analysis revealed significant main effects between control and HMWO $(\mathrm{p}<0.05)$, HMWO and HMWO + Nilva $(\mathrm{p}<0.05)$, HMWO and HMWO + U73122 $(\mathrm{p}<0.05)$, HMWO and HMWO + KN62 $(\mathrm{p}<0.05)$ for IL-6 and IL-8. 


\section{REFERENCES:}

1. Akiyama H, Mori H, Saido T, Kondo H, Ikeda K, McGeer PL. Occurrence of the diffuse amyloid beta-protein (Abeta) deposits with numerous Abeta-containing glial cells in the cerebral cortex of patients with Alzheimer's disease. Glia. 25 (1999) 324-331.

2. Akiyama H, Barger S, Barnum S, Bradt B, Bauer J, Cole GM, Cooper NR, Eikelenboom P, Emmerling M, Fiebich BL, Finch CE, Frautschy S, Griffin WS, Hampel H, Hull M, Landreth G, Lue L, Mrak R, Mackenzie IR, McGeer PL, O'Banion MK, Pachter J, Pasinetti G, Plata-Salaman C, Rogers J, Rydel R, Shen Y, Streit W, Strohmeyer R, Tooyoma I, Van Muiswinkel FL, Veerhuis R, Walker D, Webster S, Wegrzyniak B, Wenk G, Wyss-Coray T. Inflammation and Alzheimer's disease. Neurobiol Aging. 21 (2000) 383-421.

3. Benveniste EN. Cytokine actions in the central nervous system. Cytokine Growth Factor Rev. 9 (1998) 259-275.

4. Benveniste EN, Nguyen VT, O'Keefe GM. Immunological aspects of microglia: relevance to Alzheimer's disease. Neurochem Int. 39 (2001) 381-391.

5. Bourne KZ, Ferrari DC, Lange-Dohna C, Rossner S, Wood TG, Perez-Polo JR. Differential regulation of BACE1 promoter activity by nuclear factor-kappaB in neurons and glia upon exposure to beta-amyloid peptides. J Neurosci Res. 85 (2007) 1194-204.

6. de Jager W, te Velthuis H, Prakken BJ, Kuis W, Rijkers GT. Simultaneous detection of 15 human cytokines in a single sample of stimulated peripheral blood mononuclear cells. Clin Diagn Lab Immunol. 10 (2003) 133-139.

7. Forette F, Seux ML, Staessen JA, Thijs L, Babarskiene MR, Babeanu S, Bossini A, Fagard R, Gil-Extremera B, Laks T, Kobalava Z, Sarti C, Tuomilehto J, Vanhanen H, 
Webster J, Yodfat Y, Birkenhager WH. Systolic Hypertension in Europe Investigators. The prevention of dementia with antihypertensive treatment: new evidence from the Systolic Hypertension in Europe (Syst-Eur) study. Arch Intern Med. 162 (2002) 20462052.

8. Franciosi S, Choi HB, Kim SU, McLarnon JG. IL-8 enhancement of amyloid-beta (Abeta 1-42)-induced expression and production of pro-inflammatory cytokines and COX-2 in cultured human microglia. J Neuroimmunol. 159 (2005) 66-74.

9. Goghari V, Franciosi S, Kim SU, Lee YB, McLarnon JG. Acute application of interleukin-1beta induces $\mathrm{Ca}(2+)$ responses in human microglia. Neurosci Lett. 281 (2000) 83-86.

10. Hoffmann A, Kann O, Ohlemeyer C, Hanisch UK, Kettenmann H. Elevation of basal intracellular calcium as a central element in the activation of brain macrophages (microglia): suppression of receptor-evoked calcium signaling and control of release function. J Neurosci. 23 (2003) 4410-4419.

11. Kempuraj D, Huang M, Kandere-Grzybowska K, Basu S, Boucher W, Letourneau R, Athanassiou A, Theoharides TC. Azelastine inhibits secretion of IL-6, TNF-alpha and IL8 as well as NF-kappaB activation and intracellular calcium ion levels in normal human mast cells. Int Arch Allergy Immunol. 132 (2003) 231-239.

12. Kim MS, Lim WK, Park RK, Shin T, Yoo YH, Hong SH, An NH, Kim HM. Involvement of mitogen-activated protein kinase and NF-kappaB activation in $\mathrm{Ca} 2+-$ induced IL-8 production in human mast cells.Cytokine. 32 (2005) 226-233. 13. Morga E, Faber C, Heuschling P. Stimulation of endothelin B receptor modulates the inflammatory activation of rat astrocytes. J Neurochem. 74 (2000) 603-612. 
14. Mattson MP, Barger SW, Furukawa K, Bruce AJ, Wyss-Coray T, Mark RJ, Mucke L. Cellular signaling roles of TGF beta, TNF alpha and beta APP in brain injury responses and Alzheimer's disease. Brain Res Brain Res Rev. 23 (1997) 47-61.

15. Mattson MP, Chan SL. Neuronal and glial calcium signaling in Alzheimer's disease. Cell Calcium. 34 (2003) 385-397.

16. Menne J, Park JK, Agrawal R, Lindschau C, Kielstein JT, Kirsch T, Marx A, Muller D, Bahlmann FH, Meier M, Bode-Boger SM, Haller H, Fliser D. Cellular and molecular mechanisms of tissue protection by lipophilic calcium channel blockers. FASEB J. $\mathbf{2 0}$ (2006) 994-996.

17. Mitsuyama H, Kambe F, Murakami R, Cao X, Ishiguro N, Seo H. Calcium signaling pathway involving calcineurin regulates interleukin- 8 gene expression through activation of NF-kappaB in human osteoblast-like cells. J Bone Miner Res. 19 (2004) 671-679.

18. Patel NS, Paris D, Mathura V, Quadros AN, Crawford FC, Mullan MJ. Inflammatory cytokine levels correlate with amyloid load in transgenic mouse models of Alzheimer's disease. J Neuroinflammation. 2 (2005):9.

19. Quadros A, Patel N, Crescentini R, Crawford F, Paris D, Mullan M. Increased TNFalpha production and Cox-2 activity in organotypic brain slice cultures from APPsw transgenic mice. Neurosci Lett. 353 (2003) 66-68.

20. Rowan MJ, Klyubin I, Wang Q, Anwyl R. Synaptic plasticity disruption by amyloid beta protein: modulation by potential Alzheimer's disease modifying therapies. Biochem Soc Trans. 33 (2005) 563-567. 
21. Schwaninger M, Sallmann S, Petersen N, Schneider A, Prinz S, Libermann TA, Spranger M. Bradykinin induces interleukin-6 expression in astrocytes through activation of nuclear factor-kappaB. J Neurochem. 73 (1999) 1461-1466.

22. Tarkowski E, Liljeroth AM, Minthon L, Tarkowski A, Wallin A, Blennow K. Cerebral pattern of pro- and anti-inflammatory cytokines in dementias. Brain Res Bull. 61 (2003) 255-260.

23. Toescu EC, Verkhratsky A, Landfield PW. Ca2+ regulation and gene expression in normal brain aging. Trends Neurosci. 27 (2004) 614-620.

24. Trompet S, Westendorp RG, Kamper AM, de Craen AJ. Use of calcium antagonists and cognitive decline in old age The Leiden 85-plus study. Neurobiol Aging. 2006 25. Watson D, Castano E, Kokjohn TA, Kuo YM, Lyubchenko Y, Pinsky D, Connolly ES Jr, Esh C, Luehrs DC, Stine WB, Rowse LM, Emmerling MR, Roher AE. Physicochemical characteristics of soluble oligomeric Abeta and their pathologic role in Alzheimer's disease. Neurol Res. 27 (2005) 869-881. 


\title{
CHAPTER FOUR
}

\section{Effect of calcium channel blockers on $A \beta$ induced neurodegeneration in human neurons}

\begin{abstract}
:
Abnormalities in calcium ion homeostasis have been linked to the neurotoxic effects of $A \beta$. My previous data with human astrocyes and microglia reveal that high molecular weight oligomers (HMWO) of A $\beta 1-42$ increased the release of proinflammatory cytokines by stimulating calcium entry via L-type calcium channels and phospholipase $\mathrm{C}$ activation. My aim was to identify if HMWO A $\beta$ could also increase inflammation in human neuronal precursor cells (HNPCs) via modulation of calcium influx in HNPCs. In addition, I also wanted to determine the neurotoxic effect of HMWO A $\beta$ and elucidate if this neurotoxic effect could be mitigated by using L-type calcium channel blockers and other inhibitors involved in the calcium signaling pathway such as calmodulin kinase II inhibitors. My data show that HMWO A $\beta$ significantly increased inflammation and neurotoxicity by stimulating calcium entry by L-type calcium channels. My results further demonstrate that the pro-inflammatory and neurotoxic effect of HMWO A $\beta$ can be blocked by using calmodulin kinase II inhibitors further suggesting that HMWO A $\beta$ mediated inflammation and neurotoxicity is calcium dependent.

Interestingly, I also observed reduction of calcium entry in HNPCs by anti-inflammatory agents suggesting that there is a link between inflammation and altered calcium influx resulting in subsequent neurodegeneration.
\end{abstract}

Keywords: human neuronal precursor cells, calcium channel blockers, calmodulin kinase II inhibitors, and inflammation 
Alzheimer's disease (AD) which is characterized by abnormal accumulation of beta-amyloid $(\mathrm{A} \beta)$ peptide in the brain is thought to be responsible for the neurodegeneration associated with AD. However, the mechanisms that contribute to neuronal degeneration in $\mathrm{AD}$ are not fully understood. Altered calcium homeostasis is considered to be one of the mechanisms involved in the neurodegeneration associated with normal aging, AD and related disorders (Thibault 2007). Studies with hippocampal neurons treated with aggregated $A \beta$ peptide undergo neurodegeneration by a mechanism involving an increase in intracellular calcium levels (Mattson 2007). In vitro studies on cultured neurons with the calcium ionophore A23187 indicated that calcium influx resulted in microtubule disruption due to altered tau phosphorylation (Mattson 1992). In our present study we evaluated which conformation of $A \beta$ was most toxic to human neuronal precursor cells (HNPC). I have previously established that HMWO A $\beta$ were most potent in increasing intracellular calcium influx in glial cells and this same conformation was also able to induce the production of proinflammatory IL-6 and IL-8 (Quadros 2007). Elevated levels of IL-6 and IL-8 are found in the brain of mild cognitive impaired (MCI) patients as well as traumatic brain injury (TBI) patients as compared to non-MCI and non-TBI subjects (Magaki 2007, Kushi 2003). Elevated levels of IL-6 have also been reported in AD patients (Nelson 2001). Hence, I wanted to determine whether HMWO A $\beta$ were responsible for the disruption of neurons via inflammation through a mechanism involving an increase in intracellular levels of calcium. Based on our previous results with glial cells our hypothesis for the mechanism involved in HMWO $A \beta$ mediated increase in calcium entry was that $A \beta$ may be affecting the activity 
of L-type calcium channels or other calcium signaling pathways (Figure 1). To support my hypothesis I used Nilvadipine (a selective L-type calcium channel blocker) and KN62 (a calmodulin kinase II inhibitor). My rationale for using KN62 was because calmodulin kinase II is activated when intracellular calcium levels are elevated. I also wanted to determine if there was a link between altered levels of intracellular calcium and inflammation, so we treated HNPCs with Ibuprofen (a NSAID) and NS-398 (a selective COX-2 inhibitor).

\section{EXPERIMENTAL PROCEDURES:}

Preparation of the different forms of $A \beta 1-42$ :

The different conformations of $\mathrm{A} \beta 1-42$ peptide were prepared as per the protocol listed in the previous chapter.

\section{Cell culture of HNPC:}

Primary culture of HNPCs (Clonexpress Inc., MD) was cultured in DMEM/F12 media (Invitrogen, CA) supplemented with $5 \%$ fetal bovine serum (Invitrogen, CA), 10ng/ml basic fibroblast growth factor (Sigma-Aldrich, MO), 10ng/ml epidermal growth factor (Sigma-Aldrich, MO), 1X neuronal cell supplement (Clonexpress Inc., MD) and 1X Penicillin-Streptomycin-Fungizone mixture (Cambrex Corp., NJ). The treatment groups included $1 \mu \mathrm{M}$ of freshly solubilized (FS), low molecular weight oligomers (LMWO), and HMWO forms of $\mathrm{A} \beta 1-42$. The other treatments include $5 \mu \mathrm{M}$ Nilvadipine (Fujisawa,

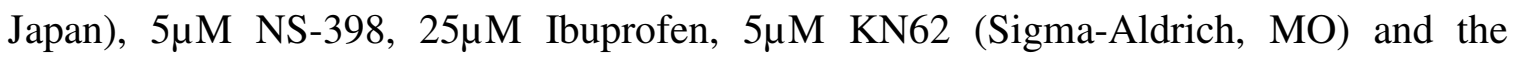
various combination treatments along with control (cells treated with vehicle only). The 
cell culture plates were incubated at $37^{\circ} \mathrm{C}$ and media from these plates was collected after $24 \mathrm{~h}$ of treatment and tested for cytokine profiling using human cytokine 2-plex panel kits (Bio-Rad, CA) according to the recommendation of the manufacturer.

Measurement of intracellular calcium levels:

HNPC's were grown on a poly-L-lysine coated black costar 96-well plate for $24 \mathrm{hrs}$. Confluent cells were treated with $5 \mu \mathrm{M}$ of Fluo-4 (Molecular Probes) in DMEM for 30 minutes at $37^{\circ} \mathrm{C}$ in a cell culture incubator. Cells were subsequently washed in DMEM followed by 3 washes in calcium-free HBSS in order to remove any unincorporated Fluo4. Intracellular calcium levels were quantified using a Bio-tek spectrofluorometer equipped with two plate microinjectors (Bio-tek Inc., VT) at specific excitation (485 nm) and emission (516 nm) wavelengths. Baseline intracellular calcium levels were continuously recorded for 1 minute every $1 / 100$ second. Immediately following treatment of the cells with $1 \mu \mathrm{M}$ FS, LMWO and HMWO A $\beta 1-42$, intracytoplasmic calcium was continuously recorded for one minute to determine the impact of the different forms of $A \beta$ on calcium release by intracellular calcium stores. Finally, following one minute of treatment with different forms of $\mathrm{A} \beta, 2 \mathrm{mM}$ of $\mathrm{CaCl}_{2}$ was added extracellularly to the culture medium and intracellular calcium levels were continuously monitored in order to evaluate the impact of the different forms of $A \beta$ on calcium entry. 
Measurement of neurotoxicity induced by $A \beta$ on HNPC:

HNPC cells were grown on a 24 well plate with the HMWO A $\beta 1-42$ alone and at a dose of $20 \mu \mathrm{M}$ and in combination with Nilvadipine $5 \mu \mathrm{M}, 5 \mu \mathrm{M}$ NS398, $25 \mu \mathrm{M}$ Ibuprofen, and $5 \mu \mathrm{M}$ KN62 over a period of 4 days. The neurotoxicity mediated by HMWO A $\beta$ was monitored at different time points $24 \mathrm{~h}, 48 \mathrm{~h} 72 \mathrm{~h}$ and $96 \mathrm{~h}$ by using the Scion Image software at 10X and 20X magnification. Media was collected at the end of 96h and LDH was performed on the media and cell lysate to evaluate the level of toxicity mediated by the various conformations of $\mathrm{A} \beta 1-42$.

\section{Statistical analyses}

For statistical analyses, ANOVA and t-tests were performed where appropriate using SPSS for Windows release 10.1. Results are represented as Mean +/- SEM. Post-hoc analysis was conducted using Bonferroni $\mathrm{p}<0.05$ or $\mathrm{p}<0.01$.

\section{RESULTS:}

Effect of FS, LMWO and HMWO A $\beta 1-42$ on the release of IL-6 and IL-8 in HNPCs:

Media from HNPC collected after $24 \mathrm{~h}$ was used to measure the levels of IL-6 and IL-8 following treatment with $1 \mu \mathrm{M}$ FS, LMWO, and HMWO A $\beta 1-42$. Levels of both proinflammatory cytokines IL-6 and IL-8 were significantly elevated following treatment with the HMWO A $\beta$ as compared to FS A $\beta$ and LMWO A $\beta$ (Fig $2 a \& 2 b$ ). 
Effect of HMWO A $\beta 1-42$ on the release of IL-6 and IL-8 in HNPCs after co-treatment with calmodulin kinase II inhibitor and the L-type calcium channel blocker: After establishing that HMWO A $\beta 1-42$ is most potent in stimulating both IL-6 and IL-8 in HNPCs, I wanted to determine if Nilvadipine (a selective L-type calcium channel blocker), and KN62 (a calmodulin kinase II inhibitor) could inhibit or reduce levels of these pro-inflammatory molecules stimulated by $1 \mu \mathrm{M}$ HMWO A $\beta 1-42$. My results demonstrated that $5 \mu \mathrm{M}$ Nilvadipine significantly reduces the production of both IL- 6 and IL-8 mediated by $1 \mu \mathrm{M}$ HMWO $\mathrm{A} \beta$ in HNPCs (Fig.3a, 3b), suggesting that $\mathrm{A} \beta$ mediates the production of IL-6 and IL-8 in astrocytes and microglia by stimulating calcium entry via L-type calcium channels. My results also revealed a significant reduction in both IL-6 and IL-8 in astrocytes and microglia following treatment with $5 \mu \mathrm{M}$ KN62 (Fig. 3a, 3b), strongly suggesting that compounds affecting calcium entry and calcium signaling pathways can oppose the pro-inflammatory effect of HMWO A $\beta$ on HNPCs.

Intracellular levels of calcium in HNPC following HMWO $A \beta$ stimulation and in combination with Nilvadipine, Ibuprofen and NS398:

My results demonstrate that HNPCs showed an increase in intracellular calcium influx with $20 \mu \mathrm{M}$ HMWO A $\beta 1-42$ and this increase in calcium influx mediated by HMWO A $\beta$ is blocked significantly by $5 \mu \mathrm{M}$ Nilvadipine (Fig. $4 \mathrm{a} \& 4 \mathrm{~b}$ ), $5 \mu \mathrm{M}$ NS398 (Fig.5a $\& 5 \mathrm{~b}$ ) and $25 \mu \mathrm{M}$ Ibuprofen (Fig.6a \& 6b) suggesting that inflammation stimulates calcium influx which can be blocked by using anti-inflammatory agents. 
Effect of calcium antagonists and anti-inflammatory agents on HMWO A 1 -42 mediated neurotoxicity of HNPCs:

My results with HNPC's grown for a period of 4 days after treatment with $20 \mu \mathrm{M}$ HMWO $\mathrm{A} \beta$ and in conjunction with $5 \mu \mathrm{M}$ Nilvadipine, $5 \mu \mathrm{M}$ KN62, $5 \mu \mathrm{M}$ NS398 and $25 \mu \mathrm{M}$ Ibuprofen reveal that the neurodegeneration induced by HMWO A $\beta$ was significantly reduced by $5 \mu \mathrm{M}$ Nilvadipine, $5 \mu \mathrm{M}$ KN62 (Fig. 7a), $5 \mu \mathrm{M}$ NS398, $25 \mu \mathrm{M}$ Ibuprofen (Fig. 7b) even after 96h. The LDH levels were measured after $96 \mathrm{~h}$ and our results indicate that the amount of LDH released by the HMWO A $\beta$ was significantly higher as compared to HNPCs co-treated with HMWO and Nilvadipine, KN62, NS-398, and Ibuprofen respectively (Fig. 8). My data suggest that these compounds may either have a direct neuroprotective effect or prevent neurodegeneration by reducing inflammation via modulation of intracellular calcium levels.

\section{DISCUSSION:}

Several studies suggest that $\mathrm{A} \beta$ may cause neurodegeneration in $\mathrm{AD}$ (Rasool 1986, Chiarini 2006). However, different conformations of $A \beta$ have different effects on the pathophysiology of AD resulting in a cascade of events (Deshpande 2006, Standridge 2006). I used primary HNPCs to elucidate the effect of the various conformations of $A \beta$ on neurotoxicity. My other aim was to determine if this neurotoxic effect of $A \beta$ was mediated by an increase in intracellular calcium levels. My previous studies with human astrocytes and microglia revealed that HMWO and to some extent LMWO increased intracellular levels of calcium more than FS A $\beta 1-42$. This is supported by other studies 
on hippocampal neurons revealing that $A \beta \quad 1-42$ oligomers are more toxic to neurons than the fibrillar or monmeric/dimeric species (De Felice 2004). The oligomeric conformations significantly increased the release of pro-inflammatory interleukins IL-6 and IL-8 via modulation of calcium influx as previously seen in glial cells. Furthermore, my results with HNPC reveal that HMWO A $\beta$ are toxic to neurons, and this neurotoxicity is mitigated by using $5 \mu \mathrm{M}$ Nilvadipine suggesting that HMWO A $\beta$ increases the activity of L-type VGCC in neurons. The neurotoxic effect of HMWO A $\beta$ was also blocked by using $5 \mu \mathrm{M}$ KN62 thereby suggesting that the neurotoxic effect is calcium dependent. It has been demonstrated that calmodulin kinase inhibitors reduce NFkB activity in neurons (Lilienbaum 2003). My previous results in astrocytes and microglia treated with Nilvadipine and KN62, reveal that these compounds reduce the production of IL-6 and IL-8 induced by HMWO A $\beta 1-42$ (previous chapter). This suggests that the neuroprotective effect mediated by these compounds on HNPCs maybe due to their ability to decrease the pro-inflammatory effect of HMWO A $\beta$ by modulating calcium entry. To further demonstrate a link between altered calcium levels and inflammation in mediating neurotoxicity of HNPCs I used two anti-inflammatory agents Ibuprofen and NS398 together with HMWO Aß1-42 and showed that even after 96h there was very little neurodegeneration ( Fig. 7b). My results with these two anti-inflammatory agents on calcium influx indicated that they significanty reduced calcium entry in HNPCs following treatment with HMWO A $\beta$ (Fig.5 and 6). Altogether my data suggest that elevated intracellular levels of calcium mediated by oligomeric forms of $A \beta 1-42$ promote the release of pro-inflammatory cytokines and chemokines in human neurons. This highly 
elevated load of inflammatory cytokines and chemokines is responsible for the neurodegeneration associated in AD patients (Griffin 1998) and hence blocking inflammation by modulating intracellular levels of calcium could have potential therapeutic implications in various neuroinflammatory diseases including multiple sclerosis, Parkinson's disease, AIDS etc. 
Figure 10: Proposed hypothesis for $A \beta$ mediated neurotoxicity.

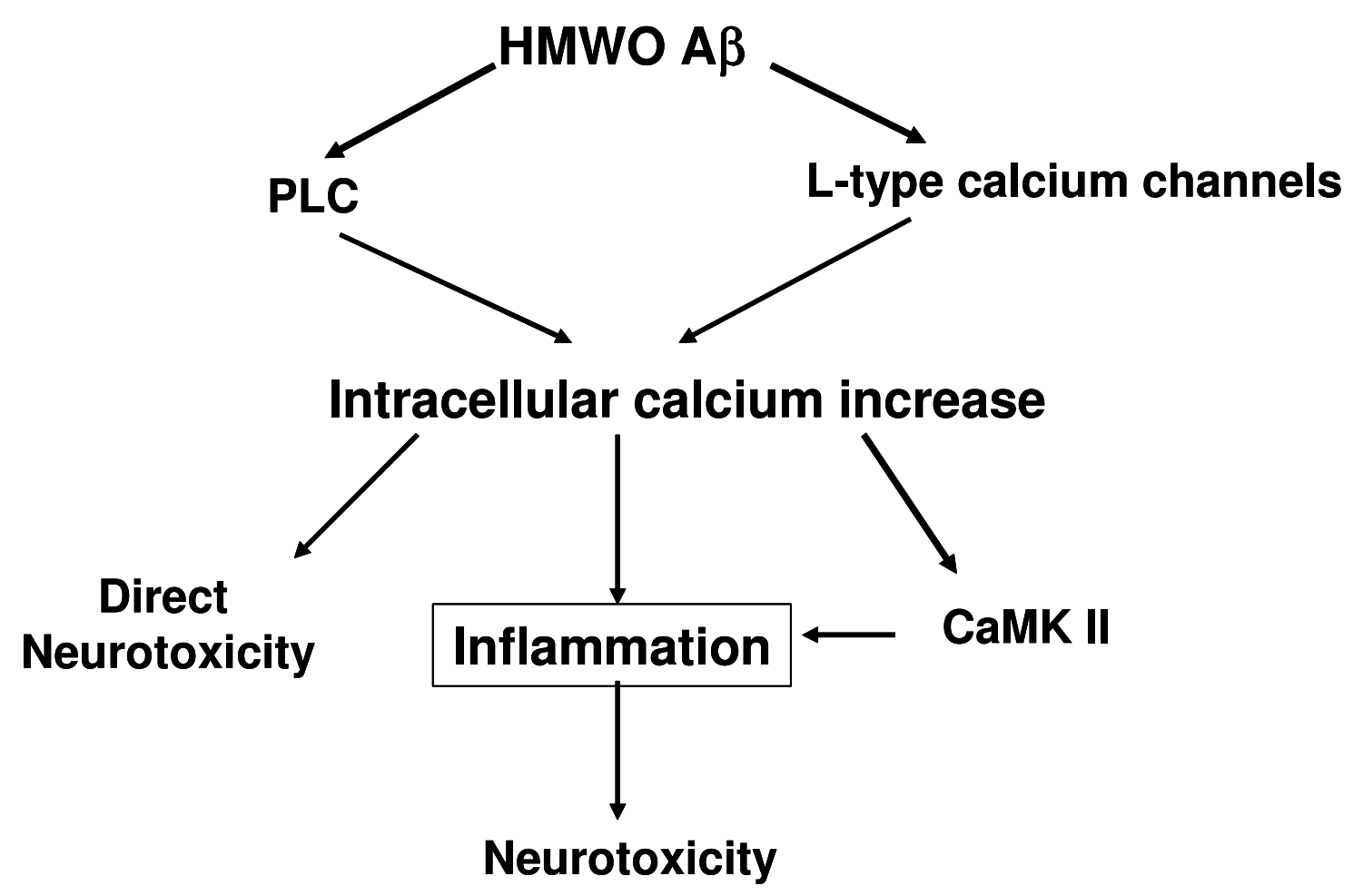


Figure 11a: IL-6 levels in HNPCs

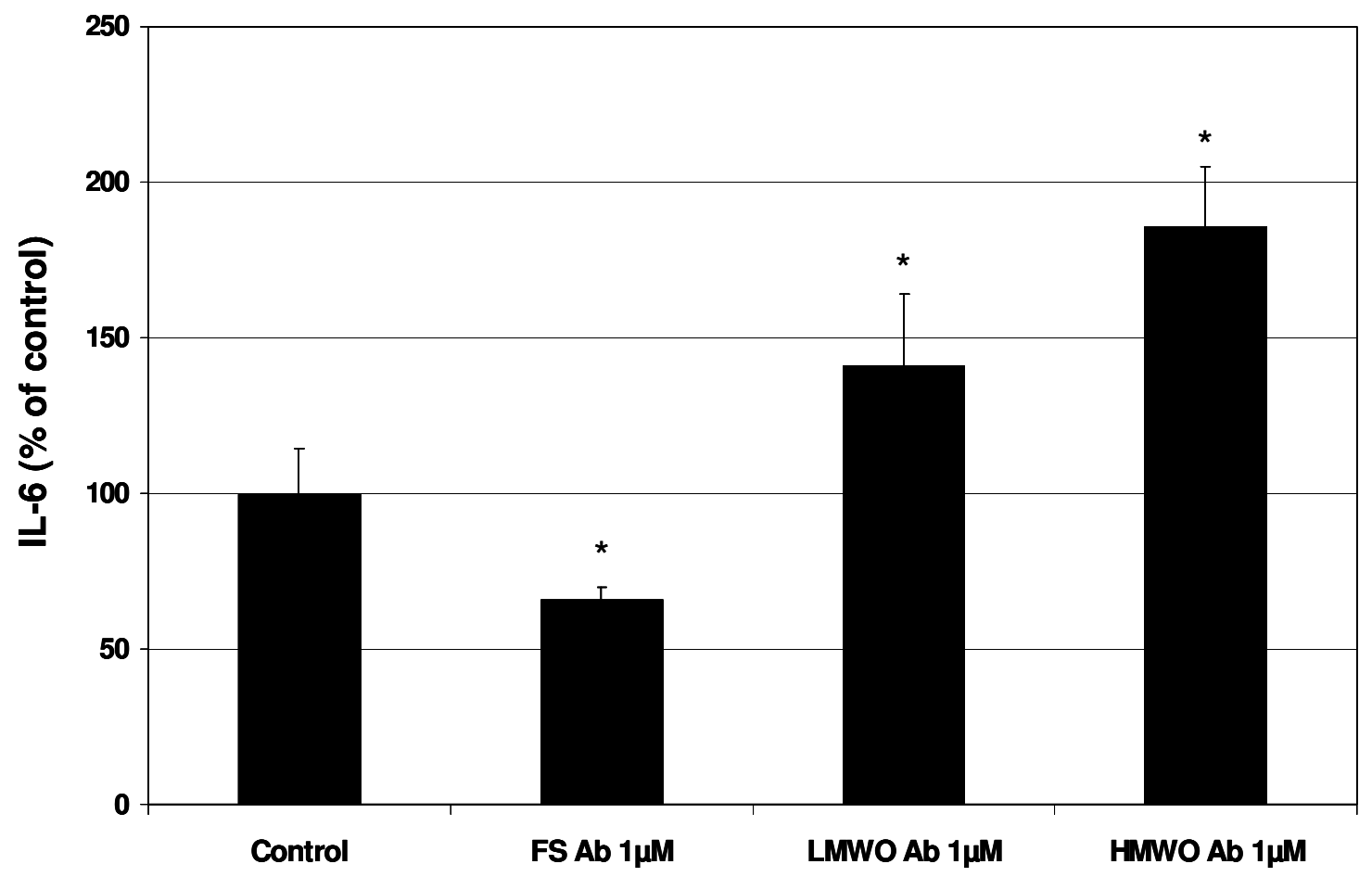

Figure 11b: IL-8 levels in HNPCs

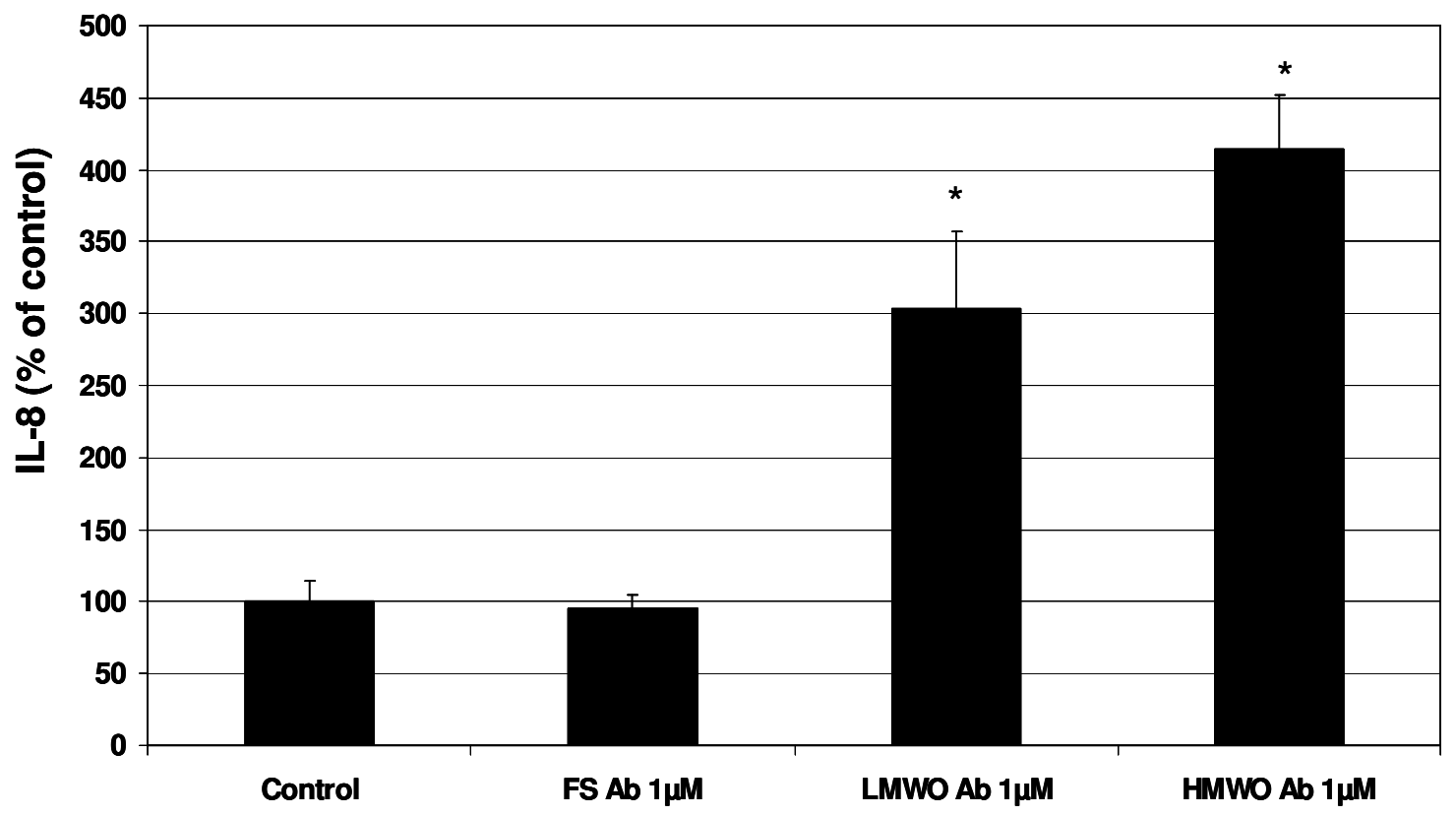


Fig. 11: a) Bar graph of IL-6 levels in media following $24 \mathrm{~h}$ treatment with $1 \mu \mathrm{M}$ FS, LMWO, HMWO A $\mathrm{A} 1-42$ and Control ( $\mathrm{n}=6$ for each treatment group) in HNPCs. ANOVA followed by post-hoc analysis revealed significant differences between control and HMWO (p<0.05), FSA $\beta$ and HMWO ( $<<0.05)$, LMWO and HMWO $(\mathrm{p}<0.05)$.

b) Bar graph of IL-8 levels in media following $24 \mathrm{~h}$ treatment with $1 \mu \mathrm{M} \mathrm{FS}$, LMWO, HMWO A $1-42$ and Control ( $\mathrm{n}=6$ for each treatment group) in HNPCs. ANOVA followed by post-hoc analysis revealed significant differences between control and HMWO ( $p<0.05)$, FSA $\beta$ and HMWO $(\mathrm{p}<0.05)$, LMWO and HMWO $(\mathrm{p}<0.05)$. 
Figure 12a: IL-6 levels in HNPCs

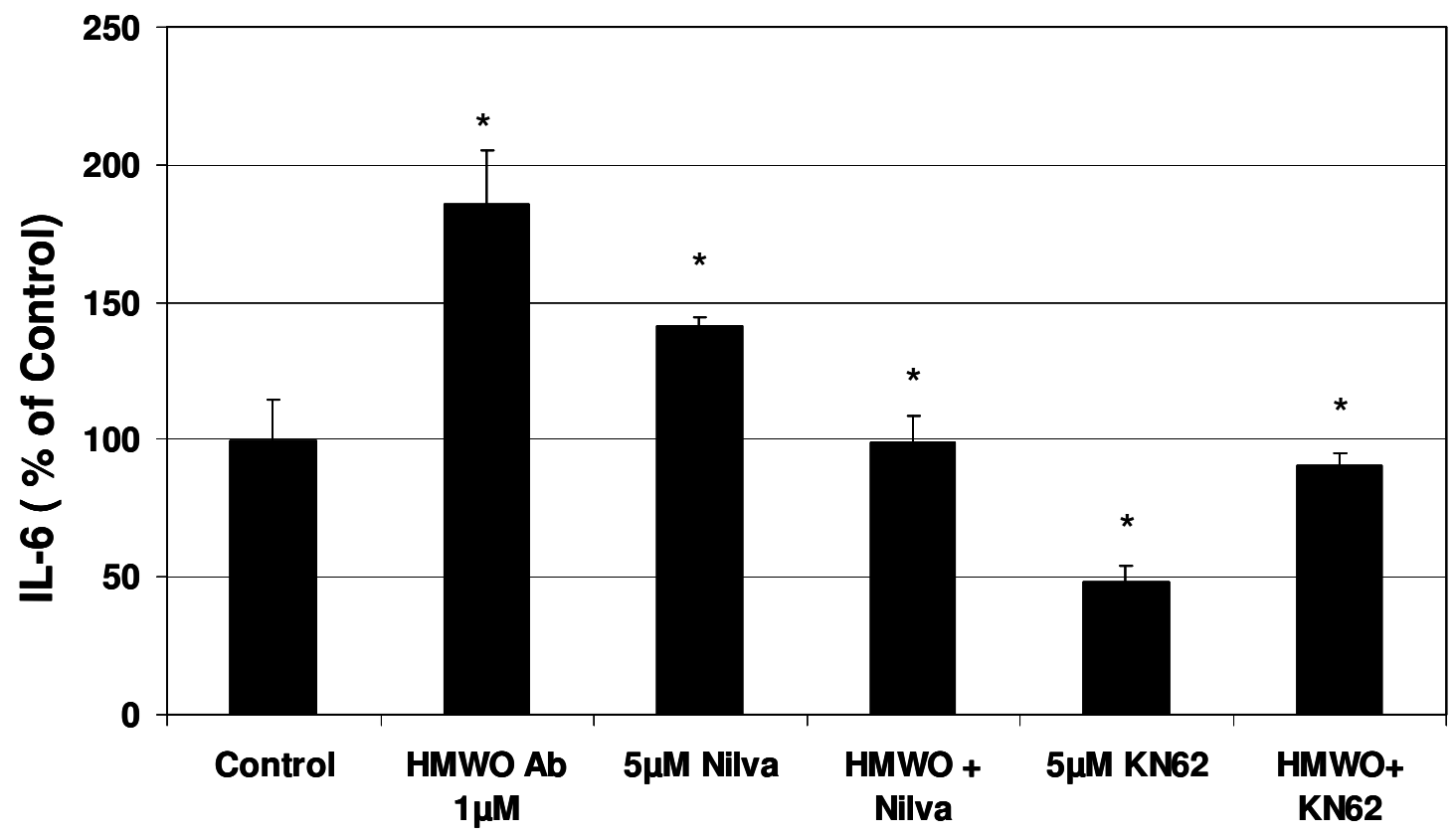

Figure 12b: IL-8 levels in HNPCs

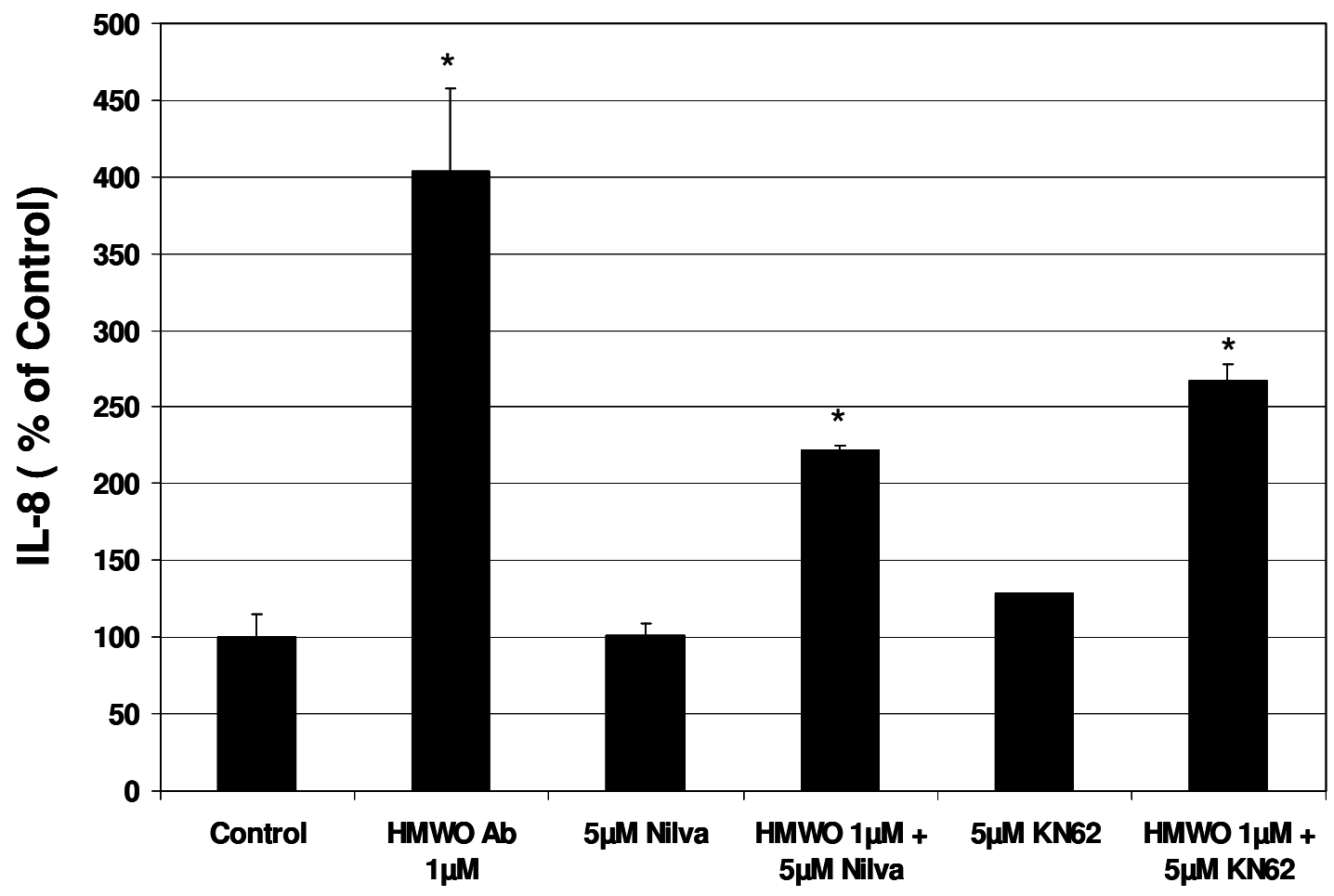


Fig. 12: a) Bar graph of IL-6 levels in media after $24 \mathrm{~h}$ following treatment with $5 \mu \mathrm{M}$ Nilvadipine, $1 \mu \mathrm{M}$ HMWO A $\beta 1-42,1 \mu \mathrm{M}$ HMWO $+5 \mu \mathrm{M}$ Nilvadipine, $5 \mu \mathrm{M}$ KN62, and $1 \mu \mathrm{M}$ HMWO $+5 \mu \mathrm{M}$ KN62 and Control ( $\mathrm{n}=6$ for each treatment group) in HNPCs. ANOVA followed by post-hoc analysis revealed significant differences between control and HMWO, HMWO and HMWO + Nilvadipine (p<0.05), HMWO and HMWO + KN62 b) Bar graph of IL-8 levels in media after $24 \mathrm{~h}$ following treatment with $5 \mu \mathrm{M}$ Nilvadipine, $1 \mu \mathrm{M}$ HMWO A $\beta 1-42,1 \mu \mathrm{M}$ HMWO $+5 \mu \mathrm{M}$ Nilva, $5 \mu \mathrm{M}$ KN62, and $1 \mu \mathrm{M}$ HMWO $+5 \mu \mathrm{M}$ KN62 and Control ( $\mathrm{n}=6$ for each treatment group) in HNPCs. ANOVA followed by post-hoc analysis revealed significant differences between Control and HMWO, HMWO and HMWO + Nilvadipine, HMWO and HMWO + KN62 ( $<0.05)$. 
Figures 13a \& 13b: Calcium entry in HNPC following treatment with Nilva
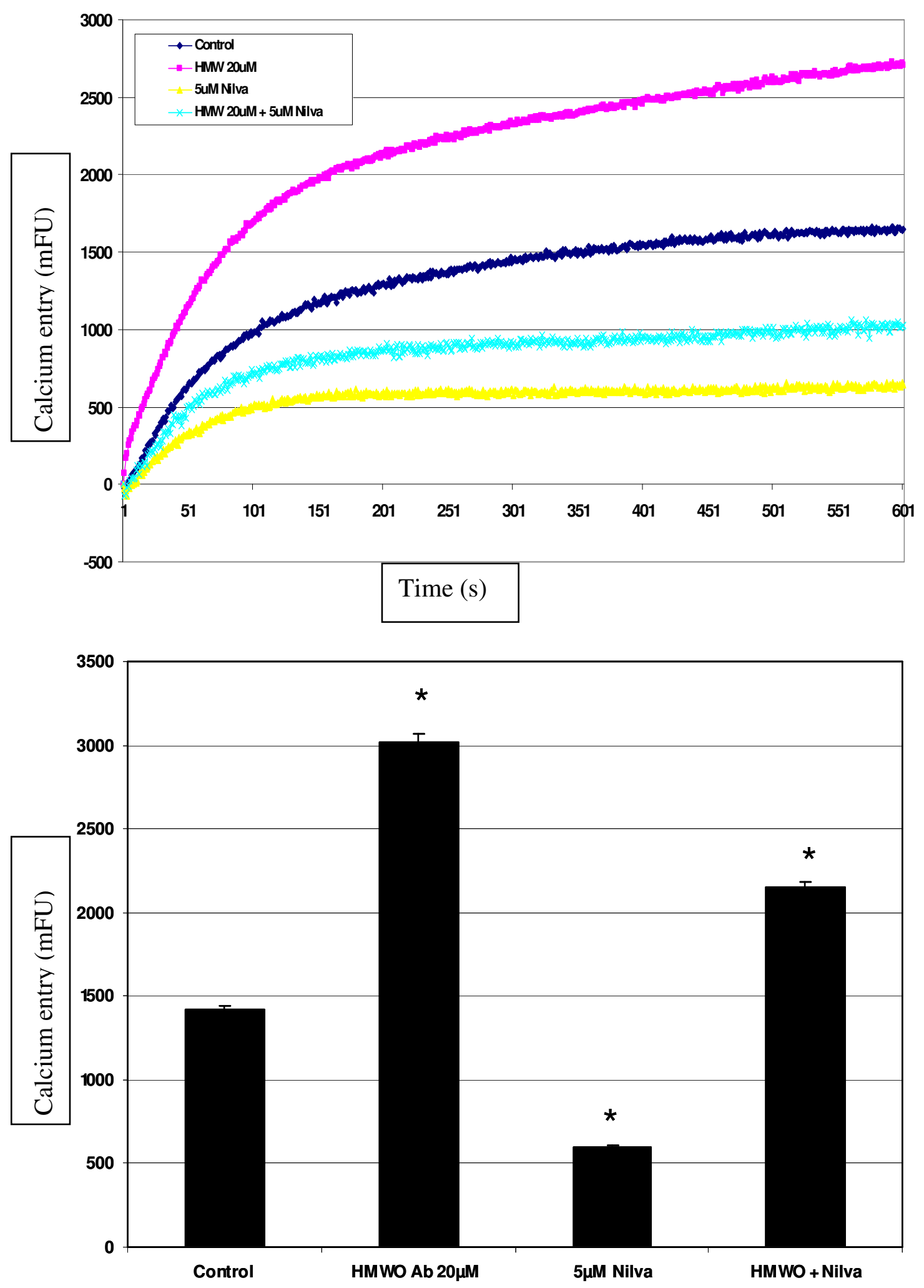
Fig. 13: a) Fluorometric measurement of calcium entry in human HNPCs following treatment with $20 \mu \mathrm{M}$ HMWO A $\beta 1-42,5 \mu \mathrm{M}$ Nilvadipine, HMWO + Nilvadipine ( $\mathrm{n}=6$ for each treatment group). b) Quantification of intracellular calcium entry in HNPCs following the above mentioned treatments. ANOVA followed by post-hoc analysis revealed significant differences between control and HMWO $(\mathrm{p}<0.05)$, HMWO and HMWO + Nilvadipine $(\mathrm{p}<0.05)$. 
Figures 14a \& 14b: Calcium entry in HNPC following treatment with NS-398

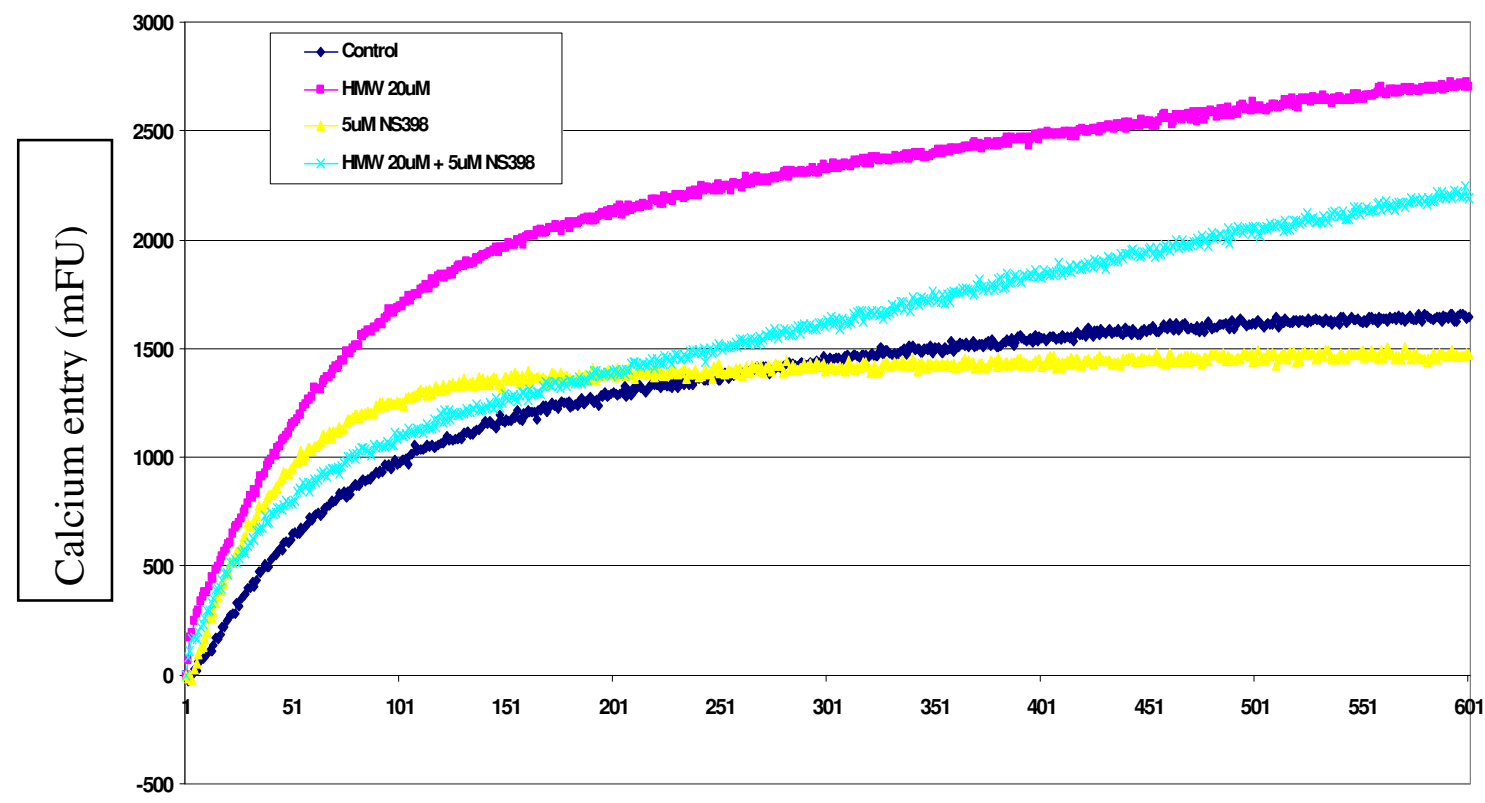

Time (s)

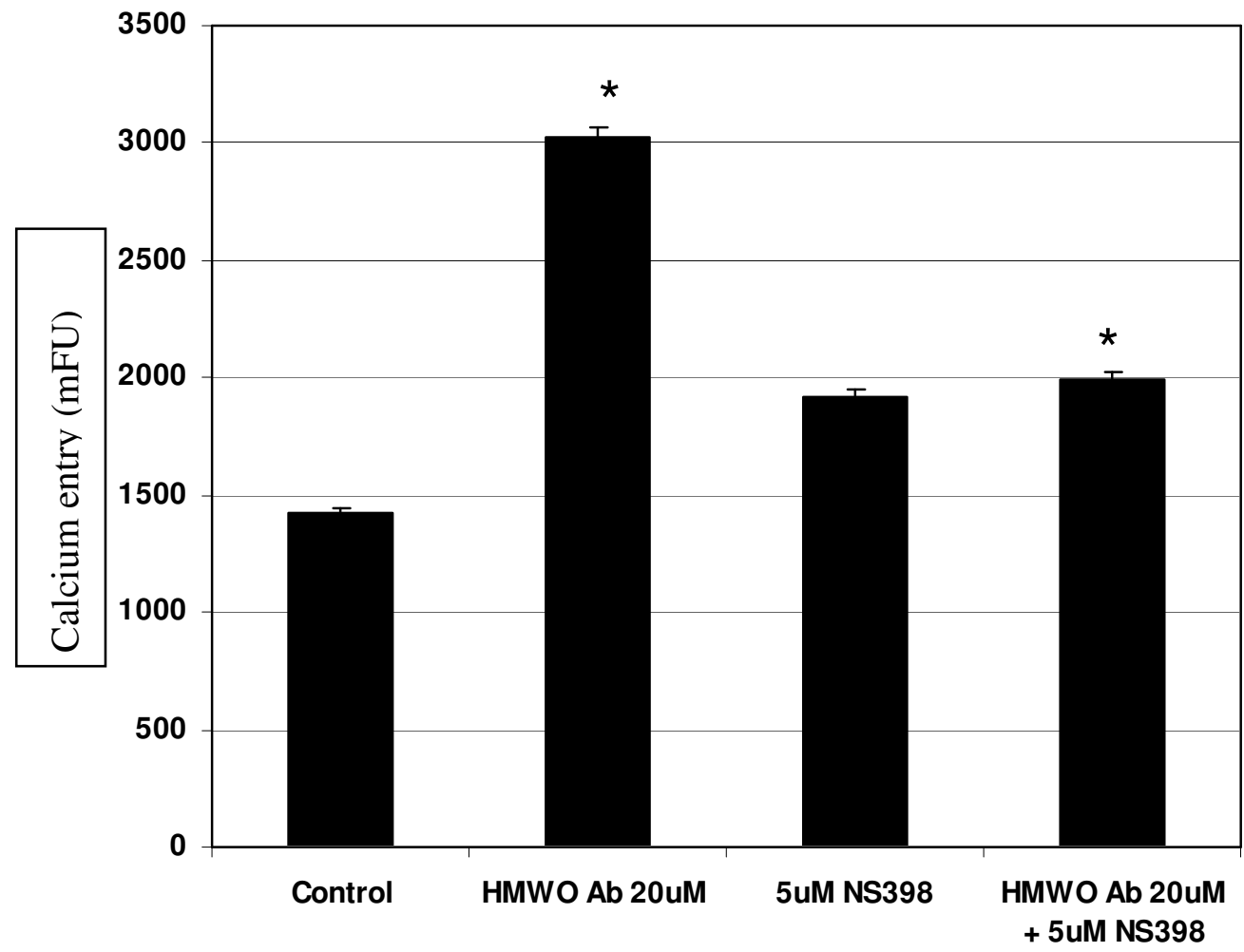


Fig. 14: a) Real time measurement of calcium entry in human HNPCs following treatment with $20 \mu \mathrm{M}$ HMWO A $31-42,5 \mu \mathrm{M}$ NS398, HMWO + NS398 ( $\mathrm{n}=6$ for each treatment group). b) Quantification of intracellular calcium entry in HNPCs following the above mentioned treatments. ANOVA followed by post-hoc analysis revealed significant main effects between control and HMWO (p<0.05), HMWO and HMWO + NS398 $(\mathrm{p}<0.05)$ 
Figures 15a \& 15b: Calcium entry in HNPC following treatment with Ibuprofen
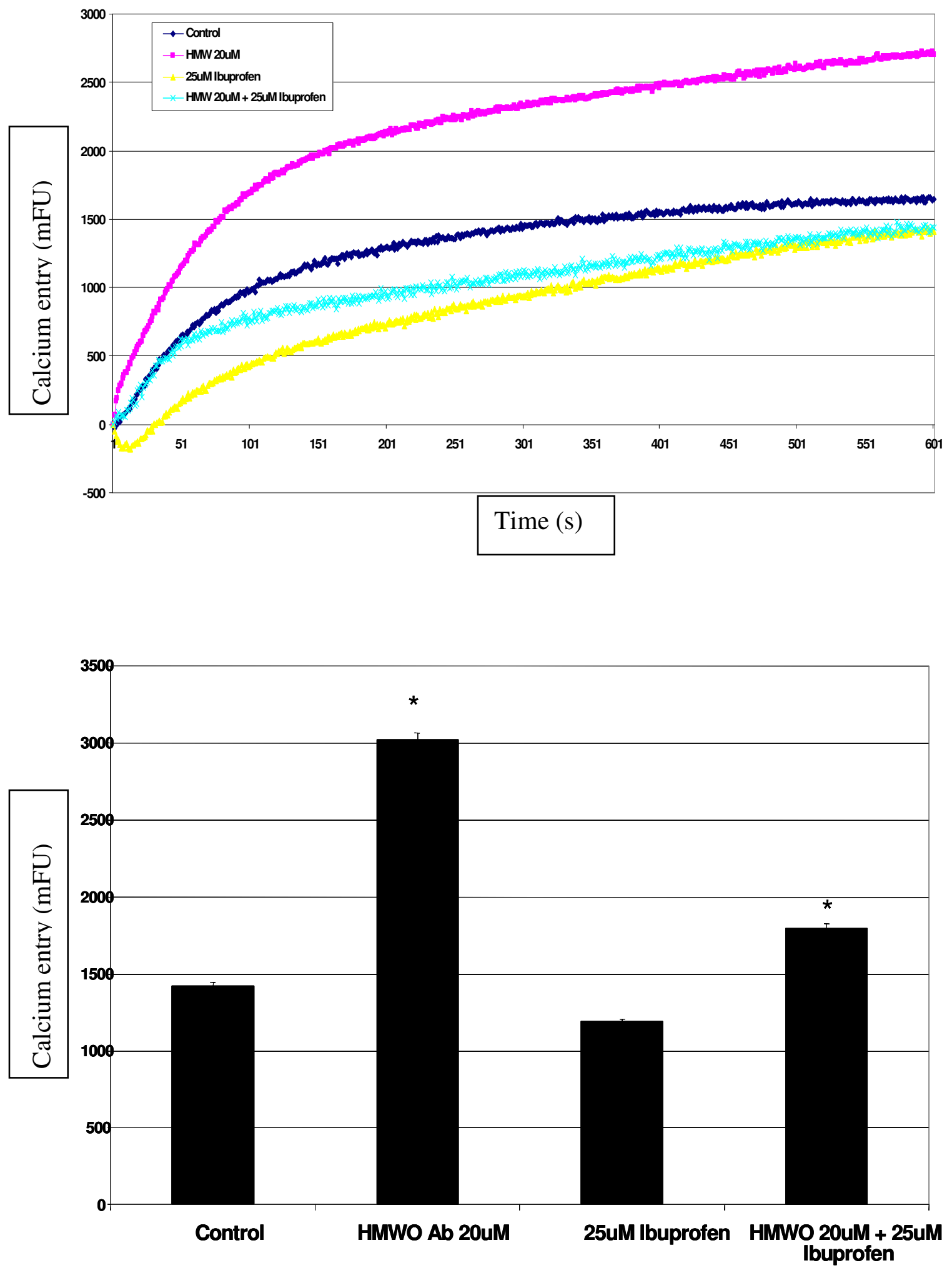
Fig. 15: a) Real time measurement of calcium entry in human HNPCs following treatment with $20 \mu \mathrm{M}$ HMWO A $\beta 1-42,25 \mu \mathrm{M}$ Ibuprofen, HMWO + Ibuprofen ( $\mathrm{n}=6$ for each treatment group). b) Quantification of intracellular calcium entry in HNPCs following the above mentioned treatments. ANOVA followed by post-hoc analysis revealed significant main effects between control and HMWO $(\mathrm{p}<0.05)$, HMWO and HMWO + Ibuprofen $(\mathrm{p}<0.05)$ 
Figure 16: HNPC cells using 20X magnification - Day 4
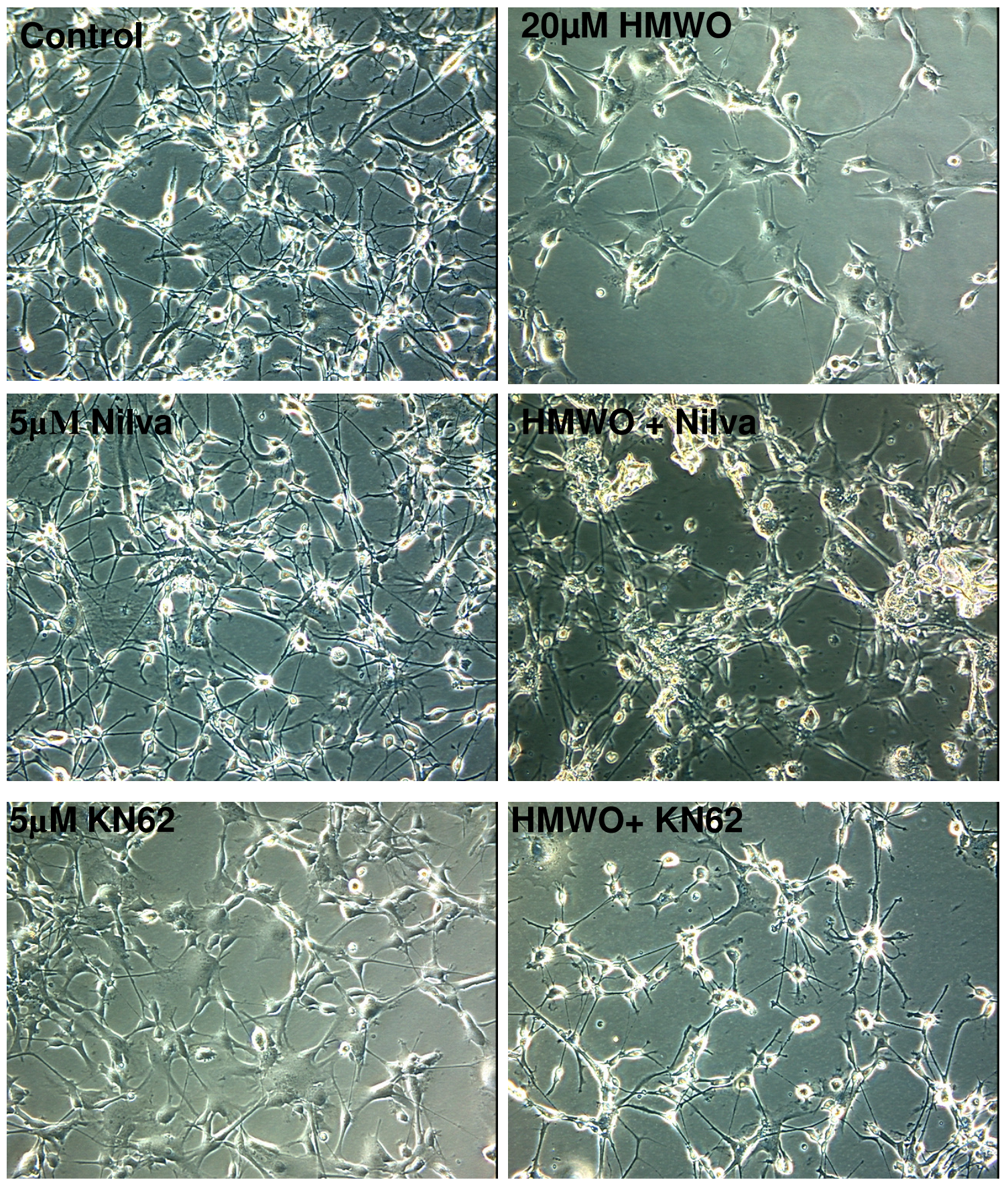

Fig. 16: Neurotoxicity observed in HNPCs following treatment with $20 \mu \mathrm{M}$ HMWO A $\beta 1$ -

42 alone and in combination with $5 \mu \mathrm{M}$ Nilvadipine and $5 \mu \mathrm{M}$ KN62 after $96 \mathrm{~h}$ as recorded using the Scion software imager at $20 \mathrm{X}$ magnification. 
Figure 17: HNPC cells using 10X magnification - Day 4
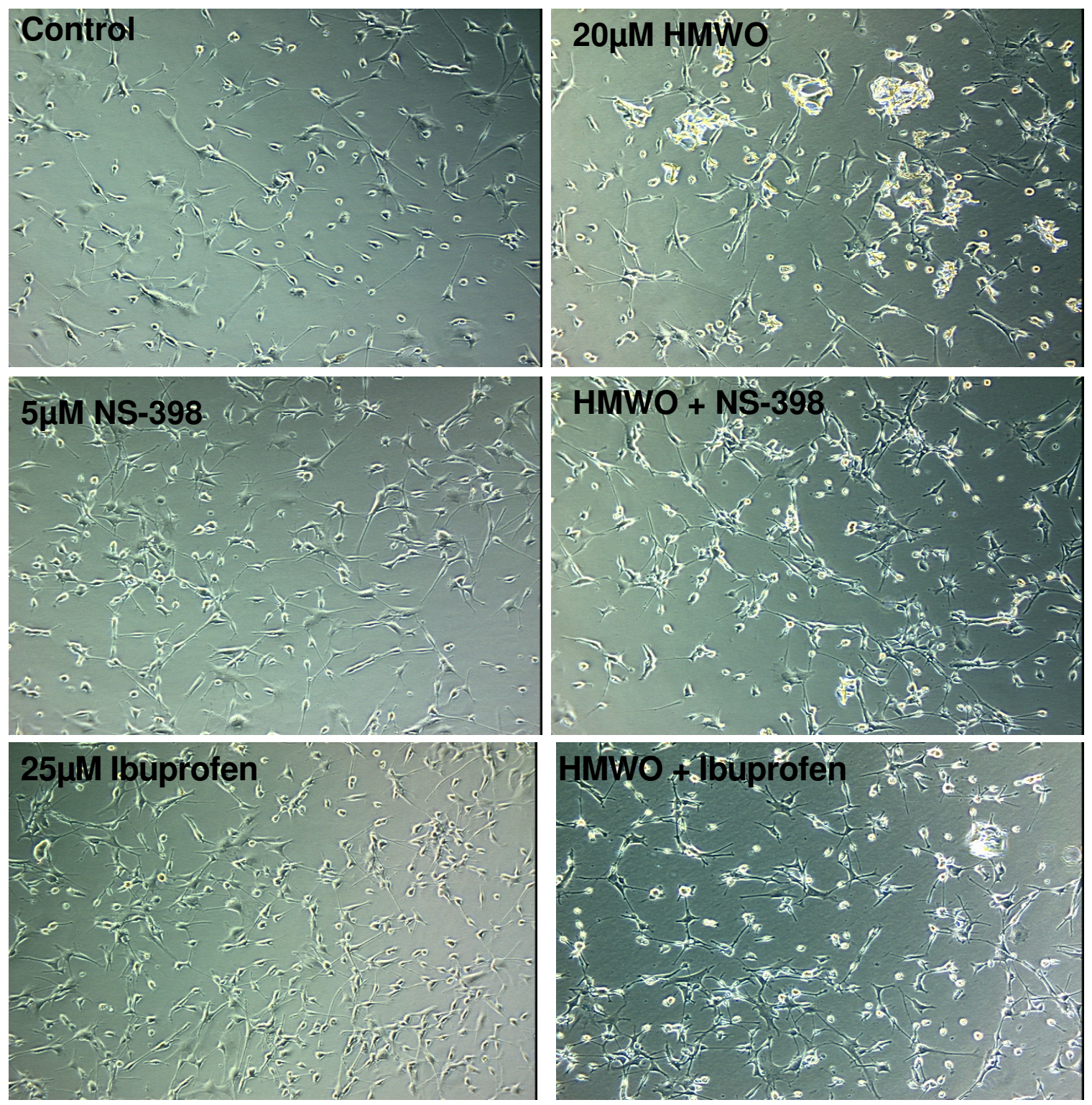

Fig. 17: Neurotoxicity observed in HNPCs following treatment with $20 \mu \mathrm{M}$ HMWO A $\beta 1$ 42 alone and in combination with $5 \mu \mathrm{M}$ NS-398 and $25 \mu \mathrm{M}$ Ibuprofen after $96 \mathrm{~h}$ as recorded using the Scion software imager at 10X magnification. 
Fig. 18: LDH in HNPCs

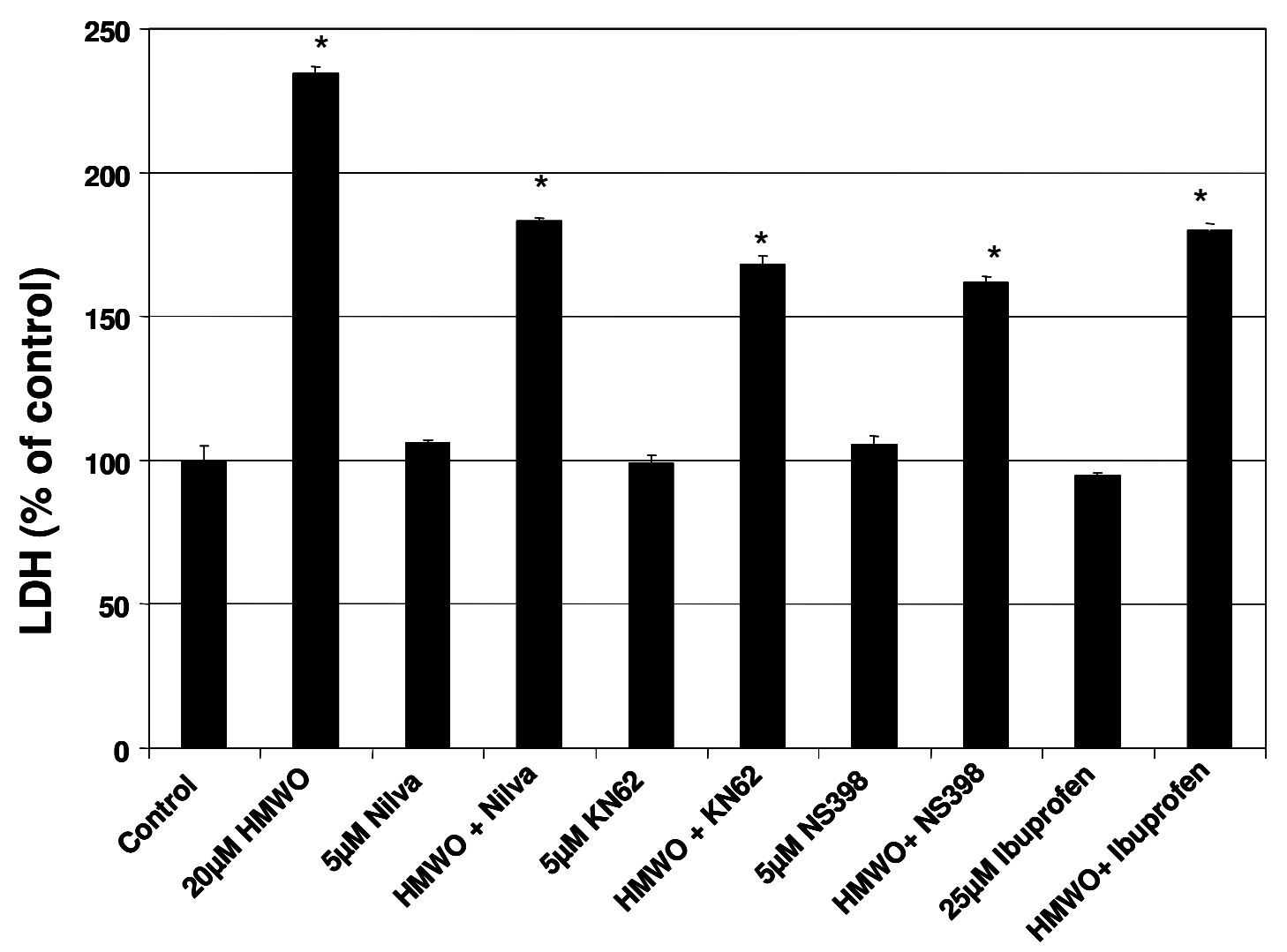

Fig. 18: LDH ratio of media versus lysate of HNPCs after treatment with $20 \mu \mathrm{M}$ HMWO A $\beta 1-42$ alone and in combination with $5 \mu \mathrm{M}$ Nilvadipine, $5 \mu \mathrm{M}$ KN62, $5 \mu \mathrm{M}$ NS-398, $25 \mu \mathrm{M}$ Ibuprofen after $96 \mathrm{~h}$. ANOVA followed by post-hoc analysis revealed significant main effects between control and HMWO $(\mathrm{p}<0.05)$, HMWO and HMWO + Nilvadipine $(\mathrm{p}<0.05)$, HMWO and HMWO + KN62 (p<0.05), HMWO and HMWO + NS-398 $(\mathrm{p}<0.05)$, HMWO and HMWO + Ibuprofen $(\mathrm{p}<0.05)$. 


\section{REFERENCES:}

1. Chiarini A, Dal Pra I, Whitfield JF, Armato U. The killing of neurons by betaamyloid peptides, prions, and pro-inflammatory cytokines. Ital J Anat Embryol. 111:221-246, 2006.

2. Deshpande A, Mina E, Glabe C, Busciglio J. Different conformations of amyloid beta induce neurotoxicity by distinct mechanisms in human cortical neurons. J Neurosci. 26:6011-6018, 2006.

3. De Felice FG, Vieira MN, Saraiva LM, Figueroa-Villar JD, Garcia-Abreu J, Liu R, Chang L, Klein WL, Ferreira ST. Targeting the neurotoxic species in Alzheimer's disease: inhibitors of Abeta oligomerization. FASEB J. 18:13661372, 2004.

4. Griffin WS, Sheng JG, Royston MC, Gentleman SM, McKenzie JE, Graham DI, Roberts GW, Mrak RE. Glial-neuronal interactions in Alzheimer's disease: the potential role of a 'cytokine cycle' in disease progression. Brain Pathol. 8:65-72, 1998

5. Lilienbaum A, Israel A. From calcium to NF-kappa B signaling pathways in neurons. Mol Cell Biol. 23:2680-2698, 2003.

6. Kushi H, Saito T, Makino K, Hayashi N. IL-8 is a key mediator of neuroinflammation in severe traumatic brain injuries. Acta Neurochir Suppl.86:347-350, 2003.

7. Magaki S, Mueller C, Dickson C, Kirsch W. Increased production of inflammatory cytokines in mild cognitive impairment. Exp Gerontol. 42:233-240, 2007. 
8. Mattson MP. Calcium and neurodegeneration. Aging Cell. 6:337-350, 2007.

9. Mattson MP. Effects of microtubule stabilization and destabilization on tau immunoreactivity in cultured hippocampal neurons. Brain Res. 582:107-118, 1992.

10. Nelson TE, Ur CL, Gruol DL. Chronic interleukin-6 exposure alters electrophysiological properties and calcium signaling in developing cerebellar purkinje neurons in culture. J Neurophysiol. 88:475-486, 2002.

11. Paris D, Patel N, Quadros A, Linan M, Bakshi P, Ait-Ghezala G, Mullan M. Inhibition of Abeta production by NF-kappaB inhibitors. Neurosci Lett. 415:11$16,2007$.

12. Quadros A, Patel N, Weeks OI, Brown B, Linan M, Mullan M, Paris D. Dysregulation of calcium entry by $\mathrm{A} \beta$ oligomers promotes inflammation in human astrocytes and microglia. submitted Journal of Neuroinflammation.

13. Rasool CG, Svendsen CN, Selkoe DJ. Neurofibrillary degeneration of cholinergic and noncholinergic neurons of the basal forebrain in Alzheimer's disease. Ann Neurol. 20:482-488, 1986.

14. Standridge JB. Vicious cycles within the neuropathophysiologic mechanisms of Alzheimer's disease. Curr Alzheimer Res. 3:95-108, 2006.

15. Thibault O, Gant JC, Landfield PW. Expansion of the calcium hypothesis of brain aging and Alzheimer's disease: minding the store. Aging Cell. 6:307-317, 2007. 


\section{CHAPTER FIVE}

\section{DISCUSSION and CONCLUSIONS}

\section{DISCUSSION:}

My previous studies and several other reports have established that $\mathrm{A} \beta$ causes inflammation which is evident by increased activation/expression of Cox-2 enzyme (Paris et al 2002, Quadros et al 2003), activation of astrocytes and microglia in response to A $\beta$ deposition (Sastre et al 2006). Other evidence supporting that inflammation is one of the pathogenic factors involved in $\mathrm{AD}$ is based on epidemiological studies with NSAIDs which show protective effects with long-term intake in AD patients (McGeer and McGeer 2007, Stewart et al 1997). A $\beta$ which is derived from its substrate APP assumes different conformations capable of assuming different biological activities. Several earlier reports differentiated $A \beta$ as soluble and aggregated forms and the soluble forms of $A \beta$ were demonstrated to be more pathogenic in AD (Mclean et al 1999). Subsequent studies by atomic force microscopy revealed that the soluble pool of $A \beta$ consisted of monomers/dimers and oligomers (Mastrangelo et al 2006). I have tried to determine which conformation of $A \beta 1-42$ is most toxic to neurons by correlating its toxicity to inflammation in glial cells and its subsequent effect on neurons. My results demonstrate that $\mathrm{A} \beta 1-42$ in its monomer/dimer form also referred to as freshly solubilized (FS) is not toxic to neurons nor does it stimulate inflammation as observed by the release of interleukins IL-6 and IL-8 in astrocytes and microglia. However oligomeric forms of $\mathrm{A} \beta$, more specifically the high molecular weight oligomers (HMWO) as opposed to the low molecular weight oligomers (LMWO) are more toxic to neurons and also produce 
significantly higher levels of proinflammatory IL-6 and IL-8 in both astrocytes and microglia (Quadros chapter 3). IL-6 and IL-8 are both pro-inflammatory molecules found to be elevated in the brains of patients with diseases such as $\mathrm{AD}$, mild cognitive impairment (MCI) and traumatic brain injury (TBI) (McGeer and McGeer 1999, Lue et al 2001, Kushi et al 2003). Studies in rat cortical neurons reveal that A $\beta$ together with IL-6 activate NMDA receptors resulting in neuronal damage (Quiz and Gruol 2003, Conroy et al 2004). Similar studies in rat neurons with IL-8 treatment resulted in neurotoxicity via increase in the release of neurotoxins and pro-apoptotic proteins (Thirumangalakudi et al 2007).

The other part of my thesis was to determine if excess influx of calcium into cells is responsible for the inflammation observed in $\mathrm{AD}$. It is well established that in $\mathrm{AD}$ there is a dysregulation of calcium within the cells (Mattson and Chan 2003). Recent reports have shown that calcium accelerates the change in conformation of $A \beta$ (Isaacs et al 2006) and this change from soluble to oligomeric forms is probably responsible for the neurotoxicity observed in AD (Hartley et al 1999, Watson et al 2005). In addition, increase in cytosolic calcium also affects APP processing in rat cortical neurons resulting in an increase in intraneuronal production of A $\beta 1-42$ (Pierrot et al 2004). But I wanted to correlate this increase in intracellular calcium mediated by $A \beta$ with increases in inflammation. My results with astrocytes and microglia demonstrate that oligomeric forms of $A \beta$ (more specifically HMWO A $\beta$ ) that increased IL-6 and IL-8 were also the most potent form in increasing intracellular levels of calcium within these cells. This proinflammatory effect mediated by calcium was blocked when an intracellular calcium chelator BAPTA-AM was used and conversely was potentiated significantly with the 
calcium ionophore A23187. Hence my results strongly suggest that blocking increased intracellular levels of calcium could reduce inflammation mediated by activated glia in response to $A \beta$. Acute inflammation is neuroprotective in nature, however chronic inflammation is neurotoxic. My hypothesis was that L-type calcium channel blockers and other inhibitors of the calcium signaling pathway like NFkB inhibitors and calmodulin kinase inhibitors could block $A \beta$ mediated inflammation via modulation of calcium inside the cell. The reason I chose L-type calcium channel blockers over other types of voltage gated calcium channel blockers such as $\mathrm{N}, \mathrm{P} / \mathrm{Q}$, and $\mathrm{R}$ was because of previous in vitro studies on neurons indicating an increase in L-type calcium channel activity following exposure to beta amyloid (Ekinci et al 1999, Ho et al 2001). Hence blocking Ltype calcium channels would reduce inflammation in glia and decrease neurodegeneration which is supported by my results shown on glia and HNPCs (Quadros et al. 2007, chapter 4). L-type calcium channel blockers and calmodulin kinase inhibitors could therefore act as dual antagonists of inflammation and calcium influx and possibly have potential therapeutic effects not only in AD but also in other neuroinflammatory diseases like multiple sclerosis, Parkinson's disease, TBI etc. Studies in rat cortical neurons revealed that L-type calcium channel blockers reduced neuronal apoptosis mediated by activation of spla2 enzyme (Yagami et al 2004). My results with known anti-inflammatory agents NS-398, a selective COX-2 inhibitor and Ibuprofen, a NSAID reveal significant reduction in neuronal loss even after day 4 compared to control and HMWO A $\beta 1-42$. Both NS-398 and Ibuprofen were capable of inhibiting the effect of HMWO A $\beta$ mediated neurodegeneration. Similar effects were observed with Nilvadipine, the L-type calcium channel blocker and KN62, the calmodulin kinase 
inhibitor. Interestingly, both known anti-inflammatory agents NS-398 and Ibuprofen were capable of reducing the increased calcium influx in human neuronal precursor cells (HNPCs) mediated by HMWO A $\beta 1-42$ thereby suggesting that there is a correlation between calcium influx and inflammation.

\section{CONCLUSIONS:}

It is well established that several etiological factors are responsible for the pathogenesis in AD. However, my hypothesis was that there is a connection between excess calcium influx into glial cells and inflammation in AD. Regulating excess calcium influx in glial cells would decrease subsequent activation of these cells from releasing proinflammatory cytokines and chemokines which could be toxic to neurons. Several reports on astrocytes indicate that $A \beta$ mediated toxicity on neurons is via changes in intracellular levels of calcium (Abramov et al 2003, Monnerie et al 2005). My results with Nilvadipine, the L-type calcium channel blocker, and KN62, a calmodulin kinase inhibitor reveal that blocking excess levels of intracellular calcium in HNPCs mediated by HMWO A $\beta$ and to some extent LMWO A $\beta$ may be responsible for the attenuation of neurotoxicity observed in these cells. Calmodulin kinase and NFkB are actively involved in the regulation of calcium signaling across cells (Lin et al 2004, Choi et al 2006). Studies with NFkB inhibitors demonstrate that they have anti-inflammatory effects (Lopez-Franco et al 2006, Lopez-Franco et al 2002). My data with L-type calcium channel blocker and calmodulin kinase inhibitor on glial cells reveal that they reduce the production of IL-6 and IL-8 which are both pro-inflammatory thereby suggesting that increase in intracellular calcium causes inflammation. The reason these inhibitors 
mitigate neurotoxicity in HNPCs could be due to reduction in the production of these proinflammatory molecules. To further demonstrate that the neuroprotection offered by these calcium channel blockers or inhibitors associated with calcium binding were as a result of their anti-inflammatory effect, I used anti-inflammatory agents such as NS-398, a Cox-2 inhibitor and Ibuprofen, an NSAID on HNPCs. Previous studies with Ibuprofen on TgAPPsw mice early in the course of the disease reveal that it reduced amyloid deposition and the treatment also reduced activation of microglia around plaques resulting in a subsequent reduction in dystrophic neurites (Lim et al 2000, Heneka et al 2005). Reports indicate that increased Cox-2 activity caused neuronal damage in primary cortical neurons when induced by LPS and iron (Im et al 2006). My results with Ibuprofen and NS-398 reveal significant reduction in neurotoxicity mediated by HMWO $\mathrm{A} \beta$. Another interesting result is that these anti-inflammatory agents (NS-398 and Ibuprofen) were capable of inhibiting the increase in calcium influx mediated by HMWO $\mathrm{A} \beta$. This suggests that there is a correlation between inflammation and calcium influx and my results further indicate that HMWO A $\beta 1-42$ are most potent than monomers/dimers or fibrillar forms in mediating inflammation via disruption of intracellular calcium levels and causing neurotoxicity to cells. Hence, modulating intracellular calcium levels by using calcium channel blockers or calmodulin kinase inhibitors may reduce HMWO A $\beta$ mediated chronic inflammation in glial cells and protect neurons in $\mathrm{AD}$ patients. 


\section{REFERENCES:}

1. Abramov AY, Canevari L, Duchen MR. Changes in intracellular calcium and glutathione in astrocytes as the primary mechanism of amyloid neurotoxicity. $\mathrm{J}$ Neurosci. 2003 Jun 15;23(12):5088-95.

2. Choi S, Kim JH, Roh EJ, Ko MJ, Jung JE, Kim HJ. Nuclear factor-kappaB activated by capacitative $\mathrm{Ca} 2+$ entry enhances muscarinic receptor-mediated soluble amyloid precursor protein (sAPPalpha) release in SH-SY5Y cells. J Biol Chem. 2006 May 5;281(18):12722-8.

3. Conroy SM, Nguyen V, Quina LA, Blakely-Gonzales P, Ur C, Netzeband JG, Prieto AL, Gruol DL. Interleukin-6 produces neuronal loss in developing cerebellar granule neuron cultures. J Neuroimmunol. 2004 Oct;155(1-2):43-54.

4. Ekinci FJ, Malik KU, Shea TB. Activation of the L voltage-sensitive calcium channel by mitogen-activated protein (MAP) kinase following exposure of neuronal cells to beta-amyloid. MAP kinase mediates beta-amyloid-induced neurodegeneration. J Biol Chem. 1999 Oct 15;274(42):30322-7.

5. Hartley DM, Walsh DM, Ye CP, Diehl T, Vasquez S, Vassilev PM, Teplow DB, Selkoe DJ. Protofibrillar intermediates of amyloid beta-protein induce acute electrophysiological changes and progressive neurotoxicity in cortical neurons. J Neurosci. 1999 Oct 15;19(20):8876-84.

6. Heneka MT, Sastre M, Dumitrescu-Ozimek L, Hanke A, Dewachter I, Kuiperi C, O'Banion K, Klockgether T, Van Leuven F, Landreth GE. Acute treatment with the PPARgamma agonist pioglitazone and ibuprofen reduces glial inflammation and Abeta1-42 levels in APPV717I transgenic mice.Brain. 2005 Jun;128(Pt 6):1442-53. 
7. Ho R, Ortiz D, Shea TB. Amyloid-beta promotes calcium influx and neurodegeneration via stimulation of $\mathrm{L}$ voltage-sensitive calcium channels rather than NMDA channels in cultured neurons. J Alzheimers Dis. 2001 Oct;3(5):479483.

8. Isaacs AM, Senn DB, Yuan M, Shine JP, Yankner BA. Acceleration of amyloid beta-peptide aggregation by physiological concentrations of calcium.J Biol Chem. 2006 Sep 22;281(38):27916-23.

9. Im JY, Kim D, Paik SG, Han PL. Cyclooxygenase-2-dependent neuronal death proceeds via superoxide anion generation. Free Radic Biol Med. 2006 Sep $15 ; 41(6): 960-72$.

10. Kushi H, Saito T, Makino K, Hayashi N. IL-8 is a key mediator of neuroinflammation in severe traumatic brain injuries. Acta Neurochir Suppl. 2003;86:347-50.

11. Lim GP, Yang F, Chu T, Chen P, Beech W, Teter B, Tran T, Ubeda O, Ashe KH, Frautschy SA, Cole GM. Ibuprofen suppresses plaque pathology and inflammation in a mouse model for Alzheimer's disease. J Neurosci. 2000 Aug 1;20(15):5709-14.

12. Lin KF, Chang RC, Suen KC, So KF, Hugon J. Modulation of calcium/calmodulin kinase-II provides partial neuroprotection against beta-amyloid peptide toxicity.Eur J Neurosci. 2004 Apr;19(8):2047-55.

13. Lopez-Franco O, Suzuki Y, Sanjuan G, Blanco J, Hernandez-Vargas P, Yo Y, Kopp J, Egido J, Gomez-Guerrero C. Nuclear factor-kappa B inhibitors as potential novel anti-inflammatory agents for the treatment of immune glomerulonephritis. Am J Pathol. 2002 Oct;161(4):1497-505. 
14. Lopez-Franco O, Hernandez-Vargas P, Ortiz-Munoz G, Sanjuan G, Suzuki Y, Ortega L, Blanco J, Egido J, Gomez-Guerrero C. Parthenolide modulates the NFkappaB-mediated inflammatory responses in experimental atherosclerosis. Arterioscler Thromb Vasc Biol. 2006 Aug;26(8):1864-70.

15. Lue LF, Rydel R, Brigham EF, Yang LB, Hampel H, Murphy GM Jr, Brachova L, Yan SD, Walker DG, Shen Y, Rogers J. Inflammatory repertoire of Alzheimer's disease and nondemented elderly microglia in vitro. Glia. $2001 \mathrm{Jul} ; 35(1): 72-9$.

16. Mastrangelo IA, Ahmed M, Sato T, Liu W, Wang C, Hough P, Smith SO. Highresolution atomic force microscopy of soluble Abeta42 oligomers. J Mol Biol. 2006 Apr 21;358(1):106-19.

17. Mattson MP, Chan SL. Neuronal and glial calcium signaling in Alzheimer's disease. Cell Calcium. 2003 Oct-Nov;34(4-5):385-97.

18. McGeer EG, McGeer PL. Brain inflammation in Alzheimer disease and the therapeutic implications. Curr Pharm Des. 1999 Oct;5(10):821-36.

19. McGeer PL, McGeer EG. NSAIDs and Alzheimer disease: epidemiological, animal model and clinical studies. Neurobiol Aging. 2007 May;28(5):639-47.

20. McLean CA, Cherny RA, Fraser FW, Fuller SJ, Smith MJ, Beyreuther K, Bush AI, Masters CL. Soluble pool of Abeta amyloid as a determinant of severity of neurodegeneration in Alzheimer's disease. Ann Neurol. 1999 Dec;46(6):860-6.

21. Monnerie H, Esquenazi S, Shashidhara S, Le Roux PD. Beta-amyloid-induced reactive astrocytes display altered ability to support dendrite and axon growth from mouse cerebral cortical neurons in vitro. Neurol Res. 2005 Jul;27(5):525-32. 
22. Paris D, Townsend KP, Obregon DF, Humphrey J, Mullan M. Pro-inflammatory effect of freshly solubilized beta-amyloid peptides in the brain. Prostaglandins Other Lipid Mediat. 2002 Sep; 70(1-2):1-12.

23. Pierrot N, Ghisdal P, Caumont AS, Octave JN. Intraneuronal amyloid-beta1-42 production triggered by sustained increase of cytosolic calcium concentration induces neuronal death. J Neurochem. 2004 Mar; 88(5):1140-1150.

24. Quadros A, Patel N, Crescentini R, Crawford F, Paris D, Mullan M. Increased TNFalpha production and Cox-2 activity in organotypic brain slice cultures from APPsw transgenic mice. Neurosci Lett. 2003 Dec 15;353(1):66-8.

25. Quadros A, Patel N, Weeks OI, Brown B, Linan M, Mullan M, Paris D. Increase of calcium entry by $\mathrm{A} \beta$ promotes inflammation in human astrocytes and microglia. Journal of Neuroinflammation submitted.

26. Qiu Z, Gruol DL. Interleukin-6, beta-amyloid peptide and NMDA interactions in rat cortical neurons. J Neuroimmunol. 2003 Jun;139(1-2):51-7.

27. Sastre M, Klockgether T, Heneka MT. Contribution of inflammatory processes to Alzheimer's disease: molecular mechanisms. Int J Dev Neurosci. 2006 AprMay;24(2-3):167-76.

28. Stewart WF, Kawas C, Corrada M, Metter EJ. Risk of Alzheimer's disease and duration of NSAID use. Neurology. 1997 Mar;48(3):626-32.

29. Thirumangalakudi L, Yin L, Rao HV, Grammas P. IL-8 induces expression of matrix metalloproteinases, cell cycle and pro-apoptotic proteins, and cell death in cultured neurons. J Alzheimers Dis. 2007 Jun;11(3):305-11. 
30. Watson D, Castano E, Kokjohn TA, Kuo YM, Lyubchenko Y, Pinsky D, Connolly ES Jr, Esh C, Luehrs DC, Stine WB, Rowse LM, Emmerling MR, Roher AE. Physicochemical characteristics of soluble oligomeric Abeta and their pathologic role in Alzheimer's disease. Neurol Res. 2005 Dec;27(8):869-81.

31. Yagami T, Ueda K, Sakaeda T, Itoh N, Sakaguchi G, Okamura N, Hori Y, Fujimoto M. Protective effects of a selective L-type voltage-sensitive calcium channel blocker, S-312-d, on neuronal cell death. Biochem Pharmacol. 2004 Mar $15 ; 67(6): 1153-65$. 
VITA

\section{AMITA QUADROS}

\section{EDUCATIONAL QUALIFICATIONS:}

MS: University of Bombay, 1994, in Biochemistry, India

BS: $\quad$ University of Bombay, 1992, in Microbiology- Biochemistry, India

PUBLICATIONS \& PRESENTATIONS:

1. Townsend KP, Obregon D, Quadros A, et al. Proinflammatory and vasoactive effects of $A \beta$ in the cerebrovasculature. Ann N Y Acad Sci. 2002 Nov; 977:65-76.

2. Paris D, Townsend K, Obregon D, Humphrey J, Quadros A, et al. Modulation of angiogenesis by A beta peptides. Neurobiology of Aging 23 (1): 2046 Suppl. 1 JUL-AUG 2002.

3. Paris D, Humphrey J, Quadros A, et al. Vasoactive effects of A beta in isolated human cerebrovessels and in a transgenic mouse model of Alzheimer's disease: role of inflammation. Neurol Res. 2003 Sep; 25(6): 642-51.

4. Quadros A, Patel N, Crescentini R, Crawford F, et al. Increased TNF $\alpha$ production and Cox-2 activity in organotypic brain slice cultures from APPsw transgenic mice. Neurosci Lett. 2003 Dec 15; 353(1): 66-8.

5. Paris D, Quadros A, Humphrey J, Patel N, et al. Nilvadipine antagonizes both Abeta vasoactivity in isolated arteries, and the reduced cerebral blood flow in APPsw transgenic mice. Brain Res. 2004 Feb 27; 999(1): 53-61.

6. Paris D, Townsend K, Quadros A, Humphrey J, et al. Inhibition of angiogenesis by abeta peptides. Angiogenesis. 2004; 7(1): 75-85.

7. Paris D, Ait-Ghezala G, Mathura VS, Patel N, Quadros A, et al. Anti-angiogenic activity of the mutant Dutch Abeta peptide on human brain microvascular endothelial cells.Brain Res Mol Brain Res. 2005 May 20;136(1-2):212-30.

8. Paris D, Quadros A, Patel N, Delledonne A, et al. Inhibition of angiogenesis and tumor growth by beta and gamma-secretase inhibitors. Eur J Pharmacol. 2005 May 2;514(1):1-15.

9. Patel NS, Paris D, Mathura V, Quadros AN, Crawford FC, Mullan MJ. Inflammatory cytokine levels correlate with amyloid load in transgenic mouse models of Alzheimer's disease.J Neuroinflammation. 2005 Mar 11; 2(1):9.

10. Ait-Ghezala G, Mathura VS, Laporte V, Quadros A, et al. Genomic regulation after CD40 stimulation in microglia: relevance to Alzheimer's disease. Brain Res Mol Brain Res. 2005 Oct 31; 140(1-2):73-85. 
11. Paris D, Patel N, Quadros A, Linan M, Bakshi P, et al. Inhibition of Abeta production by NF-kappaB inhibitors. Neurosci Lett. 2007 Mar 19; 415(1):11-6.

12. Quadros A, Weeks O, Ait-Ghezala G. Role of Tau in Alzheimer's Dementia and Other Neurodegenerative Diseases: Review. J. Appl. Biomed. 5: 1-12, 2007.

13. Patel N, Quadros A, Brem S, Wotoczek-Obadia M, et al. Potent anti-angiogenic motifs within the Alzheimer $\beta$-amyloid peptide.In press Amyloid.

14. Quadros A, Patel N, Weeks OI, Brown B, et al. Dysregulation of calcium entry by A $\beta$ promotes inflammation in human astrocytes and microglia. Submitted Journal of Neuroinflammation.

15. Quadros A, Patel N, Mullan M, Paris D. Effect of calcium channel blockers on $\mathrm{A} \beta$ induced neurodegeneration in human neurons. To be submitted Neuroscience IBRO

16. A. Quadros, D. Paris, K. Townsend, et al. Pro-inflammatory effect of freshly solubilized $\beta$-amyloid peptides in the brain. Poster presentation at the 8th International Conference on Alzheimer's Disease and Related Disorders, Stockholm, Sweden 2002.

17. A. Quadros, D. Paris, N. Patel, J. Humphrey, R. et al. Eicosanoid and TNF $\alpha$ production in the brain of transgenic mouse model of Alzheimer's disease. Poster presentation at the 6th IBRO World Congress of Neuroscience at Prague,Czech Republic 2003

18. A. Quadros, D. Paris, N. Patel, M. Mullan. Effect of Calcium Channel Blockers on Pro-inflammatory Cytokines, Chemokines and Prostaglandins Release by Activated Human Microglia. Poster presentation at Society for Neuroscience Conference at San Diego, U.S.A 2004.

19. A.Quadros, N.Patel, M.J.Mullan, D.Paris. Capacitative Calcium entry mediates inflammation in activated human astrocytes. Poster presentation at Society for Neuroscience at Washington DC, U.S.A. 2005.

20. A. Quadros, N. Patel, M. Mullan, D. Paris: Effect of beta amyloid on calcium homeostasis and inflammation in human astrocytes and microglia. Poster presentation at Society for Neuroscience at Atlanta, U.S.A 2006.

\section{BOOK CHAPTER}

1. RELEVANCE OF COX-2 INHIBITORS IN ALZHEIMER'S DISEASE

Amita Quadros, Laila Abdullah, Nikunj Patel, Claude-Henry Volmar

'Trends in COX-2 Inhibitor Research', ISBN: 1-60021-222-0, Dec. 2006.

Editor and Reviewer for Scientific Journals International (SJI): Beginning March 2007: http://www.scientificjournals.org, Telephone: 320-253- 3139, Fax : 320-252-2615 